\title{
Knee orthoses for treating patellofemoral pain syndrome (Review)
}

\author{
Smith TO, Drew BT, Meek TH, Clark AB
}

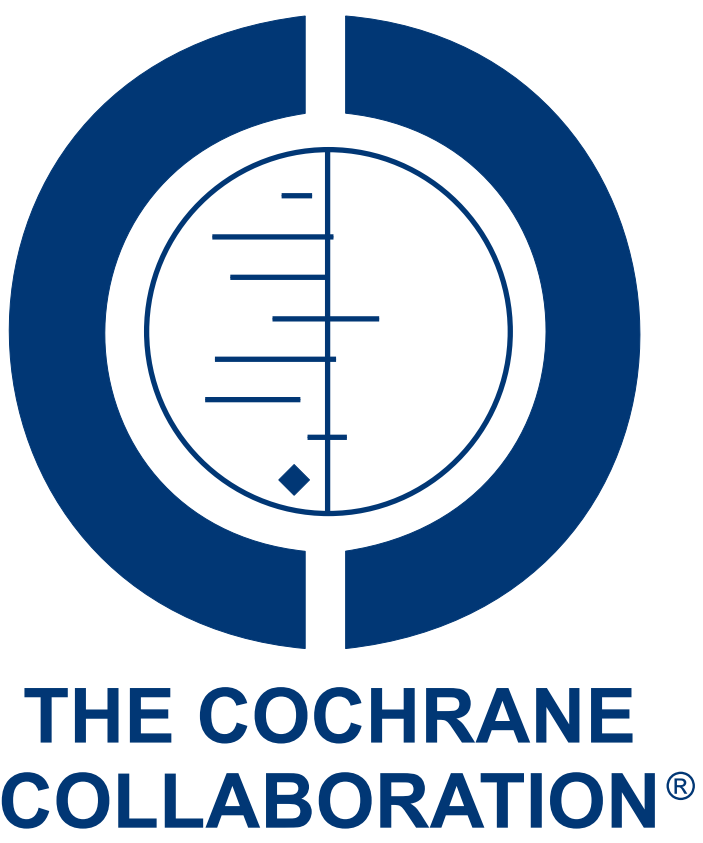

This is a reprint of a Cochrane review, prepared and maintained by The Cochrane Collaboration and published in The Cochrane Library 2015, Issue 12

http://www.thecochranelibrary.com

\section{WILEY}


TABLE OF CONTENTS

HEADER

ABSTRACT . . . . . . . . . . . . . . . . . . . . . . . . . . . . . . . . . . . . . . .

PLAIN LANGUAGE SUMMARY . . . . . . . . . . . . . . . . . . . . . . . . . . . . . . .

SUMMARY OF FINDINGS FOR THE MAIN COMPARISON . . . . . . . . . . . . . . . . . . . . . . . 4

BACKGROUND . . . . . . . . . . . . . . . . . . . . . . . . . . . . . . . . . . . . . . . . 7

OBJECTIVES . . . . . . . . . . . . . . . . . . . . . . . . . . . . . . . . . . . . . . . . . . . . . . . . . .

METHODS . . . . . . . . . . . . . . . . . . . . . . . . . . . . . . . . . . . . . . 8

RESUlTS . . . . . . . . . . . . . . . . . . . . . . . . . . . . . . . . . . . . 10

Figure 1. . . . . . . . . . . . . . . . . . . . . . . . . . . . . . . . . . . . . . 12

Figure 2. . . . . . . . . . . . . . . . . . . . . . . . . . . . . . . . . . . . . . 16

Figure 3. . . . . . . . . . . . . . . . . . . . . . . . . . . . . . . . . . . . . . 17

Figure $4 . \quad$. . . . . . . . . . . . . . . . . . . . . . . . . . . . . . . . . . . . . 19

DISCUSSION . . . . . . . . . . . . . . . . . . . . . . . . . . . . . . . . . . . . .

AUTHORS' CONCLUSIONS . . . . . . . . . . . . . . . . . . . . . . . . . . . . . . . . 23

ACKNOWLEDGEMENTS . . . . . . . . . . . . . . . . . . . . . . . . . . . . . . . . . 24

REFERENCES . . . . . . . . . . . . . . . . . . . . . . . . . . . . . . . . . . . . . . 24

CHARACTERISTICS OF STUDIES . . . . . . . . . . . . . . . . . . . . . . . . . . . . . . . . . . . . . . . . . .

DATA AND ANALYSES . . . . . . . . . . . . . . . . . . . . . . . . . . . . . . . . . . . . . . . . . . . . . . . . . . . 444

Analysis 1.1. Comparison 1 Knee orthosis and non-operative intervention (exercises) versus non-operative intervention (exercises) alone, Outcome 1 Pain during activity (0 to 10; higher score means worse pain).

Analysis 1.2. Comparison $1 \mathrm{Knee}$ orthosis and non-operative intervention (exercises) versus non-operative intervention (exercises) alone, Outcome 2 Pain scores (0 to 10; higher score means worse pain).

Analysis 1.3. Comparison 1 Knee orthosis and non-operative intervention (exercises) versus non-operative intervention (exercises) alone, Outcome 3 Different pain scores (0 to 10; higher score means worse pain) at 12 weeks.

Analysis 1.4. Comparison $1 \mathrm{Knee}$ orthosis and non-operative intervention (exercises) versus non-operative intervention (exercises) alone, Outcome 4 Excellent or good results in terms of reduction in symptoms.

Analysis 1.5. Comparison 1 Knee orthosis and non-operative intervention (exercises) versus non-operative intervention (exercises) alone, Outcome 5 Functional scores (higher score means higher function).

Analysis 1.6. Comparison 1 Knee orthosis and non-operative intervention (exercises) versus non-operative intervention (exercises) alone, Outcome 6 Discontinuation of a basic military training programme. . . . . . . . . . . .

Analysis 2.1. Comparison 2 One type of orthosis versus another type, Outcome 1 Pain score (0 to 10: higher score means worse pain).

Analysis 2.2. Comparison 2 One type of orthosis versus another type, Outcome 2 Functional score (0 to 53: higher scores means greater function).

Analysis 2.3. Comparison 2 One type of orthosis versus another type, Outcome 3 Discontinuation of a basic military training programme.

Analysis 2.4. Comparison 2 One type of orthosis versus another type, Outcome 4 Complications.

Analysis 3.1. Comparison 3 Orthosis versus exercise, Outcome 1 Pain during activity (0 to 10: higher score means worse pain).

Analysis 3.2. Comparison 3 Orthosis versus exercise, Outcome 2 Sensitivity analyses (knees): Pain during activity (0 to 10 : higher score means worse pain).

Analysis 3.3. Comparison 3 Orthosis versus exercise, Outcome 3 Functional scores (0 to 53: higher scores means greater function).

APPENDICES

CONTRIBUTIONS OF AUTHORS . . . . . . . . . . . . . . . . . . . . . . . . . . . . . . . . . . .

DECLARATIONS OF INTEREST . . . . . . . . . . . . . . . . . . . . . . . . . . . . . . . . . . . . . . . . . . . .

DIFFERENCES BETWEEN PROTOCOL AND REVIEW

Knee orthoses for treating patellofemoral pain syndrome (Review)

Copyright () 2015 The Cochrane Collaboration. Published by John Wiley \& Sons, Ltd. 


\title{
[Intervention Review]
}

\section{Knee orthoses for treating patellofemoral pain syndrome}

\author{
Toby O Smith ${ }^{1}$, Benjamin T Drew ${ }^{2}$, Toby H Meek ${ }^{3}$, Allan B Clark ${ }^{1}$ \\ ${ }^{1}$ Faculty of Medicine and Health Sciences, University of East Anglia, Norwich, UK. ${ }^{2}$ Leeds Institute of Rheumatic and Musculoskeletal \\ Medicine, University of Leeds, Leeds, UK. ${ }^{3}$ Department of Physiotherapy, Addenbrookes Hospital, Cambridge University Hospitals \\ NHS Foundation Trust, Cambridge, UK
}

Contact address: Toby O Smith, Faculty of Medicine and Health Sciences, University of East Anglia, Queen's Building, Norwich, Norfolk, NR4 7TJ, UK. toby.smith@uea.ac.uk.

Editorial group: Cochrane Bone, Joint and Muscle Trauma Group.

Publication status and date: New, published in Issue 12, 2015.

Review content assessed as up-to-date: 1 June 2015.

Citation: Smith TO, Drew BT, Meek TH, Clark AB. Knee orthoses for treating patellofemoral pain syndrome. Cochrane Database of Systematic Reviews 2015, Issue 12. Art. No.: CD010513. DOI: 10.1002/14651858.CD010513.pub2.

Copyright (C) 2015 The Cochrane Collaboration. Published by John Wiley \& Sons, Ltd.

\begin{abstract}
A B S T R A C T
Background

Patellofemoral pain syndrome (PFPS) is a painful musculoskeletal condition, which is characterised by knee pain located in the anterior aspect (front) and retropatellar region (behind) of the knee joint. Various non-operative interventions are suggested for the treatment of this condition. Knee orthoses (knee braces, sleeves, straps or bandages) are worn over the knee and are thought to help reduce knee pain. They can be used in isolation or in addition to other treatments such as exercise or non-steroidal anti-inflammatory medications.
\end{abstract}

\section{Objectives}

To assess the effects (benefits and harms) of knee orthoses (knee braces, sleeves, straps or bandages) for treating PFPS.

\section{Search methods}

We searched the Cochrane Bone, Joint and Muscle Trauma Group Specialised Register (11 May 2015), the Cochrane Central Register of Controlled Trials (CENTRAL) (The Cochrane Library 2015 Issue 5), MEDLINE (1946 to 8 May 2015), EMBASE (1980 to 2015 Week 18), SPORTDiscus (1985 to 11 May 2015), AMED (1985 to 8 May 2015), CINAHL (1937 to 11 May 2015), PEDro (1929 to June 2015), trial registries and conference proceedings.

\section{Selection criteria}

Randomised and quasi-randomised controlled clinical trials evaluating knee orthoses for treating people with PFPS. Our primary outcomes were pain and function.

\section{Data collection and analysis}

Two review authors independently assessed studies for eligibility, assessed study risk of bias and extracted data. We calculated mean differences (MD) or, where pooling data from different scales, standardised mean differences (SMD) with $95 \%$ confidence intervals (CI) for continuous outcomes and risk ratios (RR) with 95\% CIs for binary outcomes. We pooled data using the fixed-effect model.

Knee orthoses for treating patellofemoral pain syndrome (Review)

Copyright $\odot 2015$ The Cochrane Collaboration. Published by John Wiley \& Sons, Ltd. 


\section{Main results}

We included five trials (one of which was quasi-randomised) that reported results for 368 people who had PFPS. Participants were recruited from health clinics in three trials and were military recruits undergoing training in the other two trials. Although no trials recruited participants who were categorised as elite or professional athletes, military training does comprise intensive exercise regimens. All five trials were at high risk of bias, including performance bias reflecting the logistical problems in these trials of blinding of participants and care providers. As assessed using the GRADE approach, the available evidence for all reported outcomes is 'very low' quality. This means that we are very uncertain about the results.

The trials covered three different types of comparison: knee orthosis and exercises versus exercises alone; one type of orthosis versus another; and knee orthosis versus exercises. No trials assessed the mode of knee orthosis use, such as whether the orthosis was worn all day or only during physical activity. Two trials had two groups; two trials had three groups; and one trial had four groups.

All five trials compared a knee orthosis (knee sleeve, knee brace, or patellar strap) versus a 'no treatment' control group, with all participants receiving exercises, either through a military training programme or a home-based exercise programme. There is very low quality evidence of no clinically important differences between the two groups in short-term (2 to 12 weeks follow-up) knee pain based on the visual analogue scale ( 0 to 10 points; higher scores mean worse pain): MD - 0.46 favouring knee orthoses, $95 \%$ CI -1.16 to 0.24 ; $\mathrm{P}=0.19 ; 234$ participants, 3 trials). A similar lack of clinically important difference was found for knee function (183 participants, 2 trials). None of the trials reported on quality of life measures, resource use or participant satisfaction. Although two trials reported on the impact on sporting or occupational participation, one trial (35 participants) did not provide data split by treatment group on the resumption of sport activity and the other reported only on abandonment of military training due to knee pain (both cases were allocated a knee orthosis). One trial (59 participants, 84 affected knees) recording only adverse events in the two knee orthoses (both were knee sleeves) groups, reported 16 knees (36\% of 44 knees) had discomfort or skin abrasion.

Three trials provided very low quality evidence on single comparisons of different types of knee orthoses: a knee brace versus a knee sleeve (63 participants), a patella strap with a knee sleeve (31 participants), and a knee sleeve with a patellar ring versus a knee sleeve only (44 knees). None of three trials found an important difference between the two types of knee orthosis in pain. One trial found no clinically important difference in function between a knee brace and a knee sleeve. None of the three trials reported on quality of life, resource use or participant satisfaction. One trial comparing a patella strap with a knee sleeve reported that both participants quitting military training due to knee pain were allocated a knee sleeve. One poorly reported trial found three times as many knees with adverse effects (discomfort or skin abrasion) in those given knee sleeves with a patella ring than those given knee sleeves only.

One trial compared a knee orthosis (knee brace) with exercise (66 participants). It found very low quality evidence of no clinically important difference between the two intervention groups in pain or knee function. The trial did not report on quality of life, impact on sporting or occupational participation, resource use, participant satisfaction or complications.

\section{Authors' conclusions}

Overall, this review has found a lack of evidence to inform on the use of knee orthoses for treating PFPS. There is, however, very low quality evidence from clinically heterogeneous trials using different types of knee orthoses (knee brace, sleeve and strap) that using a knee orthosis did not reduce knee pain or improve knee function in the short term (under three months) in adults who were also undergoing an exercise programme for treating PFPS. This points to the need for good-quality clinically-relevant research to inform on the use of commonly-available knee orthoses for treating PFPS.

\section{PLAIN LANGUAGE SUMMARY}

\section{Knee braces, sleeves or straps for treating anterior knee pain (patellofemoral pain syndrome)}

\section{Background}

Patellofemoral pain syndrome (PFPS) is a painful knee condition that frequently affects young, physically active people. It is characterised by pain either to the front of the knee or behind the patella (knee cap). It is suggested that this may be caused by faulty alignment of the knee cap during knee movements. To help, some physiotherapists provide or people may purchase knee braces, sleeves or straps (termed 'orthoses') believed to correct this faulty alignment.

\section{Review question}

Knee orthoses for treating patellofemoral pain syndrome (Review)

Copyright $\odot 2015$ The Cochrane Collaboration. Published by John Wiley \& Sons, Ltd. 
We wanted to find out whether wearing knee orthoses in people with anterior knee pain reduces knee pain, improves knee function and increases the ability to do everyday activities and sports. We also wanted to find out whether there are adverse effects, such as skin problems, associated with using a knee orthosis. We also wanted to find out what is the best type of knee orthosis and whether wearing a knee orthosis is better than other types of intervention such as exercise.

\section{Study characteristics}

We searched electronic databases and other sources up to June 2015 and found five relevant studies that reported the results for 368 adults with PFPS. Participants were recruited from health clinics in three studies and were military trainees in the other two studies. All five studies were small and at high risk of bias, which means that their findings may not be reliable.

The studies covered three different types of comparison: knee orthosis and exercises versus exercises alone; one type of orthosis versus another; and knee orthosis versus exercises. No study assessed the mode of knee orthosis use, such as whether the orthosis was worn all day or only during physical activity.

\section{Key results}

All five trials compared a knee orthosis (either sleeve, brace or strap) plus exercise versus exercise alone. These provided very low quality evidence that wearing a knee orthosis made no difference to knee pain (data from three studies) and function (data from two studies). None of the three studies reported on quality of life, resource use or participant satisfaction. One study reported that both participants quitting military training due to knee pain were allocated a knee orthosis. One poorly reported study found over a third of knees had discomfort or skin abrasion in those given a knee sleeve.

Three studies provided very low quality evidence on single comparisons of different types of knee orthoses: a knee brace versus a knee sleeve (63 participants), a patella strap with a knee sleeve (31 participants), and a knee sleeve with a patellar ring versus a knee sleeve only (44 knees). None of three studies found an important difference between the two types of knee orthosis in knee pain. One study found no important difference in function between a knee brace and a knee sleeve. None of the three studies reported on quality of life, resource use or participant satisfaction. One study comparing a patella strap with a knee sleeve reported that both participants quitting military training due to knee pain were allocated a knee sleeve. One poorly reported study found three times as many knees with discomfort or skin abrasion in those given knee sleeves with a patella ring than those given knee sleeves only.

One study (66 participants) compared a knee orthosis (knee brace) with exercise. It provided very low quality evidence of no clinically important difference between the two intervention groups in pain or knee function. It did not report on other outcomes including complications.

\section{Conclusion}

Overall, we found a lack of evidence to inform on the use of knee orthoses for treating PFPS. Our review found very low quality evidence from trials testing different knee orthoses (knee brace, sleeve and strap) that using a knee orthosis may not reduce knee pain or improve knee function in the short term (under three months) in adults who were also undergoing an exercise programme for treating PFPS. These findings point to the need for good-quality clinically-relevant research to inform on the use of commonly-available knee orthoses for treating PFPS.

Knee orthoses for treating patellofemoral pain syndrome (Review) 
SUMMARY OF FINDINGS FOR THE MAIN COMPARISON [Explanation]

\section{Knee orthosis and exercise versus exercise alone for patellofemoral pain syndrome (PFPS)}

Patient or population: Adults (recruited from health clinics or military recruits) with PFPS (duration of symptoms ranged from acute, under 2 to 3 weeks in two trials, to predominantly chronic in three trials: mean durations 8.3 months, 21 months, 21 months)

Settings: Health clinics, home and military training establishments

Intervention: Knee orthosis (various types: knee sleeve, knee brace or patellar strap) and exercise (military training, home exercise programme) Comparison: Exercise alone

\begin{tabular}{|c|c|c|c|c|c|c|}
\hline \multirow[t]{3}{*}{ Outcomes } & \multicolumn{2}{|c|}{ Illustrative comparative risks* $(95 \% \mathrm{Cl})$} & \multirow{3}{*}{$\begin{array}{l}\text { Relative effect } \\
(95 \% \mathrm{Cl})\end{array}$} & \multirow{3}{*}{$\begin{array}{l}\text { No of Participants } \\
\text { (studies) }\end{array}$} & \multirow{3}{*}{$\begin{array}{l}\text { Quality of the evidence } \\
\text { (GRADE) }\end{array}$} & \multirow[t]{3}{*}{ Comments } \\
\hline & Assumed risk & Corresponding risk & & & & \\
\hline & Exercise alone & $\begin{array}{l}\text { Knee orthosis and exer- } \\
\text { cise }\end{array}$ & & & & \\
\hline $\begin{array}{l}\text { Pain score (VAS) } \\
\text { Scale from: } 0 \text { to } 10 \\
\text { (higher scores mean } \\
\text { worse pain) } \\
\text { Follow-up: } 3 \text { to } 12 \text { weeks } \\
\text { (short-term) }\end{array}$ & $\begin{array}{l}\text { The mean pain score for } \\
\text { the exercise alone group } \\
\text { ranged across the control } \\
\text { groups from } 2.7 \text { to } 3.2 \\
\text { points; the mean change } \\
\text { score from }-0.47 \text { to }-0.96 \\
\text { points }\end{array}$ & $\begin{array}{l}\text { The mean pain score in } \\
\text { the knee orthosis and ex- } \\
\text { ercise group was } \mathbf{0 . 4 6} \\
\text { points lower ( } 1.16 \text { lower } \\
\text { to } 0.24 \text { higher) }\end{array}$ & MD $-0.46(-1.16$ to 0.24$)$ & $234(3)$ & $\begin{array}{l}\oplus \bigcirc \bigcirc \bigcirc \\
\text { very low }{ }^{1}\end{array}$ & $\begin{array}{l}\text { The MD and } 95 \% \text { Cls do } \\
\text { not include clinically im- } \\
\text { portant treatment effects } \\
\text { MCID: } 30 \text { mm on an } 100 \\
\text { mm VAS (Lee 2003) }\end{array}$ \\
\hline $\begin{array}{l}\text { Functional outcomes } \\
\text { Scale various }{ }^{2} \\
\text { Follow-up: } \\
6 \text { and } 12 \text { weeks (short- } \\
\text { term) }\end{array}$ & & $\begin{array}{l}\text { The mean functional } \\
\text { score in the knee orthosis } \\
\text { and exercise group was } \\
0.15 \text { points lower ( } 0.69 \\
\text { lower to } 0.38 \text { higher) } \\
\text { The mean difference in } \\
\text { knee function (short- } \\
\text { term) in the knee ortho- } \\
\text { sis group was } \mathbf{0 . 2 5} \text { stan- } \\
\text { dard deviations lower ( } 0 \text {. } \\
55 \text { lower to } 0.05 \text { higher) }\end{array}$ & $\begin{array}{l}\text { SMD }-0.25(-0.55 \text { to } 0 \text {. } \\
05) \\
\end{array}$ & $183(2)$ & $\begin{array}{l}\oplus \bigcirc \bigcirc \bigcirc \\
\text { very low } 3\end{array}$ & $\begin{array}{l}\text { Lower values equate to } \\
\text { higher disability. } \\
\text { The SMD result equates } \\
\text { to a small difference at } \\
\text { most and in absolute } \\
\text { terms, the mean differ- } \\
\text { ences for each trial were } \\
\text { small (e.g. } 0.9 \text { for a range } \\
0 \text { to } 68 \text { ) and not clinically } \\
\text { important }\end{array}$ \\
\hline
\end{tabular}




\begin{tabular}{|c|c|c|c|c|c|}
\hline $\begin{array}{l}\text { Quality of Life and Gen- } \\
\text { eral Health Assessments }\end{array}$ & See comment & See comment & & & $\begin{array}{l}\text { No study reported this } \\
\text { outcome }\end{array}$ \\
\hline $\begin{array}{l}\text { Impact on sporting and } \\
\text { occupational participa- } \\
\text { tion }\end{array}$ & See comment & See comment & $51(1)^{4}$ & $\begin{array}{l}\oplus \bigcirc \bigcirc \bigcirc \\
\text { very low } 5\end{array}$ & $\begin{array}{l}\text { One trial reported that } 2 \\
\text { out of } 31(6.5 \%) \text { partici- } \\
\text { pants in the knee ortho- } \\
\text { sis groups versus } 0 \text { of } 20 \\
(0 \%) \text { in the control group } \\
\text { withdrew from their mili- } \\
\text { tary training programme }\end{array}$ \\
\hline Resource use & See comment & See comment & & & $\begin{array}{l}\text { No study reported this } \\
\text { outcome }\end{array}$ \\
\hline Participant satisfaction & See comment & See comment & & & $\begin{array}{l}\text { No study reported this } \\
\text { outcome }\end{array}$ \\
\hline $\begin{array}{l}\text { Complications } \\
\text { Follow-up: } 14 \text { weeks }\end{array}$ & See comment & See comment & $\begin{array}{l}59 \text { with } 84 \text { affected knees } \\
\text { (1) }\end{array}$ & $\begin{array}{l}\oplus \bigcirc \bigcirc \bigcirc \\
\text { very low } 7\end{array}$ & $\begin{array}{l}\text { Trial reported } 16 \text { compli- } \\
\text { cations (skin abrasions or } \\
\text { discomfort) for } 44 \text { knees } \\
\text { (36\%) of participants in } \\
\text { the knee orthosis group }\end{array}$ \\
\hline
\end{tabular}

*The basis for the assumed risk (e.g. the median control group risk across studies) is provided in footnotes. The corresponding risk (and its $95 \%$ confidence interval) is based on the assumed risk in the comparison group and the relative effect of the intervention (and its $95 \% \mathrm{Cl}$ ).

CI: Confidence Interval; MCID: Minimal Clinically Important Difference; MD: Mean Difference; RR: Risk Ratio; SMD: Standardised Mean Difference; VAS: Visual Analogue Scale

\section{GRADE Working Group grades of evidence}

High quality: Further research is very unlikely to change our confidence in the estimate of effect.

Moderate quality: Further research is likely to have an important impact on our confidence in the estimate of effect and may change the estimate.

Low quality: Further research is very likely to have an important impact on our confidence in the estimate of effect and is likely to change the estimate.

Very low quality: We are very uncertain about the estimate.

1. The quality of the evidence was downgraded two levels for major study limitations resulting in very serious risk of bias (including selection bias (1 trial) and performance bias (all 3 trials)), and one level for indirectness (this reflects the clinical heterogeneity such as variation in the interventions and outcome measures and measurement, and the generally inadequate description of these). There was, however, no statistical heterogeneity in the pooled data. 
2. One trial reported WOMAC functional scores ( 0 to 68 ; higher values mean worse function) at six weeks and the other the results of a modified version of the Knee Function Scale ( 0 to 53; higher values mean better function) at 12 weeks.

3. The quality of the evidence was downgraded two levels for major study limitations resulting in very serious risk of bias (including selection bias ( 1 trial) and performance bias (both trials)), and one level for imprecision (wide confidence intervals and limited data).

4. Data on resumption of sports activities were not split by treatment group in one trial ( 35 participants).

5. The quality of the evidence was downgraded two levels for major study limitations resulting in very serious risk of bias (including performance and detection biases), and one level for indirectness (abandonment of military training may be for other reasons than serious knee pain)

6. The single study recording this outcome did not record complications for all groups. The follow-up for complications appeared be during use; i.e. the basic military training programme of 14 weeks.

7. The quality of the evidence was downgraded two levels for major study limitations resulting in very serious risk of bias (including performance and detection biases and serious unit of analyses issues relating to the inclusion of participants with anterior knee pain in both knees), and imprecision (incomplete data from one small trial). 


\section{B A C K G ROU N D}

\section{Description of the condition}

The term 'patellofemoral pain syndrome' (PFPS) is associated with anterior and retropatellar pain (Grelsamer 2009). This term has been used interchangeably with other terms, most notably anterior knee pain and patellofemoral syndrome (Grelsamer 2009). It is more commonly seen in females than in males, and has an estimated prevalence of $12 \%$ to $45 \%$ amongst young, physically active people (Bizzini 2003; Cook 2010; Dixit 2007; Roush 2012). This wide variation has been attributed to the diversity of people who may experience this condition; from sedentary adolescents to military recruits during basic training (Callaghan 2007). PFPS is characterised by pain behind and around the patella, which is aggravated during prolonged sitting, descending stairs or slopes, squatting or kneeling (Dixit 2007; Grelsamer 2009).

The aetiology of PFPS remains unclear (Lankhorst 2012; Waryasz 2008). However, the basic premise is that the patella 'moves' abnormally within the femoral trochlear. This is termed patella maltracking. The patella is most frequently thought to maltrack laterally and therefore tries to deviate against the lateral femoral trochlear. Repetitive maltracking is associated with increased sheering and compressive forces between the retropatellar and femoral trochlear articulation (Song 2011; Waryasz 2008). The causes of maltracking are largely acknowledged to be multifactorial. Factors that may contribute to this include lateral retinaculum shortening (Hudson 2009), an imbalance between the activation and intensity of vastus lateralis and vastus medialis muscles (Chester 2008), reduced hip muscle control (Barton 2013; Cowan 2009), hamstring, quadriceps or calf muscle tightness (Erkula 2002; Waryasz 2008), excessive tibial rotation from foot pronation (Barton 2011), femoral anteversion (Keser 2008) and trochlear dysplasia (Parikh 2011). The diagnosis of PFPS is usually derived from a person's reported history and their symptoms. A physical examination is important to exclude other injuries such as meniscal or ligament tear, tendinopathy, fracture and dislocation (Dixit 2007). Whilst no specific criteria exist, typically a person diagnosed with PFPS will have had symptoms for greater than six weeks, which reflects the standard research eligibility criteria found in the literature. Physical examination is also necessary to assess the various different factors, listed above, which may contribute to the presentation of PFPS.

Conservative treatment is widely accepted as the primary management of PFPS (Powers 2012) with one particular high-quality randomised controlled trial (Van Linschoten 2009) showing that conservative treatment had better outcomes in pain and function in both the short- and long-term compared to a 'wait and see' group. In part reflecting the multifactorial nature of PFPS, a number of different interventions have been advocated. These include quadriceps strengthening and stretching exercises (Chiu 2012), patellar adhesive taping and biofeedback exercises
(Cowan 2002), foot orthotics (Barton 2010), manual therapy (Brantingham 2012), acupuncture (Jensen 1999) and knee orthoses (Bizzini 2003; Powers 2004).

\section{Description of the intervention}

This review examined the use of knee orthoses for people with PFPS. Knee orthoses are essentially external, non-adhesive devices that aim to modify the position of the patella. The term 'knee orthosis' encompasses a variety of different interventions including knee braces, sleeves, bandages and straps. They are frequently made of neoprene and are available in a variety of sizes to account for different limb circumferences (Shellock 2000). The majority of orthoses have a 'patella hole', which is a hole cut out of a neoprene sleeve. In addition, in some designs, a strap or buttress is incorporated into the orthosis. These features are intended to help maintain the patella in a more central position (Chew 2007).

Knee orthoses have been described as simple, inexpensive and associated with negligible adverse effects (Warden 2008). People can purchase orthoses independently, or they may be prescribed by a healthcare professional. The user can apply the knee orthosis without assistance, which allows them greater control over managing their knee condition. Knee orthoses can be worn during normal activities of daily living, as well as during sporting and occupational pursuits. There is no consensus as to whether bracing should be used as an adjunct to treatment or on its own for the treatment of pain for those with PFPS (Dixit 2007).

\section{How the intervention might work}

Whilst consensus regarding the aetiology of PFPS is lacking, abnormal patellar tracking is largely considered to be the primary cause (Powers 2004). It has been suggested that knee orthoses work by centralising the patella within the femoral trochlea, thereby correcting abnormal patellar tracking and reducing pain (Powers 2004). However, whilst some studies have corroborated that knee orthoses can alter patellar alignment (Shellock 1994; Shellock 2000), others have reported the contrary during radiological investigations (Muhle 1999; Powers 1999; Powers 2004).

Knee orthoses may also have other therapeutic effects. For instance, wearing the neoprene orthosis may have a thermal effect, which could increase sensory feedback and proprioception, while also altering knee circulation (Herrington 2005; Shellock 1995; Van Tiggelen 2004). Added to this, Earl 2004 reported that knee orthoses work by 'unloading' the patellofemoral joint when orthoses are used during exercise compared with not wearing a brace. They postulated that a knee orthosis, by reducing contact forces between the patella and the femoral trochlea, may reduce the symptoms related to PFPS. Through this symptomatic relief, it is speculated that knee orthoses can facilitate greater exercise tolerance and capability, thus optimising the clinical effects of exercise (Swart 2012). 


\section{Why it is important to do this review}

The use of knee orthoses has been widely documented in the literature for assisting the management of people with PFPS. However, no systematic reviews have rigorously assessed their application for this population. There remains mixed evidence as to the effectiveness of knee orthoses for this population.

Patellofemoral pain syndrome is acknowledged as a potentially disabling condition, which can impact on the occupational and sporting pursuits of children and young adults. Furthermore, previous authors have acknowledged a potential link between adolescent PFPS and the development of patellofemoral osteoarthritis (Thomas 2010; Utting 2005). The failure of treatment for PFPS is currently high. Over $90 \%$ of people with PFPS continue to experience pain for more than four years following treatment (Stathopulu 2003). Given this impact, both in the short- and potentially longer-term, and limited consensus in the effectiveness of knee orthoses, this review is important to better inform clinicians and the public on the use of these interventions for treating this musculoskeletal condition.

\section{O B J E C T IVES}

To assess the effects (benefits and harms) of knee orthoses (knee braces, sleeves, straps or bandages) for treating PFPS.

\section{METHODS}

\section{Criteria for considering studies for this review}

\section{Types of studies}

We included randomised controlled trials (RCTs) and quasi-randomised (using a method of allocating participants to a treatment that is not strictly random, e.g. by hospital number) controlled clinical trials evaluating knee orthoses for treating PFPS. Crossover study designs were excluded due to the potential for treatment 'carry-over' from one randomised arm to another, irrespective of the duration of the 'wash-out' period.

\section{Types of participants}

We included trials of participants subjectively reporting pain diagnosed by trial authors as 'patellofemoral pain syndrome', 'patellofemoral pain', 'anterior knee pain syndrome', 'patellar dysfunction', 'chondromalacia patellae', 'patellar syndrome', 'patellofemoral syndrome' or 'chondropathy'. No restrictions were placed on the age of the participant, duration of symptoms or stage of disease as we planned to explore these variables as subgroup analyses.

Trials where participants were asymptomatic or non-pathological were excluded. Trials that recruited participants with a history of fracture, patellar dislocation, patellar tendinopathy, Hoffa's syndrome, Osgood Schlatter syndrome, Sinding-Larsen-Johansson syndrome, iliotibial band friction syndrome, osteoarthritis, rheumatoid arthritis, plica syndromes, or tibiofemoral injury or dysfunction were also excluded.

Trials reporting the use of orthoses following operative interventions (either immediately post-operatively or at any point following surgery) were excluded.

Trials including mixed population studies where a percentage of the cohort may have some other (possibly undiagnosed) knee pathology, such as patellar tendinopathy, were excluded unless the results for the PFPS cohort were presented separately or the numbers of such 'undiagnosed' participants were small and sufficiently balanced between the intervention groups.

\section{Types of interventions}

We included trials evaluating the use of a knee orthosis. A knee orthosis was defined as a device that aimed to control or change patellar tracking or loading or both, and could have taken the form of a knee brace, sleeve, bandage or strap.

Comparisons included:

1. Knee orthosis and non-operative intervention (e.g. exercise) versus the same non-operative intervention alone.

2. One type of knee orthosis versus another.

3. Knee orthosis versus another non-operative intervention (e.g. exercise).

4. Mode of knee orthosis use: e.g. length of time worn per day; whether orthosis is only worn during physical activity versus all day.

Trials looking at adhesive taping techniques were not included as they have been assessed in another Cochrane review (Callaghan 2012).

\section{Types of outcome measures}

\section{Primary outcomes}

1. Pain, e.g. during activity or at rest, measured using a visual analogue scale (VAS) or similar, preferably at 12 months after commencing the intervention. Pain could be assessed during a specific activity (e.g. single leg squat), or more globally, e.g. as usual pain during the previous week.

2. Functional outcomes, e.g. Western Ontario and McMaster Universities Index (WOMAC) (Klassbo 2003); Knee Injury and Osteoarthritis Outcome Score (KOOS) (Roos 1998); Lower Extremity Functional Scale (LEFS) (Blinkley 1999); Kujala Patellofemoral Disorder Score/Anterior Knee Pain Scale (Kujala 1993) 


\section{Secondary outcomes}

1. Quality of life and general health assessments, e.g. EQ-5D

(EuroQol Group 1990); Short Form-12 (Ware 1996).

2. Impact on sporting or occupational participation, e.g. duration of occupational sick leave, or time to return to sports at the same pre-injury level.

3. Resource use/costs of intervention.

4. Participant satisfaction, e.g. Likert scale, VAS or validated score.

5. Complications of orthoses, e.g. allergies or subsequent injury.

Biomechanical outcomes such as postural sway, joint proprioception, force-plate distribution and muscle dynamometry were not included in this review.

For a study to be included in the review, it had to have measured one or more of the listed outcomes.

\section{Timing of outcome assessment}

For each outcome, the primary end-point for analysis was 12 months. Short-term (zero to three months), medium-term (more than three months up to 12 months) and long-term (12 months and over) analyses were also planned in the protocol (Smith 2013). If there were multiple points within a category, the latest followup period was recorded.

\section{Search methods for identification of studies}

\section{Electronic searches}

We searched the Cochrane Bone, Joint and Muscle Trauma Group Specialised Register (11 May 2015), the Cochrane Central Register of Controlled Trials (CENTRAL) (The Cochrane Library, 2015 Issue 5), MEDLINE (1946 to May Week 1 2015), MEDLINE In-Process \& Other Non-Indexed Citations (8 May 2015), MEDLINE Daily Update (8 May 2015), EMBASE (1980 to 2015 Week 18), SPORTDiscus (1985 to 11 May 2015), Allied and Complementary Medicine (AMED) (1985 to 8 May 2015), the Cumulative Index to Nursing and Allied Health Literature (CINAHL) (1937 to 11 May 2015), and the Physiotherapy Evidence Database (PEDro) (1929 to June 2015). There were no restrictions on language, date or publication status.

We searched the WHO International Clinical Trials Registry Platform, the ISRCTN registry, ClinicalTrials.gov and OpenGrey (System for Information on Grey Literature in Europe) for ongoing or unpublished trials (June 2015). We also searched The Bone and Joint Journal Orthopaedic Proceedings for conference proceedings and abstracts (June 2015).

In MEDLINE, a subject-specific search was combined with the Cochrane Highly Sensitive Search Strategy to identify randomised trials (sensitivity-maximising version), as described by Lefebvre
2011. Search strategies and associated platforms for all databases are shown in Appendix 1.

\section{Searching other resources}

We scrutinised the reference lists of all pertinent review papers and eligible trials.

\section{Data collection and analysis}

\section{Selection of studies}

Two review authors (TS and BD) independently screened the titles and abstracts of the search strategy results to identity all potentially eligible trials, for which full-text reports were sought. The same two authors independently performed study selection. Disagreements in respect to final eligibility were resolved through discussion between the two review authors. The final eligibility of all papers was adjudicated by a third review author (TM).

\section{Data extraction and management}

Two review authors (TM and BD) independently reviewed and extracted data from each included trial. Disagreements on data extracted from the original papers were resolved through discussion between the two review authors. Adjudication by a third review author (TS) was not required for the data extraction phase.

\section{Assessment of risk of bias in included studies}

Two review authors (TM and BD) independently assessed the risk of bias of the included trials using The Cochrane 'Risk of bias' tool (Higgins 2011a). The following domains were evaluated: sequence generation, allocation concealment, blinding of participants and personnel, blinding of outcome assessment, completeness of outcome data reporting, selective outcome reporting and other sources of bias. Since orthoses are visible interventions, worn by participants, we acknowledged that it was impossible to blind participants or personnel to group allocation. However, some blinding of outcome assessment would still be possible. Any disagreements were resolved through discussion, adjudicated if necessary by a third review author (TS), until a consensus was reached.

\section{Measures of treatment effect}

We calculated risk ratios (RR) with $95 \%$ confidence intervals (CI) for dichotomous outcomes and mean differences (MD) with $95 \%$ CI for continuous outcomes. For pooling continuous outcome data where different scales or scores were used, we calculated standardised mean differences (SMD). To assist interpretation, we used mean differences for pain visual analogue scales. 


\section{Unit of analysis issues}

We included two trials that involved a substantial number of participants treated for bilateral symptoms and which reported data for knees rather than participants. Where possible we reported participant data and used the number of participants as denominators for continuous outcomes to provide a conservative estimate. We performed sensitivity analyses where possible to explore the effects on the confidence intervals when using the number of knees as denominators. We were alert to other potential unit of analysis issues such as those relating to multiple observations for the same outcome. Thus, each follow-up period, within the categories defined in Types of outcome measures, was assessed separately to minimise the risks of unit of analysis errors (Deeks 2011).

\section{Dealing with missing data}

We contacted trialists to provide missing data. Unless we could calculate missing standard deviations from standard errors, exact P values or $95 \%$ confidence intervals, we did not impute these or any other missing outcome data. If a paper only provided imputed data, we emailed the corresponding study author to request the specific data required on outcomes only from participants who were assessed. Where possible and appropriate, we used intentionto-treat analysis results for all review analyses.

\section{Assessment of heterogeneity}

We evaluated study heterogeneity from an inspection of the characteristics of the included studies. We assessed statistical heterogeneity using $\mathrm{Chi}^{2}$ and $\mathrm{I}^{2}$ statistics, in addition to visual inspection of the forest plots (Higgins 2003). We interpreted $\mathrm{I}^{2}$ values as recommended by Deeks 2011. Thus, an $\mathrm{I}^{2}$ value of $0 \%$ to $40 \%$ might 'not be important'; $30 \%$ to $60 \%$ may represent 'moderate' heterogeneity; $50 \%$ to $90 \%$ may represent 'substantial' heterogeneity; and $75 \%$ to $100 \%$ represents 'considerable' heterogeneity.

\section{Assessment of reporting biases}

We did not construct a funnel plot to assess possible publication bias (Sterne 2011) as there were insufficient data.

\section{Data synthesis}

When there was heterogeneity between the studies in respect to the interventions, population or method of assessment, we presented a narrative review of the results. Otherwise, where possible, we pooled results of comparable groups of trials using both fixed-effect and random-effects models. The choice of the model to report was guided by a careful consideration of the degree of heterogeneity, as classified in the Assessment of heterogeneity section, and whether it could be explained through study design or cohort differences, in addition to other factors such as the number and size of studies that were included. We considered not pooling data where there was considerable heterogeneity $\left(\mathrm{I}^{2}>75 \%\right)$ that could not be explained by the diversity of methodological or clinical features among the trials.

To assess treatment effect, we used mean differences to assess continuous data, whilst risk ratios were used to assess dichotomous data. We presented 95\% CIs throughout. When there was insufficient data to perform this assessment of treatment effect, or significant heterogeneity was evident, we presented a narrative review of the original trial's findings.

\section{Subgroup analysis and investigation of heterogeneity}

Planned subgroup analyses included:

1. Different forms of orthoses: custom-made orthoses; prefabricated ('off-the-shelf') versions; bandages; straps.

2. Age (18 years or over versus under 18 years) and gender.

3. Level of activity (participants who were professional athletes or in the military forces versus recreational athletes).

There was a lack of data to conduct subgroup analyses for these parameters.

We considered factors such as age, gender, duration of PFPS symptoms prior to randomisation, type of intervention, length of follow-up, level of pre-injury activity and adjusted/unadjusted analyses during the interpretation of heterogeneity.

\section{Sensitivity analysis}

We planned to conduct sensitivity analyses to explore different aspects of trial and review methodology, for example, assessing outcomes after the exclusion of trials at high risk of selection bias. However, all included trials were at high risk of various biases and it was inappropriate to discriminate between these. As all trials described their population sufficiently, no sensitivity analyses were performed to see the effect of excluding trials where the population was poorly defined. There were insufficient data to explore the effects of missing data, such as studies that presented more than or equal to $90 \%$ of their originally randomised cohort at follow-up, as recommended by Higgins $2011 \mathrm{~b}$. The only sensitivity analyses performed were to explore the effects of unit of analysis issues relating the inclusion of participants with bilateral symptoms.

\section{'Summary of findings' tables}

We summarised the results for the main comparison described in Types of interventions in a 'Summary of findings' table. For all comparisons, we used the GRADE approach to assess the quality of evidence related to each of the primary outcomes and, if possible, to at least the first two secondary outcomes listed in Types of outcome measures (Schünemann 2011).

\section{R E S U L T S}




\section{Description of studies}

\section{Results of the search}

A summary of the study selection process is shown in Figure 1.

Copyright $\odot 2015$ The Cochrane Collaboration. Published by John Wiley \& Sons, Ltd. 
Figure I. Study flow diagram

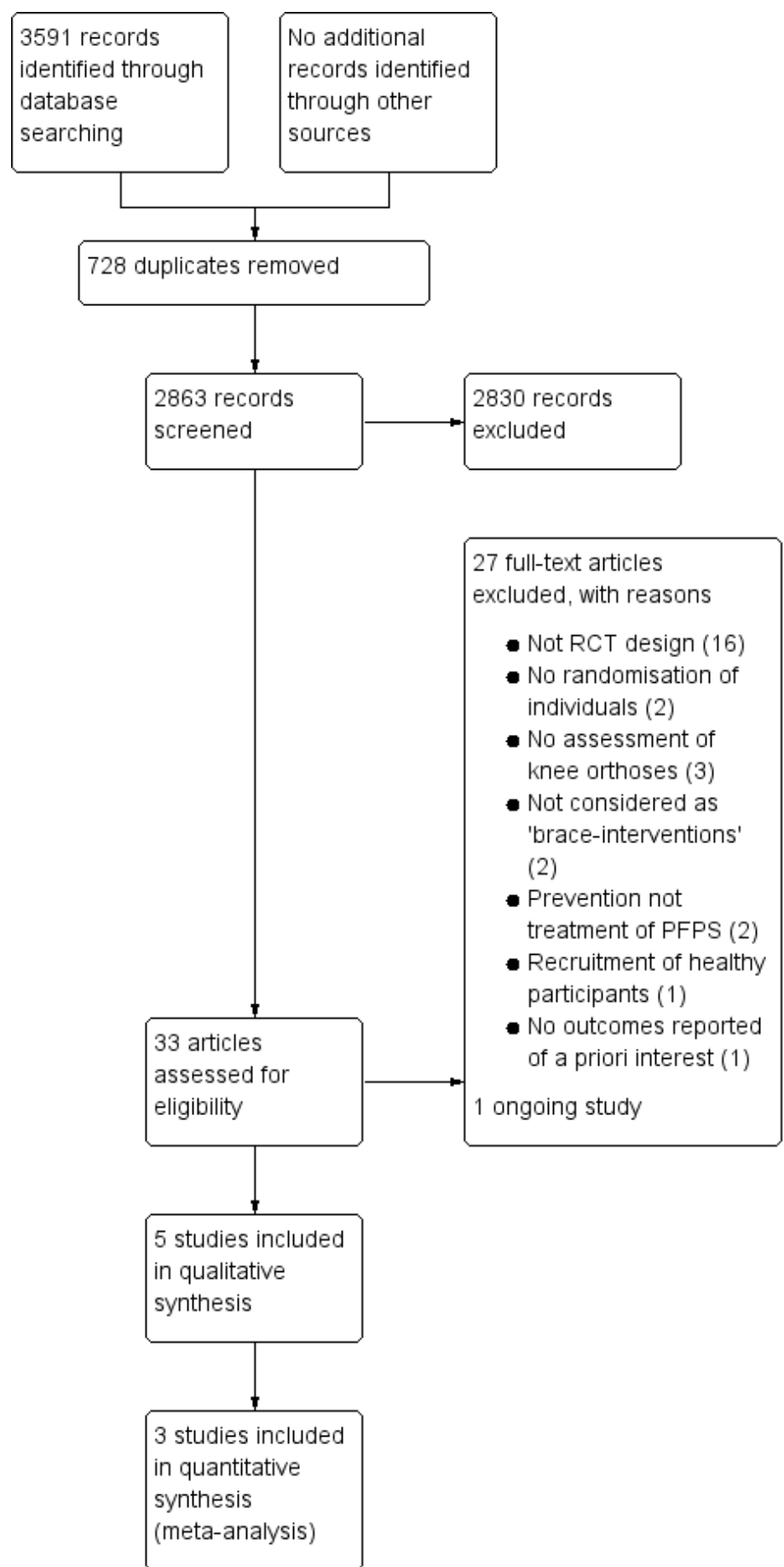


The search was completed in June 2015. We screened a total of 3463 records from the following databases: Cochrane Bone, Joint and Muscle Trauma Group Specialised Register (20 records); CENTRAL (319), MEDLINE (452), EMBASE (500), AMED (99), SportDiscus (63), CINAHL (85), the WHO International Clinical Trials Registry Platform (133), Current Controlled Trials (42), the PEDro database (1682) and OpenGrey (68). We also identified 128 potentially eligible trials from a search of the Bone and Joint Journal's Orthopaedic Proceedings.

The search identified a total of 33 trials for potential inclusion, for which, where possible, full reports were obtained. We included five trials (Evcik 2010; Finestone 1993; Lun 2005; Miller 1997; Moller 1986) and excluded 26 (Antich 1986; Avraham 2007; BenGal 1997; Denton 2005; Draper 2009; Farkas 1997; Fukuschima 1992; Greenwald 1996; Gulling 1996; Lindberg 1988; Lysholm 1984; McCrory 2004; McCrory 2007; Palumbo 1981; Powers 1999; Powers 2004; Roostayi 2009; Sathe 2002; Selfe 2008; Selfe 2011; Straub 2012; Timm 1998; Van Tiggelen 2004; Van Tiggelen 2011; Wijnen 1996; Worrell 1998). Two ongoing studies were identified (DRKS00003291; IRCT138810293101N1); of these, one was excluded (IRCT138810293101N1). No studies await classification.

\section{Included studies}

This review included five trials which recruited a total of 391 participants and reported results for 368 of these. Details of the individual trials are presented in the Characteristics of included studies.

\section{Design}

All five included trials were described as randomised trials but provided either no or limited information on the method used. Based on the information supplied, Evcik 2010 appears to be quasi-randomised. Two trials had two groups (Evcik 2010; Moller 1986); two trials had three groups (Finestone 1993; Miller 1997); and one trial had four groups (Lun 2005). From the description provided and the numbers allocated in each group in Finestone 1993, it is uncertain whether there was randomisation between the two orthosis groups (see below). The unit of randomisation appeared to be individual participants in all five trials. Two trials were described as single-blinded (Evcik 2010; Lun 2005).

\section{Sample size}

The number of participants for whom data were reported in each trial ranged from 35 (Moller 1986) to 129 (Lun 2005).

\section{Setting}

The trials were performed in one of five different countries: Canada (Lun 2005), Denmark (Moller 1986), Israel (Finestone 1993), Turkey (Evcik 2010), and USA (Miller 1997). All trials were singlecentre trials.

\section{Participants}

Participants in two trials were military recruits undergoing training (Finestone 1993; Miller 1997). The other three trials recruited participants from health clinics (Evcik 2010; Lun 2005; Moller 1986). Although no trials recruited participants who were categorised as elite or professional athletes, military training does comprise intensive exercise regimens.

The percentages of male participants in the individual trials ranged from 16\% in Evcik 2010 to 100\% in Finestone 1993. There were more females than males in the three non-military trials. Participant age was not reported in the two military recruit trials. The mean age of participants was 42 years in Evcik 2010, 35 years in Lun 2005, and 23 years in Moller 1986.

Two trials recruited participants with bilateral symptoms: 25 participants (42\%) in Finestone 1993 and 57 participants (44\%) in Lun 2005.

Duration of symptoms varied considerably across the five trials. Symptoms were acute in both two military training trials. In Finestone 1993, duration of symptoms within two weeks of starting military training and in Miller 1997, within three weeks of starting military training. The mean duration of symptoms was 8.3 months in Lun 2005 and 21 months in both Evcik 2010 and Moller 1986. Duration of symptoms ranged from 1 to 80 months in Evcik 2010 and 3 to 120 months in Moller 1986.

The eligibility criteria for each study are presented in the Characteristics of included studies tables. The most frequently used criterion to determine PFPS in trial cohorts was reported pain on activities such as squatting, prolonged sitting, ascending or descending stairs, walking or running which was used in four trials (Evcik 2010; Finestone 1993; Lun 2005; Miller 1997). Positive signs of symptoms on physical examination including Clarke's compression test, apprehension test, maltracking or patellar tilting were used in two trials (Evcik 2010; Finestone 1993), whilst one trial included radiological evidence of patellofemoral congruence (Evcik 2010), and another trial (Moller 1986) based inclusion on the Turba Score (Turba 1979) for signs and symptoms of PFPS.

\section{Interventions}

Three trials tested more than one intervention (Finestone 1993; Lun 2005; Miller 1997). Consequently, these trials appeared in more than one comparison in the analyses.

Knee orthoses for treating patellofemoral pain syndrome (Review) 


\section{Orthoses}

Five different orthoses were used in the included trials. These were categorised for analysis as either knee braces, knee sleeves or patellar straps.

Four trials assessed four different knee sleeves (Evcik 2010; Finestone 1993; Lun 2005; Miller 1997). Evcik 2010 tested a neoprene knee sleeve with a patella cut-out (Altex Patellar Knee Support, AL-2285C). In Finestone 1993, participants received either an unnamed elastic neoprene knee sleeve without patella cut-out or a Genutrain knee sleeve with a silicone patellar ring (Bauerfeind GmbH, Kempen, Germany). In Lun 2005, the knee sleeve group participants received an unnamed, simple elastic neoprene knee sleeve, which did not have a patella cut-out. Miller 1997 tested a neoprene knee sleeve with a patella cut-out and additional supportive straps above and below the patellar (Palumbo Dynamic Knee Brace - Dynorthotics, Vienna, Virginia).

Two trials assessed knee braces (Lun 2005; Moller 1986). Lun 2005 randomised a group to a Special FX Knee Brace (Generation II Orthotics Inc, Richmond, British Columbia, USA), which was a knee brace that included a Y-shaped inferior patellar buttress pad and external stabilisation strap for the patellofemoral joint. Moller 1986 evaluated the use of a custom-made knee brace made of orthoplast. This was worn from the mid-thigh region to the foot, cupping the heel. The brace permitted a knee range of motion from zero to 30 degrees of flexion. In comparison, all other knee orthoses permitted unrestricted knee range of motion. Moller 1986 was the only study that did not use a pre-fabricated (off-the-shelf) knee orthosis.

One study assessed the outcomes of the use of a patella strap (Miller 1997). This was the Cho-Pat Knee Strap (Cho-Pat Inc, Hainesport, New Jersey, USA), which was a neoprene buttress strap that was positioned over the inferior pole of the patellasuperior aspect of the patellar tendon when standing. The orthosis was purported to reduce patellofemoral joint contact pressures by off-loading the patellar tendon (Miller 1997).

In two trials, participants randomised to these interventions were instructed to wear these orthoses throughout the day and during physical activity, and only to remove them for sleeping or rest periods (Evcik 2010; Lun 2005). Miller 1997 instructed their participants to wear either their knee sleeve or patella strap orthoses during exercising and all military training activities. Two trials did not specify when knee orthoses were worn by their participants (Finestone 1993; Moller 1986). However, Finestone 1993 reported that recruits were not allowed to discontinue their knee orthoses "without permission of their medical officer".

The knee orthoses were worn for the duration of the trial's follow-up periods with the exception of Moller 1986. Moller 1986 required participants to wear the orthosis for six weeks, and evaluated outcomes up to 12 months following randomisation.

\section{Exercise prescriptions}

The exercise prescription provided to participants differed between the included trials. In Finestone 1993, participants were advised to continue with their basic military training with no additional therapeutic exercises. In Miller 1997, participants continued on with their military training but were also enrolled on a physical therapy programme. The other three trials used a home-based exercise programme (Evcik 2010; Lun 2005; Moller 1986). All programmes incorporated basic quadriceps strengthening exercises. These included isometric and isotonic exercises (Evcik 2010), progressive squats and lunges (Lun 2005) and targeted vastus medialis strengthening (Miller 1997). Moller 1986 also included targeted hamstring strengthening whilst two trials also included stretching as part of their prescription (Lun 2005; Miller 1997). Full details of these programmes are presented in the Characteristics of included studies table.

The duration and intensity of the exercises also varied in their prescription across the trials. This ranged from one set of 10 or more repetitions five times a week (Evcik 2010), to up to 15 minutes of exercises four times a day (Moller 1986). Miller 1997 did not document clearly how many repetitions and how frequently exercises were prescribed and completed.

\section{Other co-interventions}

Only Miller 1997 acknowledged the inclusion of a second intervention as part of their exercise programme or orthosis programme. All participants in this trial were also prescribed 800 milligrams of ibuprofen, administered three-times daily.

\section{Comparisons}

All five trials compared a knee orthosis versus a 'no treatment' control group, with all participants in the comparison receiving exercises, either through a military training programme (Finestone 1993), a physical therapy programme as well as military training (Miller 1997), or a home-based exercise programme.

Two trials directly compared different categories of knee orthoses (Lun 2005; Miller 1997). Lun 2005 compared a knee brace with a knee sleeve, and Miller 1997 compared a patellar strap with a knee sleeve. Although one group in Finestone 1993 was given a knee sleeve with a patellar ring and another group was given a knee sleeve only, we are unsure whether group allocation to the two different knee orthoses was randomised.

One trial also compared a knee orthosis (knee brace) with exercise (Lun 2005).

None of the trials compared different modes of using the same knee orthosis.

\section{Outcomes}

Knee pain was reported by all five trials, with three trials using a VAS to measure this (Evcik 2010; Lun 2005; Miller 1997). Pain was assessed on a VAS during sporting activity, one hour after 
sporting activity and following 30 minutes of sitting with knees flexed in Lun 2005, whilst the change in VAS pain scores from pre-intervention to final follow-up was assessed in Miller 1997. A numerical rating of knee pain during activities was used in one trial (Finestone 1993). In addition, the resolution of pain was also assessed in Finestone 1993 using a subjectively rated one to four Likert pain assessment. Moller 1986 assessed swelling, pain, symptoms of instability, and limitations of activity using criteria developed by Turba 1979. This involved a numerical rating system to categorise patient outcomes as excellent, good, fair or poor. Functional outcomes were assessed in two trials (Evcik 2010; Lun 2005). Evcik 2010 used both the WOMAC score (Klassbo 2003) and the Fulkerson-Shea Patellofemoral Evaluation score (Owens 2002). Lun 2005 using a modified version of the Knee Function Scale that had been previously utilised and validated in PFPS ( Werner 1993).

Participant satisfaction with their treatment was assessed in Finestone 1993 using a one to four Likert system rating. No other studies specifically assessed patient satisfaction.

The impact on sporting or occupational participation was reported in two trials (Miller 1997; Moller 1986). Miller 1997 documented the number of military personnel (their participants) who continued their two months of basic military training. Moller 1986 assessed how many participants returned to sport 12 months postrandomisation.

The incidence of complications was assessed in one study ( Finestone 1993). This was a planned strategy rather than an ad hoc assessment of recording complications.

No trials reported data on a number of important outcome measures including LEFS (Blinkley 1999), the Kujala Patellofemoral Disorder Score (Kujala 1993) or the KOOS (Roos 1998) scores for functional outcomes, health-related quality of life or general health assessments, or data on resource use or costs of the interventions.

\section{Follow-up periods}

Trial follow-up periods for the included trials ranged from six weeks (Evcik 2010) to 12 months post-randomisation (Moller 1986). Miller 1997 assessed outcomes up to eight weeks, Lun 2005 assessed their participants to 12 weeks, whilst Finestone 1993 assessed outcomes fortnightly over a 14-week basic military training programme, and then two months following completion of training.

Data were collected at intervals within these follow-up periods in four trials (Finestone 1993; Lun 2005; Miller 1997; Moller 1986). Finestone 1993 assessed their outcomes every two weeks within their 14-week follow-up period, and two months after completion of basic military training. Outcomes were assessed at baseline, three, six and 12 weeks post-randomisation in Lun 2005. The Miller 1997 cohort were assessed weekly for the duration of their eight-week follow-up period. Moller 1986 assessed their participants at six weeks, three months and 12 months post-randomisation.

\section{Excluded studies}

The reasons for not including 27 potentially eligible papers following the search strategy results are summarised in the Characteristics of excluded studies.

Sixteen studies were excluded because they were neither randomised nor quasi-randomised controlled trials (Draper 2009; Farkas 1997; Fukuschima 1992; Greenwald 1996; Gulling 1996; IRCT138810293101N1; Lindberg 1988; Lysholm 1984; McCrory 2004; McCrory 2007; Palumbo 1981; Powers 1999; Powers 2004; Roostayi 2009; Sathe 2002; Worrell 1998). Two further studies were excluded because randomisation was used only to allocate the order of interventions tested within participants (Selfe 2011; Straub 2012). Two trials were excluded since they investigated the use of knee orthoses in the 'prevention' rather than 'treatment' of PFPS (BenGal 1997; Van Tiggelen 2004). In three trials, no form of knee orthosis was investigated (Antich 1986; Avraham 2007; Wijnen 1996). Two studies were excluded since they were considered as testing a resistance exercise device rather than a brace (Denton 2005; Timm 1998). Both studies used a Protonics exercise device knee brace (Inverse Technology Corporation, Lincoln, NE) but since the intervention involved a specific exercise programme, it is predominantly an exercise intervention rather than a knee orthosis. One trial was excluded since it recruited participants who were without signs or symptoms of PFPS (Selfe 2008). One trial was excluded since it did not report any of the pre-defined outcome measures of interest, solely documenting concentric isokinetic muscle outcomes (Van Tiggelen 2011).

\section{Ongoing studies}

Details of the one ongoing trial are provided in the Characteristics of ongoing studies. DRKS00003291 is a multicentre trial based in Germany that aims to compare Patella Pro Orthosis plus physiotherapy versus physiotherapy alone in 135 people who have had PFPS lasting between two months and two years.

\section{Risk of bias in included studies}

All five included trials were critically appraised using Cochrane's 'Risk of bias' tool (Higgins 2011a). The results for each included trial are presented in the Characteristics of included studies. A summary of the risk of bias results is presented graphically in Figure 2 and Figure 3. All five trials were judged at high risk of bias from a minimum of three domains, of which one was performance bias reflecting the logistical problems in these trials of blinding of participants and care providers. 
Figure 2. Risk of bias graph: review authors' judgements about each risk of bias item presented as percentages across all included studies

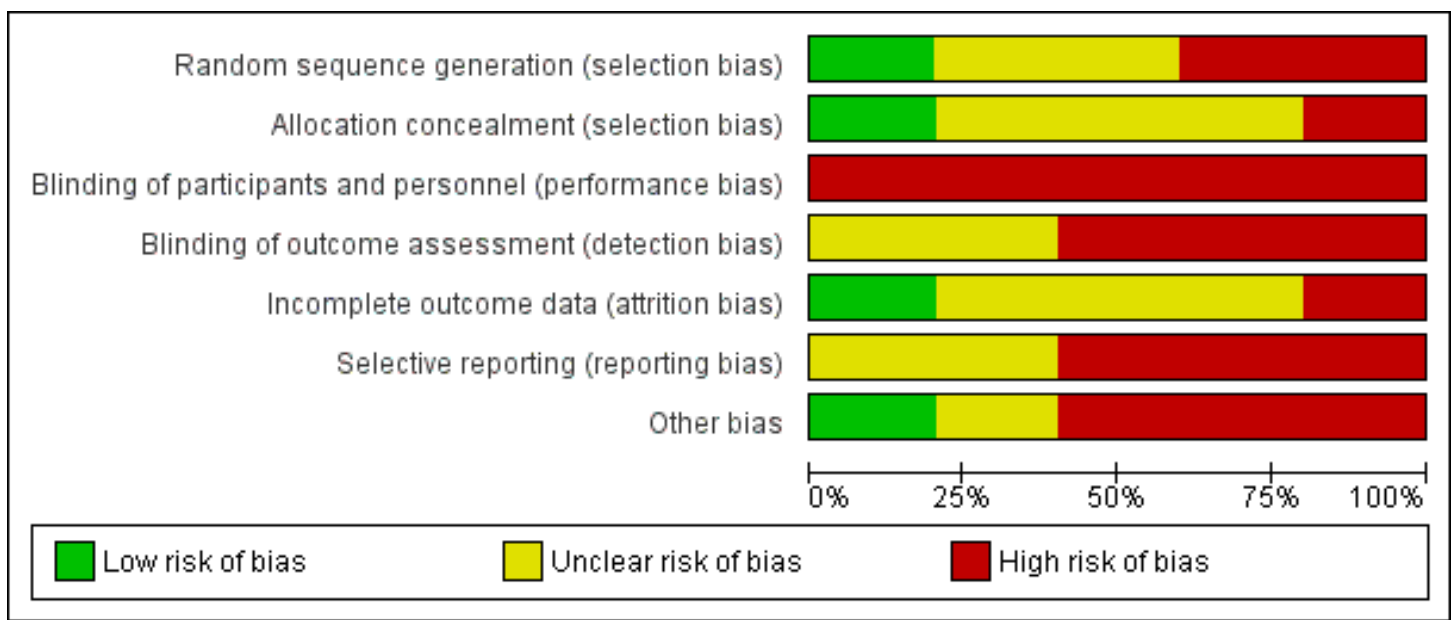


Figure 3. Risk of bias summary: review authors' judgements about each risk of bias item for each included study

\begin{tabular}{|c|c|c|c|c|c|c|c|}
\hline & 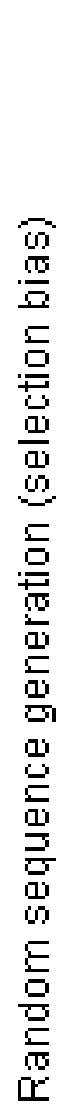 & 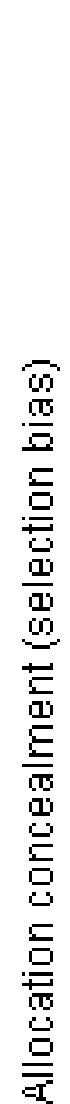 & 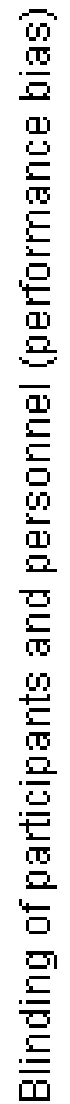 & 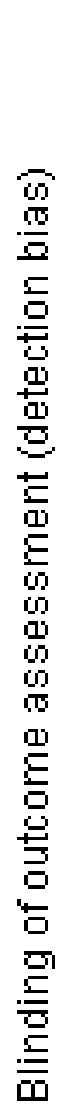 & 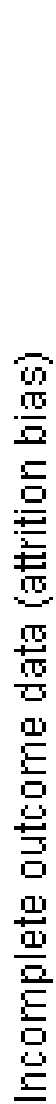 & 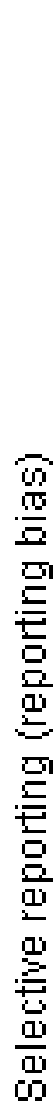 & 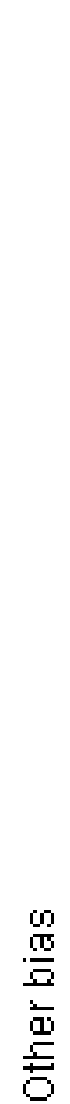 \\
\hline Evcik 2010 & & & & $?$ & & $?$ & + \\
\hline Finestone 1993 & & $?$ & & & $?$ & & \\
\hline Lun 2005 & + & $\perp$ & & $?$ & & $?$ & \\
\hline willer 1997 & $?$ & $?$ & & & $?$ & & $?$ \\
\hline Moller 1986 & $?$ & $?$ & & & ? & & \\
\hline
\end{tabular}




\section{Allocation}

Only Lun 2005 provided adequate details of the method of sequence generation (use of a random number generator) and allocation concealment (independent assignment); based on this information, we judged this trial to have a low risk of selection bias. We judged Evcik 2010 to be a high risk of selection bias reflecting the quasi-randomisation method of sequence generation, which was described as being based on "consecutive admissions". The other three trials provided no details of their methods and we judged these at unclear risk of bias for both domains, except for sequence generation for Finestone 1993. We judged this trial at high risk of bias because of the lack of clarity on the allocation into one or other of the two knee-sleeve groups.

\section{Blinding}

All five included trials had a high risk of performance bias in respect of blinding of participants and trial personnel. Due to the nature of knee orthoses and exercise interventions, it may be considered logistically impossible to blind participants or clinicians to group allocation. Lun 2005 was the only paper to document who applied the orthoses under investigation. None of the trials reported whether any standardised information or 'scripts' were used to inform the participants about their orthoses and how and when to wear them in a standardised way. Accordingly, there was a high risk of bias from not standardising assessments via this means and by not blinding clinicians or researchers or both to group allocation.

Both Evcik 2010 and Lun 2005 claimed to be 'single-blinded' but measures to ensure effective blinding to group allocation were not described. Since subjective outcomes reported by the patients were not blinded, we judged both trials to be at unclear risk of bias. We judged the other three trials to be at high risk of detection bias.

\section{Incomplete outcome data}

Although all five trials seemed to document the number of participants who started and completed the trial, only Evcik 2010 was at low risk of bias relating to incomplete data. Three trials were at unclear risk of bias, reflecting lack of data on the numbers of participants, rather than knees, allocated to the interventions in Finestone 1993, greater than 10\% loss to follow-up in Miller 1997, and incomplete reporting of results in Moller 1986. We judged Lun 2005 at high risk of attrition bias reflecting the postrandomisation exclusions for which the group allocation was not reported, and discrepancies between table and figures reporting pain and function data in the report.

\section{Selective reporting}

No trials published a priori protocols. Three trials demonstrated a high risk of reporting bias within their papers (Finestone 1993; Miller 1997; Moller 1986), either through not presenting numerical data to support the conclusions made within the paper (Moller 1986) or not presenting all follow-up interval data for pre-specified outcome measurements (Finestone 1993; Miller 1997). Of note, whilst Miller 1997 reported that their cohort was followed for eight weeks, only the one week, and two to three week data was presented in the paper. Two trials clearly presented all outcomes outlined in their methods sections (Evcik 2010; Lun 2005) and so were judged at unclear risk of bias.

\section{Other potential sources of bias}

Three trials were at high risk of other bias (Finestone 1993; Lun 2005; Moller 1986). This reflected unresolvable unit of analyses issues relating to inclusion of participants with bilateral symptoms in Finestone 1993 and Lun 2005; and a very poorly described and probably executed data collection process in Moller 1986. We judged that the lack of baseline characteristics data for the individual groups in Miller 1997 put this trial at unclear risk of other bias.

\section{Effects of interventions}

See: Summary of findings for the main comparison Summary of findings: Knee orthosis (any type) and exercise versus control (exercise only) for treating patellofemoral pain syndrome As described, two trials recruited participants with bilateral symptoms: 25 participants (42\%) in Finestone 1993 and 57 participants (44\%) in Lun 2005. Accordingly there were unit of analysis issues to be considered when conducting our analyses. Additionally, there were data discrepancies between table and figures in the article by Lun 2005, a trial that contributes to all three main comparisons for which there are data. Given the sparse data, no subgroup analysis was undertaken.

\section{Comparison I: Knee orthosis and non-operative intervention (e.g. exercise) versus non-operative intervention alone}

All five included trials compared the use of a knee orthosis and an exercise programme with an exercise programme alone. Lun 2005 and Moller 1986 assessed knee braces; Evcik 2010, Finestone 1993, Lun 2005 and Miller 1997 assessed knee sleeves; and Miller 1997 also assessed a knee strap. Four trials presented short-term outcomes (Evcik 2010; Lun 2005; Miller 1997; Moller 1986). Finestone 1993 presented medium term data with final follow- 
up completed two months after a 14 weeks military training programme. One trial presented long-term outcomes at 12 months (Moller 1986).

\section{Primary outcomes}

\section{Pain}

Individually, none of the three trials providing pain VAS ( 0 to 10 ; higher scores mean worse pain) data found a significant difference between knee orthosis versus no knee orthosis at the latest followup for which data were provided (Evcik 2010; Lun 2005; Miller 1997). Pooled final pain score data from Evcik 2010 (knee sleeve) at six weeks and Lun 2005 (knee brace and knee sleeve) at 12 weeks, and change score data up to two or three weeks for Miller 1997 (knee sleeve and patellar strap) showed no clinically important or statistically significant difference between knee orthosis plus exercise versus exercise alone (MD - 0.46 favouring knee orthoses, 95\% CI -1.16 to $0.24 ; \mathrm{P}=0.19 ; 234$ participants; Analysis 1.1; Figure 4). Although the populations and pain measures and timing are clinically heterogeneous, the lack of statistical heterogeneity is notable (Heterogeneity: $\left.\mathrm{Chi}^{2}=1.11, \mathrm{df}=4(\mathrm{P}=0.89) ; \mathrm{I}^{2}=0 \%\right)$. A sensitivity analysis using the number of knees as denominators in Lun 2005 showed a similar result, with the expected narrowing of the confidence interval ((MD -0.41, 95\% CI -1.04 to 0.23 ; Analysis 1.2).

Figure 4. Forest plot I.I. Comparison: knee orthosis and exercises versus exercises alone. Outcome: pain during activity ( 0 to 10 ; higher score means worse pain)

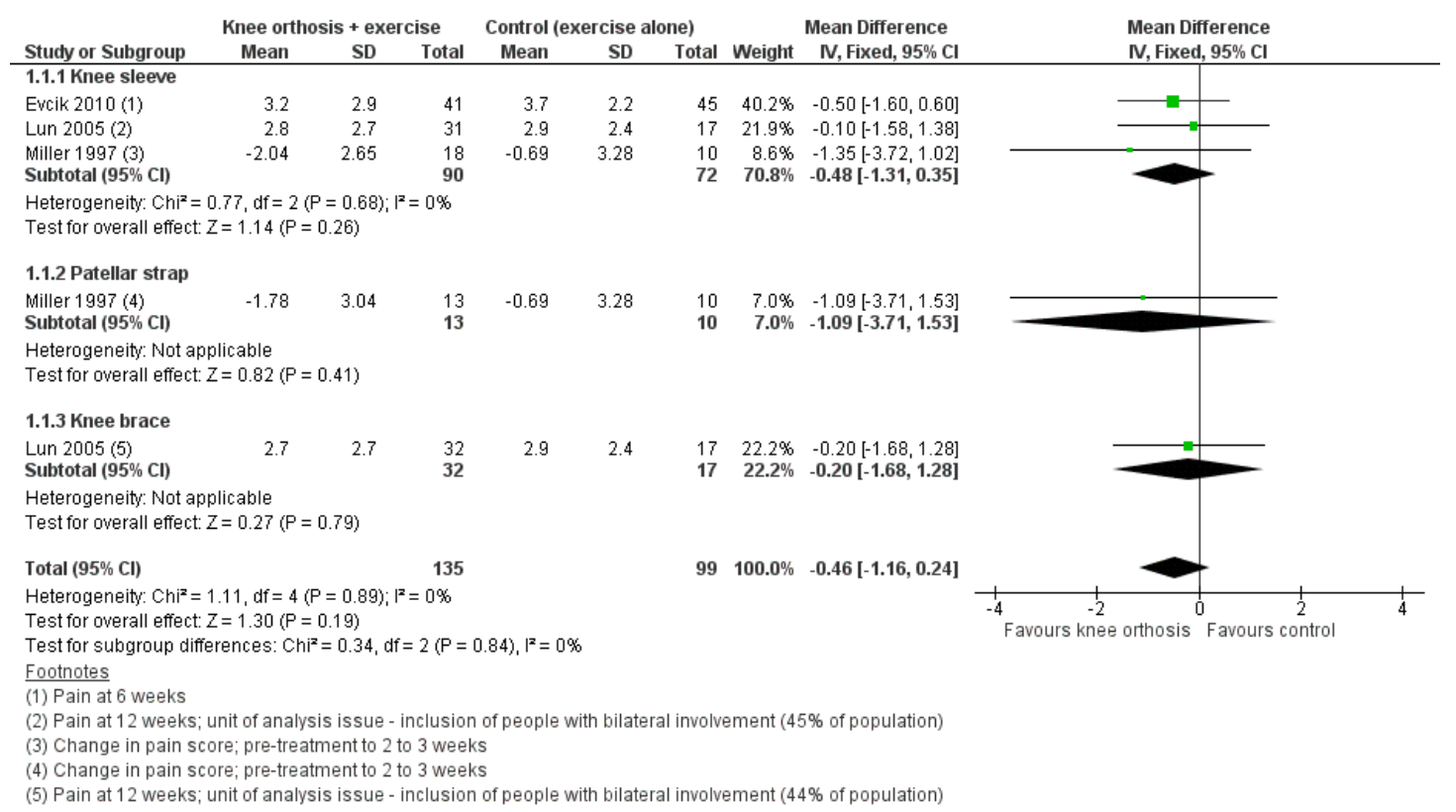

Lun 2005 reported finding no statistically significant differences between the two groups for either knee orthosis in any of the three pain assessment scores (0 to 10: higher values mean worse pain) at 12 weeks post-commencement of treatment. Pooled data from the two knee orthosis groups for the three pain measures (pain during sporting activity; pain one hour after sporting activity; pain following 30 minutes of sitting with knees flexed) are presented in Analysis 1.3. Also presented are sensitivity analyses using the number of knees as denominators, which as above display nar- rower confidence intervals. The pooled results showed no between group differences in two of the pain measures. Although the results favoured the control (exercise only) group for pain assessed one hour after sporting activity, the mean differences were not clinically important. As noted above, we also have concerns over data discrepancies in Lun 2005 where the labelling of mean values presented in the graphs indicated the converse applied.

Finestone 1993 used a subjectively rated four-point Likert pain 
scale (1 (discomfort) to 4 (very severe pain, potentially stopping training). They reported no statistically significant difference in pain scores at end of training between participants randomised to receive a knee sleeve ( 22 knees; mean score decreased 2.05 points) or a knee sleeve with a patella ring ( 22 knees; mean score decreased 1.48 points) and basic military training, compared with basic military training alone ( 40 knees; mean score decreased 1.69 points) at 14 weeks post-randomisation (reported $\mathrm{P}>0.05$ ).

In Moller 1986, pain was measured as part of the Turba Score, which was reported at 12 weeks and 12 months follow-up. They found little difference between the two groups in the numbers of participants with excellent or good results, reflecting a reduction in symptoms including swelling, pain and instability and improved function at either follow-up (Analysis 1.4).

\section{Function}

Evcik 2010 reported WOMAC functional scores (0 to 68; higher values mean worse function) at six weeks and Lun 2005 reported the results of a modified version of the Knee Function Scale (0 to 53; higher values mean better function). Pooled data from Evcik 2010 (knee sleeve) and Lun 2005 (knee brace and knee sleeve) favoured the control (exercise only) group (SMD -0.25, 95\% CI -0.55 to $0.05 ; \mathrm{P}=0.10$; Analysis 1.5 ). A sensitivity analysis using the number of knees as denominators also favoured the control group (SMD -0.28, 95\% CI -0.55 to -0.01; P = 0.04; Analysis 1.5). The SMD result equates to a small difference at most and in absolute terms, the mean differences for each trial were small and not clinically important.

\section{Secondary outcomes}

\section{Quality of life}

No studies reported this outcome.

\section{Impact on sport/participation}

Two trials assessed outcomes on the impact on sport participation in very different populations (Miller 1997; Moller 1986). Two participants in the knee orthosis group (both were in the knee sleeve group) withdrew from the two-month military training programme (2/31 versus $0 / 20$; RR 3.28, 95\% CI 0.17 to 64.99; Analysis 1.6). The data on this outcome were incomplete for Moller 1986, which reported that 29 of the 35 participants had given up sports activities at the start and that after three months, three participants of the knee brace group and two in the control group had resumed their previous activities. At 12 months, an overall total of eight participants could perform their previous activities.

\section{Resource use}

No studies reported this outcome.

\section{Participant satisfaction}

This outcome was measured but not reported in Finestone 1993.

\section{Complications}

Only Finestone 1993 actively recorded complications and in the knee orthosis groups only. Sixteen complications, consisting of discomfort or local skin abrasions, were recorded for the 44 knees in the two knee orthosis groups: 4 (18\% of 22 knees) occurred in the knee sleeve group and 12 (55\% of 22 knees) occurred in the knee sleeve with patellar ring group.

\section{Comparison 2: One type of knee orthosis versus another}

Three trials compared different types of knee orthoses (Finestone 1993; Lun 2005; Miller 1997); all participants in the three trials also received exercises. However, we are uncertain whether there was random allocation between the two types of knee orthoses used in Finestone 1993. Lun 2005 compared a knee brace with a knee sleeve, Miller 1997 compared a patellar strap with a knee sleeve, and Finestone 1993 compared knee sleeve with a patellar (cut-out) ring versus a knee sleeve only.

\section{Primary outcomes}

\section{Pain}

Three trials reported pain as an outcome (Finestone 1993; Lun 2005; Miller 1997).

Finestone 1993 used a subjectively rated four point Likert pain scale (1 (discomfort) to 4 (very severe pain, potentially stopping training). Finestone 1993 reported no statistically significant difference in pain scores at end of training between participants randomised to receive a knee sleeve ( 22 knees; mean score decreased 2.05 points) or a knee sleeve with a patella ring ( 22 knees; mean score decreased 1.48 points).

Miller 1997 found no difference between a patellar strap versus a knee sleeve in change of pain scores from pre-intervention to two to three weeks following the commencement of interventions (MD 0.26, 95\% CI -1.80 to 2.32; 31 participants; Analysis 2.1). Lun 2005 found no difference between a knee brace versus knee sleeve in pain during sporting activity scores at 12 weeks (MD $0.10,95 \%$ CI -1.43 to 1.23 ; 63 participants; Analysis 2.1). Similar findings applied to pain assessed following 30 minutes sitting with knees flexed (data not shown). Lun 2005 found no clinically important difference between the two orthoses in pain one hour 
after sporting activity scores at 12 weeks (MD 0.70 favouring knee sleeve, 95\% CI -0.46 to 1.86; 63 participants; Analysis 2.1). Sensitivity analysis using the number of knees as denominators also demonstrated the lack of differences between the two groups, with narrower confidence intervals.

\section{Function}

Only Lun 2005 assessed function as an outcome. Lun 2005 found no clinically important or statistically significant difference between the two orthoses in respect to functional outcomes when assessed using the Knee Function Scale (Werner 1993) (MD -1.00, $95 \%$ CI -4.95 to 2.95; 63 participants; Analysis 2.2) at 12 weeks post-commencement of treatment.

\section{Secondary outcomes}

\section{Quality of life}

No studies reported this outcome.

\section{Impact on sport/participation}

Miller 1997 reported the impact on sporting activity. Two participants in the knee sleeve group withdrew from the two-month military training programme ( $0 / 13$ versus $2 / 18$; RR $0.27,95 \%$ CI 0.01 to 5.22 ; 31 participants; Analysis 2.3).

\section{Resource use}

No studies reported this outcome.

\section{Participant satisfaction}

This outcome was measured but not reported in Finestone 1993.

\section{Complications}

Finestone 1993 reported 16 complications, consisting of discomfort or local skin abrasions, in the two knee sleeve groups (44 knees). Three times as many complication occurred in the knee sleeve with patellar ring group than in the knee sleeve only group: $12 / 22$ versus 4/22; RR 3.00, 95\% CI 1.14 to 7.87; Analysis 2.4). However, as well as unit of analyses problems (data were presented by knees only), it is not clear that the two knee orthoses were allocated randomly.

\section{Comparison 3: Knee orthosis versus another non- operative intervention (e.g. exercise)}

The single trial in this category compared the use of a knee orthosis versus an exercise programme in 66 participants with PFPS (Lun 2005). Thirty-one participants had bilateral symptoms.

\section{Primary outcomes}

\section{Pain}

Lun 2005 found no clinically important or statistically significant differences between the two groups in any of the three pain assessment scores (0 to 10: higher values mean worse pain) at 12 weeks post-commencement of treatment (66 participants; Analysis 3.1): pain during sporting activity (MD - 0.20 favouring exercise, $95 \%$ CI -1.22 to 0.82 ), pain one hour after sporting activity (MD 0.40 , $95 \%$ CI -0.57 to 1.37 ) and pain following 30 minutes of sitting with knees flexed (MD 0.40, 95\% CI: -0.76 to 1.56 ). Sensitivity analyses using the number of knees as denominators also demonstrated the lack of differences between the two groups, with narrower confidence intervals (Analysis 3.2).

\section{Function}

Lun 2005 found no clinically important or statistically significant differences between the two groups in functional outcome ( 0 to 53: higher scores mean greater function) at 12 weeks (MD -2.00 favouring exercise, $95 \%$ CI -5.88 to 1.88; 66 participants; Analysis 3.3). Sensitivity analyses using the number of knees as denominators also demonstrated the lack of differences between the two groups, with narrower confidence intervals (Analysis 3.3).

\section{Secondary outcomes}

Lun 2005 did not report on quality of life; impact on sport or occupational participation, resource use, participant satisfaction or complications.

\section{Comparison 4: Mode of knee orthosis use}

None of the included trials compared clinical outcomes of the parameters of knee orthosis use such as length of time worn and whether they were worn only during sporting or occupational pursuits or all day or night.

\section{DISCUSSION}

\section{Summary of main results}

This review included five single-centre trials reporting results for 368 adults, who were recruited from routine healthcare settings (three trials) or military training (two trials). The evidence for all available outcomes for all comparisons was rated very low quality. This means that we are very uncertain about the results. The trials covered three different types of comparison: knee orthosis and exercises versus exercises alone; one type of orthosis versus another; 
and knee orthosis versus exercises. No trials assessed the mode of knee orthosis use, such as whether the orthosis was worn all day or only during physical activity.

All five trials compared a knee orthosis (knee sleeve, knee brace, or patellar strap) versus a 'no treatment' control group, with all participants receiving exercises, either through a military training programme or a home-based exercise programme. The evidence available for this comparison is summarised in Summary of findings for the main comparison. This shows there is very low quality evidence of no clinically important differences between the two groups in short-term ( 2 to 12 weeks follow-up) knee pain (234 participants, 3 trials) or knee function (183 participants (2 trials)). None of the trials reported on quality of life measures such as the EQ-5D, resource use or participant satisfaction. Although two trials reported on the impact on sporting or occupational participation, one trial (35 participants) did not provide data split by treatment group on the resumption of sport activity and the other reported only on abandonment of military training due to knee pain (both cases were allocated a knee orthosis). One trial (59 participants, 84 affected knees) recording only adverse events in the two knee orthoses (both were knee sleeves) groups, reported 16 knees (36\% of 44 knees) with discomfort or skin abrasion.

Three trials provided very low quality evidence on single comparisons of different types of knee orthosis: a knee brace versus a knee sleeve (Lun 2005: 63 participants), a patella strap with a knee sleeve (Miller 1997: 31 participants), and a knee sleeve with a patellar ring versus a knee sleeve only (Finestone 1993: 44 knees). None of the three trials found an important difference between the two types of knee orthosis in pain. Only Lun 2005 reported on knee function, finding no clinically important difference between a knee brace and a knee sleeve. None of the trials reported on quality of life, resource use or participant satisfaction. Miller 1997 reported that both participants quitting military training due to knee pain were allocated a knee sleeve. While it is not clear whether Finestone 1993 randomised the allocation of the two knee sleeves, they found three times as many knees with adverse effects (discomfort or skin abrasion) in those given knee sleeves with a patella ring than those given knee sleeves only (12/22 versus 4/22).

One trial compared a knee orthosis (knee brace) with exercise (Lun 2005; 66 participants). It found very low quality evidence of no clinically important difference between the two intervention groups in pain or knee function. Lun 2005 did not report on quality of life, impact on sporting or occupational participation, resource use, participant satisfaction or complications.

\section{Overall completeness and applicability of evidence}

Despite our comprehensive search, we could include only five small trials, with a maximum of 45 participants in an intervention group. Of the 591 recruited participants, we could pool data for a maximum of $234(40 \%)$ participants for one outcome (pain) of our main comparison. The data available for other outcomes and comparisons were even more limited. Of particular note is the lack of data on complications, such as skin abrasions or irritation for people prescribed knee braces, an outcome reported only in Finestone 1993.

Below we consider applicability of evidence in terms of the sport activity, age and gender of the trial participants, the types of knee orthoses under test, and outcome measurement including timing. The current evidence has investigated adults in routine healthcare settings (three trials) or military training (two trials). Although military recruits would have participated in intensive exercise regimens, no trials specifically recruited participants categorised as elite or professional athletes. This was a surprising finding given that previous literature has suggested that PFPS is frequently seen in this population, most notably those who participate in football, volleyball and running (Blønd 1998; Myer 2010; Nejati 2011). In both athletes and military trainees, PFPS is highly prevalent and can be a major problem resulting in career change (Rauh 2010). Furthermore, while PFPS is clinically seen in adolescent and childhood populations (Bizzini 2003; Cook 2010; Dixit 2007), none of the included trials focused on this population. This limits the applicability of these findings to adults only, given the differences between children and adults in normal everyday activities undertaken, growth and development factors and potentially compliance with wearing knee orthoses.

The incidence of PFPS is highest in young, physically active females (Boling 2010). This has been attributed to a difference in biomechanical features between the genders (Barton 2009; Nakagawa 2012). It remains unclear whether the biomechanical effects in modifying patellar tracking that knee orthoses are purported to offer (Shellock 1994; Shellock 2000) have a different efficacy between males and females. Moreover, there were insufficient data from the trials in this review to perform subgroup analyses based on gender.

The current evidence has centred around evaluating the effectiveness of knee sleeves and knee braces. This is consistent with usage of these devices and with findings of previous summaries of the literature (Crossley 2001). Only Miller 1997 investigated clinical outcomes of a patellar strap, whilst no trials investigated the use of knee bandages. Overall, there were insufficient data for either direct or indirect comparisons of the knee orthoses tested by the included trials to draw conclusions on the relative effects of the different knee orthoses. Indeed, the statistical homogeneity of the results for pain is notable given the heterogeneity in the populations, outcome measurement, including timing, and the knee orthoses. The descriptions of the application of the knee orthoses were incomplete, particularly in two trials (Finestone 1993; Moller 1986). Moreover, there is no evidence available to inform on the optimal parameters for using knee orthoses, e.g. during exercise only versus during waking hours. Also of note is that an exercise programme was a co-intervention for the comparisons of knee orthoses versus control; no trial compared knee orthosis alone versus 
no knee orthosis.

Although the Kujala Patellofemoral Disorder Score (Kujala 1993) and WOMAC score (Klassbo 2003) have been shown to be valid for people with PFPS (Kujala 1993; Laprade 2002), several outcome measures presented in this review, such as the Turba score (Turba 1979) and Knee Function Score (Werner 1993), have not been validated.

The timing of outcome assessment of the included trials also limits applicability. All but Moller 1986 evaluated outcomes of knee orthoses within three months, and so it is unclear whether the results would differ if the knee orthosis was worn for longer. Where the same generic outcome was assessed, the trials used different measures and at different times. This hampers interpretation of the results and their applicability. Context is also important as illustrated by Miller 1997), where our secondary outcome of impact on sporting or occupational participation, was measured only in relation to participants discontinuing a basic military training programme due to incapacitating anterior knee pain. The relevance and applicability of this rather blunt outcome to other populations is very questionable. No trials assessed participant satisfaction, which is important in terms of the expectation of sustained use of knee orthosis by people with PFPS.

\section{Quality of the evidence}

We included five trials (one of which was quasi-randomised) that reported results for 368 people who had PFPS. All five trials were at high risk of bias, including performance bias reflecting the logistical problems in these trials of blinding of participants and care providers (see Figure 2). As assessed using the GRADE approach, the available evidence for all reported outcomes is 'very low' quality, therefore raising major questions on the reliability of the results.

The rationales for downgrading the evidence by three levels for individual outcomes for the comparison of knee orthosis and exercise versus exercise alone are provided in the footnotes of Summary of findings for the main comparison. For the comparisons of difference knee orthoses and knee orthosis versus exercise, we downgraded the evidence two levels for major study limitations resulting in very serious risk of bias and one level for imprecision reflecting that the results were from small single trials.

\section{Potential biases in the review process}

Efforts were made to limit potential biases during the review process. This included the searching of a variety of relevant published and grey literature/trial registry databases with no language restriction to ensure we identified all relevant trials. Secondly, two review authors independently conducted the trial identification, data extraction and assessment of risk of bias, adjudicated by a third review author. Through this, the process of verification of data was ensured to minimise the risk of misreporting of trial findings. The analysis results were verified by all review authors, including a medical statistician (AC). We adopted a purposefully conservative approach to the use and interpretation of data from the two trials that presented substantial unit of analysis issues.

\section{Agreements and disagreements with other studies or reviews}

We identified two recent literature reviews that considered the use of knee orthosis for treating PFPS (Al-Hakim 2012; Swart 2012). Al-Hakim 2012, which was a narrative review that evaluated the use of all non-surgical interventions for PFPS, provided brief summaries of the individual findings of no benefit from knee orthoses reported by two studies included in our review (Finestone 1993; Miller 1997). Swart 2012, which was a systematic review that evaluated the use of lower limb orthoses and taping, identified three trials testing knee orthoses (Denton 2005; Lun 2005; Miller 1997). Of note is that Denton 2005 is excluded in our review because we consider the intervention tested is essentially a resistive exercise device and not a knee orthosis. Similar to our review, Swart 2012 concluded that more high quality studies were needed "to draw definitive conclusions".

\section{AUTHORS' CONCLUSIONS}

\section{Implications for practice}

Overall, this review has found a lack of evidence to inform on the use of knee orthoses for treating PFPS. There is, however, very low quality evidence from clinically heterogeneous trials using different types of knee orthoses (knee brace, sleeve and strap) that using a knee orthosis did not reduce knee pain or improve knee function in the short term (under three months) in adults who were also undergoing an exercise programme for treating PFPS. There is either no or very limited and very low quality evidence on the long-term effects of using knee orthoses, on adverse events aside from the report of discomfort and skin abrasion in a third of knees from an extensive use of knee sleeves in one trial, on quality of life, impact on sporting or occupational participation, resource use or participant satisfaction. There is very limited and very low quality evidence on the relative effects of different types of knee orthosis or the effects of knee orthoses compared with other nonsurgical interventions such as exercise. There is no evidence to inform on the mode and duration of knee orthosis use.

\section{Implications for research}

There is a need for good-quality clinically-relevant research to inform on the routine use of commonly-available knee orthoses 
for treating PFPS in physically active adults and children. In order to optimise research effort and engender the large, preferably multicentre, randomised trials that are required to inform practice, these should be preceded by research that aims to identify priority questions and attain agreement and, where practical, standardisation regarding diagnostic criteria, including duration of symptoms, and measurement of outcome. Helpful in this regard is the recent progress in moving towards a consensus on the diagnosis and terminology used to define patellofemoral pain syndrome summarised in the International Patellofemoral Pain consensus statements published in 2014 (Witvrouw 2014). Notably, these recommendations include the adoption of the term 'patellofemoral pain'. Our call for this preliminary research and consensus echos recommendations in related Cochrane Reviews evaluating exercise (Van der Heijden 2015) and patella taping (Callaghan 2012). Obtaining agreement on diagnosis and outcome assessment should help to engender the initiation and successful delivery of the adequately powered, CONSORT-compliant randomised controlled trials and the acceptance and applicability of their findings (Boutron 2008).

Although the identification of priority topics for the treatment of people with PFPS requires input from others, we suggest that priority should be given to further randomised trials evaluating our main comparison: knee orthosis plus exercise versus exercise alone in people with PFPS. However, we anticipate the completion and publication of the only ongoing trial we identified, which compares a knee orthosis plus physiotherapy versus phys- iotherapy alone, is also likely to contribute important evidence (DRKS00003291). Consideration should be given to focusing on populations, such as professional athletes, for whom knee orthoses are routinely prescribed for extended periods and for whom persistent PFPS is likely to have more serious consequences including career change. Trials involving children and adolescents should also be prioritised. Outcomes should be investigated over a longer period, at minimum 12 months, and include direct and indirect costs associated with PFPS and the prescription of knee orthoses, participant satisfaction and return to sporting or occupational pursuits.

\section{ACKNOWLEDGEMENTS}

We thank Michael Callaghan, Nigel Hanchard and Helen Handoll for their helpful feedback about versions of the protocol and the full review, and Lindsey Elstub and Laura MacDonald for assistance in the preparation of the protocol and full review. We also thank Joanne Elliott for her assistance in developing and running the search strategies.

This project was supported by the National Institute for Health Research via Cochrane Infrastructure funding to the Cochrane Bone, Joint and Muscle Trauma Group. The views and opinions expressed therein are those of the authors and do not necessarily reflect those of the Systematic Reviews Programme, NIHR, NHS or the Department of Health.

\section{R E F E R E N C E S}

\section{References to studies included in this review}

Evcik 2010 \{published data only\}

Evcik D, Kuru I, Ay S, Maralcan G. Home-based exercise and patellar bracing in the treatment of patellofemoral pain syndrome [Patellofemoral agri sendromu tedavisinde ev egzersiz programi ve patellar breys kullanimi]. Turkiye Fiziksel Tip ve Rehabilitasyon Dergisi 2010;56:100-4. [DOI: $10.4274 / \mathrm{tftr} .56 .100]$

Finestone 1993 \{published data only\}

Finestone A, Radin EL, Lev B, Shlamkovitch N, Wiener M, Milgrom C. Treatment of overuse patellofemoral pain: Prospective randomized controlled clinical trial in a military setting. Clinical Orthopaedics and Related Research 1993; (293):208-10. [PUBMED: 7687940]

Lun 2005 \{published data only\}

Lun VM, Wiley JP, Meeuwisse WH, Yanagawa TL. Effectiveness of patellar bracing for treatment of patellofemoral pain syndrome. Clinical Journal of Sport Medicine 2005;15(4):235-40. [PUBMED: 16003037]
Miller 1997 \{published data only\} Miller MD, Hinkin DT, Wisnowski JW. The efficacy of orthotics for anterior knee pain in military trainees. A preliminary report. American Journal of Knee Surgery 1997; 10(1):10-3. [PUBMED: 9051172]

Moller 1986 \{published data only\} Moller BN, Krebs B. Dynamic knee brace in the treatment of patellofemoral disorders. Archives of Orthopaedic and Traumatic Surgery 1986;104(6):377-9. [PUBMED: 3754433]

\section{References to studies excluded from this review}

Antich 1986 \{published data only\}

Antich TJ, Randall CC, Westbrook RA, Morrissey MC, Brewster CE. Physical therapy treatment of knee extensor mechanism disorders: comparison of four treatment modalities. Journal of Orthopaedic and Sports Physical Therapy 1986;8(5):255-9. [PUBMED: 18802222]

Avraham 2007 \{published data only\}

Avraham F, Aviv S, Ya’akobi P, Faran H, Fisher Z, Goldman $\mathrm{Y}$, et al. The efficacy of treatment of different intervention 
programs for patellofemoral pain syndrome--a single blinded randomized clinical trial. Pilot study. The Scientific World Journal 2007;7:1256-62. [PUBMED: 17721640]

BenGal 1997 \{published data only\}

BenGal S, Lowe J, Mann G, Finsterbush A, Matan Y. The role of the knee brace in the prevention of anterior knee. American Journal of Sports Medicine 1997;25(1):118-22. [PUBMED: 9006705]

Denton 2005 \{published data only\} Denton J, Willson JD, Ballantyne BT, Davis IS. The addition of the Protonics brace system to a rehabilitation protocol to address patellofemoral joint syndrome. Journal of Orthopaedic and Sports Physical Therapy 2005;35(4): 210-9. [PUBMED: 15901122]

Draper 2009 \{published data only\}

Draper CE, Besier TF, Santos JM, Jennings F, Fredericson $\mathrm{M}$, Gold GE, et al. Using real-time MRI to quantify altered joint kinematics in subjects with patellofemoral pain and to evaluate the effects of a patellar brace or sleeve on joint motion. Journal of Orthopaedic Research 2009;27(5):571-7. [PUBMED: 18985690]

Farkas 1997 \{published data only\}

Farkas R, Glitsch U, Paris M. On the mechanical effects of knee bandages in the therapy of patellar chondropathy. Clinical Biomechanics 1997;12(2):116-21. [PUBMED: 11415680]

Fukuschima 1992 \{published data only\}

Fukushima M, Sigeno Y, Yamamoto K, Nakamura T, Watanabe T. Patellar band for patellofemoral disorders: results and indications. Prosthetics and Orthotics International 1992;16(2):109-13. [PUBMED: 1408668]

Greenwald 1996 \{published data only\}

Greenwald AE, Bagley AM, Frace EP, Paulos LE, Greenwald RM. The biomechanical and clinical evaluation of a patellofemoral knee brace. Clinical Orthopaedics and Related Research 1996;(324):187-95. [PUBMED: 8595755]

Gulling 1996 \{published data only\} Gulling LK, Lephart SM, Stone DA, Irrgang JJ, Pincivero $\mathrm{DM}$. The effects of patellar bracing on quadriceps EMG activity during isokinetic exercise. Isokinetics and Exercise Science 1996;6:133-8.

IRCT138810293101N1 \{published data only\} Ghasemi M. Comparing the effects of Neoprene palumbo \& Geno direxa stable orthoses on pain \& daily activities in patients with Patello Femoral Pain Syndrome. http://apps.who.int/trialsearch/Trial.aspx? TrialID=IRCT138810293101N1 (accessed 23 June 2014).

Lindberg 1988 \{published data only\}

Lindberg U, Gillquist J, Lysholm J. The effect of five different patella braces on performance and pain in an isokinetic quadriceps torque test. In: Muller W, Hackenbruch W editor(s). Surgery and Arthroscopy of the Knee. Basel, Switzerland: Springer Berlin Heidelberg, 1988: 499. [DOI: 10.1007/978-3-642-72782-5 99]
Lysholm 1984 \{published data only\}

Lysholm J, Nordin M, Ekstrand J, Gillquist J. The effect of a patella brace on performance in a knee extension strength test in patients with patellar pain. American Journal of Sports Medicine 1984;12(2):110-2. [PUBMED: 6742285]

McCrory 2004 \{published data only\}

McCrory JL, Quick NE, Shapiro R, Ballantyne BT, Davis I. The effect of a single treatment of the Protonics system on biceps femoris and gluteus medius activation during gait and the lateral step up exercise. Gait and Posture 2004;19 (2):148-53. [PUBMED: 15013503]

\section{McCrory 2007 \{published data only\}}

McCrory JL, Quick NE, Shapiro R, Ballantyne BT, Davis I. The effect of a single treatment of the Protonics system on lower extremity kinematics during gait and the lateral step up exercise. Gait and Posture 2007;25(4):544-8. [PUBMED: 16887352]

Palumbo 1981 \{published data only\} Palumbo PM. Dynamic patellar brace: a new orthosis in the management of patellofemoral disorders. A preliminary report. American Journal of Sports Medicine 1981;9(1):45-9. [PUBMED: 7468897]

Powers 1999 \{published data only\} Powers CM, Shellock FG, Beering TV, Garrido DE, Goldbach RM, Molnar T. Effect of bracing on patellar kinematics in patients with patellofemoral joint pain. Medicine and Science in Sports and Exercise 1999;31(12): 1714-20. [PUBMED: 10613420]

Powers 2004 \{published data only\} Powers CM, Ward SR, Chan LD, Chen YJ, Terk MR. The effect of bracing on patella alignment and patellofemoral joint contact area. Medicine and Science in Sports and Exercise 2004;36(7):1226-32. [PUBMED: 15235330]

Roostayi 2009 \{published data only\} Roostayi MM, Bagheri H, Moghaddam ST, Firooznia K, Razi M, Hosseini M, et al. The effects of vacuumic bracing system on the patellofemoral articulation in patients with patellofemoral pain syndrome. Complementary Therapies in Clinical Practice 2009;15(1):29-34. [PUBMED: 19161952]

Sathe 2002 \{published data only\} Sathe VM, Ireland ML, Ballantyne BT, Quick NE, McClay IS. Acute effects of the Protonics system on patellofemoral alignment: an MRI study. Knee Surgery Sports Traumatology Arthroscopy 2002;10(1):44-8. [PUBMED: 11819021]

Selfe 2008 \{published data only\}

Selfe J, Richards J, Thewlis D, Kilmurray S. The biomechanics of step descent under different treatment modalities used in patellofemoral pain. Gait and Posture 2008;27(2):258-63. [PUBMED: 17532637]

Selfe 2011 \{published data only\} Selfe J, Thewlis D, Hill S, Whitaker J, Sutton C, Richards $\mathrm{J}$. A clinical study of the biomechanics of step descent using different treatment modalities for patellofemoral pain. Gait and Posture 2011;34(1):92-6. [PUBMED: 21570291] 
Straub 2012 \{published data only\}

Straub RK, Cipriani DJ. Influence of infrapatellar and suprapatellar straps on quadriceps muscle activity and onset timing during the body-weight squat. Journal of Strength and Conditioning Research 2012;26(7):1827-37. [PUBMED: 21912298]

Timm 1998 \{published data only\}

Timm KE. Randomized controlled trial of Protonics on patellar pain, position, and function. Medicine and Science in Sports and Exercise 1998;30(5):665-70. [PUBMED: 9588606]

Van Tiggelen 2004 \{published data only\} Van Tiggelen D, Witvrouw E, Cambier D, Roget P, Danneels L, Verdonk R. Effect of bracing on the prevention of anterior knee pain - a prospective randomized study. Knee Surgery Sports Traumatology Arthroscopy 2004;12: 434-9. [DOI: 10.1007/s00167-003-0479-z]

Van Tiggelen 2011 \{published data only\} Van Tiggelen D, Coorevits P, Bernard E, Thijs Y, Witvrouw E. The effects of 6-weeks patellofemoral bracing on quadriceps muscle function. Isokinetics and Exercise Science 2011;19(3):169-73. [DOI: 10.3233/IES-2011-0411]

Wijnen 1996 \{published data only\} Wijnen LACM, Lenssen AF, Kuys-Wouters YSM, De Bie RA, Borghouts JAJ, Bulstra SK. McConnel-therapy versus Coumans-bandage in patients with patellofemoral pain. A randomized pilot study [McConnell-therapie versus Coumans-bandage bij patellofemorale pijnklachen: een gerandomiseerde pilotstudie]. Nederlands Tijdschrift voor Fysiotherapie 1996;106(Suppl 1):12-7.

Worrell 1998 \{published data only\}

Worrell T, Ingersoll CD, Bockrath-Pugliese K, Minis P. Effect of patellar taping and bracing on patellar position as determined by MRI in patients with patellofemoral pain. Journal of Athletic Training 1998;33(1):16-20. [PUBMED: 16558478]

\section{References to ongoing studies}

\section{DRKS00003291 \{published data only\}}

Petersen W. Therapy of the patellofemoral pain syndrome: A prospective randomized study with two treatment groups: Physiotherapy and 2. Recentering orthosis plus physiotherapy. http://apps.who.int/trialsearch/Trial.aspx? TrialID=DRKS00003291 (accessed 23 June 2014).

\section{Additional references}

\section{Al-Hakim 2012}

Al-Hakim W, Jaiswal PK, Khan W, Johnstone D. The nonoperative treatment of anterior knee pain. Open Orthopaedic Journal 2012;6:320-6.

Barton 2009

Barton CJ, Levinger P, Menz HB, Webster KE. Kinematic gait characteristics associated with patellofemoral pain syndrome: a systematic review. Gait and Posture 2009;30 (4):405-16.

\section{Barton 2010}

Barton CJ, Munteanu SE, Menz HB, Crossley KM. The efficacy of foot orthoses in the treatment of individuals with patellofemoral pain syndrome: a systematic review. Sports Medicine 2010;40(5):377-95.

\section{Barton 2011}

Barton CJ, Levinger P, Crossley KM, Webster KE, Menz HB. Relationships between the Foot Posture Index and foot kinematics during gait in individuals with and without patellofemoral pain syndrome. Journal of Foot and Ankle Research 2011;14(4): 10 .

\section{Barton 2013}

Barton CJ, Lack S, Malliaras P, Morrissey D. Gluteal muscle activity and patellofemoral pain syndrome: a systematic review. British Journal of Sports Medicine 2013;47(4): 207-14.

\section{Bizzini 2003}

Bizzini M, Childs JD, Piva SR, Delitto A. Systematic review of the quality of randomized controlled trials for patellofemoral pain syndrome. Journal of Orthopaedic and Sports Physical Therapy 2003;33(1):4-20.

Blinkley 1999

Binkley JM, Stratford PW, Lott SA, Riddle DL. The Lower Extremity Functional Scale (LEFS): scale development, measurement properties, and clinical application. North American Orthopaedic Rehabilitation Research Network. Physical Therapy 1999;79(4):371-83.

\section{Blønd 1998}

Blønd L, Hansen L. Patellofemoral pain syndrome in athletes: a 5.7-year retrospective follow-up study of 250 athletes. Acta Orthopaedica Belgica 1998;64(4):393-400.

Boling 2010

Boling M, Padua D, Marshall S, Guskiewicz K, Pyne $S$, Beutler A. Gender differences in the incidence and prevalence of patellofemoral pain syndrome. Scandinavian Journal of Medicine, Science and Sports 2010;20(5):725-30.

\section{Boutron 2008}

Boutron I, Moher D, Altman DG, Schulz KF, Ravaud P, CONSORT Goup. Extending the CONSORT statement to randomized trials in nonpharmacologic treatment: explanation and elaboration. Annals of Internal Medicine 2008;148(4):295-309.

Brantingham 2012

Brantingham JW, Bonnefin D, Perle SM, Cassa TK, Globe G, Pribicevic M, et al. Manipulative therapy for lower extremity conditions: update of a literature review. Journal of Manipulative \& Physiological Therapeutics 2012;35(2): 127-66.

Callaghan 2007

Callaghan M, Selfe J. Has the incidence of prevalence of patellofemoral pain in the general population in the United Kingdom been properly evaluated?. Physical Therapy in Sport 2007;8(1):37-43.

Callaghan 2012

Callaghan MJ, Selfe J. Patellar taping for patellofemoral pain syndrome in adults. Cochrane Database of 
Systematic Reviews 2012, Issue 4. [DOI: 10.1002/ 14651858.CD006717.pub2]

\section{Chester 2008}

Chester R, Smith TO, Sweeting D, Dixon J, Wood S, Song F. The relative timing of VMO and VL in the aetiology of anterior knee pain: a systematic review and meta-analysis. BMC Musculoskeletal Disorders 2008;9:64.

\section{Chew 2007}

Chew KT, Lew HL, Date E, Fredericson M. Current evidence and clinical applications of therapeutic knee braces. American Journal of Physical Medicine and Rehabilitation 2007;86(8):678-86.

\section{Chiu 2012}

Chiu JK, Wong YM, Yung PS, Ng GY. The effects of quadriceps strengthening on pain, function, and patellofemoral joint contact area in persons with patellofemoral pain. American Journal of Physical Medicine and Rehabilitation 2012;91(2):98-106.

\section{Cook 2010}

Cook C, Hegedus E, Hawkins R, Scovell F, Wyland D. Diagnostic accuracy and association to disability of clinical test findings associated with patellofemoral pain syndrome. Physiotherapy Canada 2010;62(1):17-24.

\section{Cowan 2002}

Cowan SM, Bennell KL, Crossley KM, Hodges PW, McConnell J. Physical therapy alters recruitment of the vasti in patellofemoral pain syndrome. Medicine and Science in Sports and Exercise 2002;34(12):1879-85.

\section{Cowan 2009}

Cowan SM, Crossley KM, Bennell KL. Altered hip and trunk muscle function in individuals with patellofemoral pain. British Journal of Sports Medicine 2009;43(8):584-8.

\section{Crossley 2001}

Crossley K, Bennell K, Green S, McConnell J. A systematic review of physical interventions for patellofemoral pain syndrome. Clinical Journal of Sports Medicine 2001;11(2): 103-10.

\section{Deeks 2011}

Deeks JJ, Higgins JPT, Altman DG (editors). Chapter 9: Analysing data and undertaking meta-analyses. In: Higgins JPT, Green S (editors).Cochrane Handbook for Systematic Reviews of Interventions Version 5.1.0 (updated March 2011). The Cochrane Collaboration, 2011. Available from www.cochrane-handbook.org.

Dixit 2007

Dixit S, DiFiori JP, Burton M, Mines B. Management of patellofemoral pain syndrome. American Family Physician 2007;75(2):194-202, 204.

\section{Earl 2004}

Earl JE, Piazza SJ, Hertel J. The Protonics knee brace unloads the quadriceps muscles in healthy subjects. Journal of Athletic Training 2004;39(1):44-9.

\section{Erkula 2002}

Erkula G, Demirkan F, Kiliç BA, Kiter E. Hamstring shortening in healthy adults. Journal of Back and Musculoskeletal Rehabilitation 2002;16(2-3):77-81.

\section{EuroQol Group 1990}

EuroQol Group. EuroQol - a new facility for the measurement of health-related quality of life. Health Policy 1990;16(3):199-208.

Grelsamer 2009

Grelsamer R, Moss G, Ee G, Donell S. The patellofemoral syndrome; the same problem as the Loch Ness Monster?. The Knee 2009;16(5):301-2.

\section{Herrington 2005}

Herrington L, Simmonds C, Hatcher J. The effect of a neoprene sleeve on knee joint position sense. Research in Sports Medicine 2005;13(1):37-46.

\section{Higgins 2003}

Higgins JPT, Thompson SG, Deeks JJ, Altman DG. Measuring inconsistency in meta-analyses. BMJ 2003;327 (7414):557-60.

\section{Higgins 2011a}

Higgins JPT, Altman DG, Sterne JAC (editors). Chapter 8: Assessing risk of bias in included studies. In: Higgins JPT, Green S (editors). Cochrane Handbook for Systematic Reviews of Interventions Version 5.1.0 (updated March 2011). The Cochrane Collaboration, 2011. Available from www.cochrane-handbook.org.

\section{Higgins 2011b}

Higgins JPT, Deeks JJ, Altman DG (editors). Chapter 16: Special topics in statistics. In: Higgins JPT, Green S (editors), Cochrane Handbook for Systematic Reviews of Interventions Version 5.1.0 (updated March 2011). The Cochrane Collaboration, 2011. Available from www.cochrane-handbook.org.

\section{Hudson 2009}

Hudson Z, Darthuy E. Iliotibial band tightness and patellofemoral pain syndrome: a case-control study. Manual Therapy 2009;14(2):147-51.

\section{Jensen 1999}

Jensen R, Gøthesen O, Liseth K, Baerheim A. Acupuncture treatment of patellofemoral pain syndrome. Journal of Alternative and Complementry Medicine 1999;5(6):521-7.

\section{Keser 2008}

Keser S, Savranlar A, Bayar A, Ege A, Turhan E. Is there a relationship between anterior knee pain and femoral trochlear dysplasia? Assessment of lateral trochlear inclination by magnetic resonance imaging. Knee Surgery, Sports Traumatology, Arthroscopy 2008;16(10):911-5.

\section{Klassbo 2003}

Klassbo M, Larsson E, Mannevik E. Hip disability and osteoarthritis outcome score. An extension of the Western Ontario and McMaster Universities Osteoarthritis Index. Scandinavian Journal of Rheumatology 2003;32(1):46-51. 
Kujala 1993

Kujala UM, Jaakkola LH, Koskinen SK, Taimela S, Hurme M, Nelimarkka O. Scoring of patellofemoral disorders. Arthroscopy 1993;9(2):159-63.

Lankhorst 2012

Lankhorst NE, Bierma-Zeinstra SM, Van Middelkoop M. Risk factors for patellofemoral pain syndrome: a systematic review. Journal of Orthopaedic and Sports Physical Therapy 2012;42(2):81-94.

Laprade 2002

Laprade JA, Culham EG. A self-administered pain severity scale for patellofemoral pain syndrome. Clinical Rehabilitation 2002;16(7):780-8.

Lee 2003

Lee JS, Hobden E, Stiell IG, Wells GA. Clinically important change in the visual analog scale after adequate pain control. Academic Emergency Medicine 2003;10(10):1128-30.

\section{Lefebvre 2011}

Lefebvre C, Manheimer E, Glanville J. Chapter 6: Searching for studies. In: Higgins JPT, Green S (editors). Cochrane Handbook for Systematic Reviews of Interventions Version 5.1.0 (updated March 2011). The Cochrane Collaboration, 2011. Available from www.cochrane-handbook.org.

\section{Muhle 1999}

Muhle C, Brinkmann G, Skaf A, Heller H, Resnick D. Effect of a patellar realignment brace on patients with patellar subluxation and dislocation. American Journal of Sports Medicine 1999;27(3):350-3.

Myer 2010

Myer GD, Ford KR, Barber Foss KD, Goodman A, Ceasar A, Rauh MJ, et al. The incidence and potential pathomechanics of patellofemoral pain in female athletes. Clincal Biomechanics 2010;25(7):700-7.

Nakagawa 2012

Nakagawa TH, Moriya ÉT, Maciel CD, Serrão AF. Frontal plane biomechanics in males and females with and without patellofemoral pain. Medicine and Science in Sports and Exercise 2012;44(9):1747-55.

Nejati 2011

Nejati P, Forogh B, Moeineddin R, Baradaran HR, Nejati M. Patellofemoral pain syndrome in Iranian female athletes. Acta Medicia Iranica 2011;49(3):169-72.

\section{Owens 2002}

Owens BD, Stickles BJ, Balikian P, Busconi BD. Prospective analysis of radiofrequency versus mechanical debridement of isolated patellar chondral lesions. Arthroscopy 2002;18 (2):151-5.

\section{Parikh 2011}

Parikh S, Noyes FR. Patellofemoral disorders: role of computed tomography and magnetic resonance imaging in defining abnormal rotational lower limb alignment. Sports Health 2011;3(2):158-69.

\section{Powers 2012}

Powers CM, Bolgla L, Callaghan M, Collins N, Sheehan F. Patellofemoral pain: proximal, distal and local factors. 2nd International Research Retreat. Journal of Orthopaedic Sports Physical Therapy 2012;42(6):A1-A20.

Rauh 2010

Rauh MJ, Macera CA, Trone DW, Reis JP, Shaffer RA.

Selected static anatomic measures predict overuse injuries in female recruits. Military Medicine 2010;175:329-5.

\section{Roos 1998}

Roos EM, Roos HP, Lohmander LS, Ekdahl C, Beynnon BD. Knee Injury and Osteoarthritis Outcome Score (KOOS) - development of a self-administered outcome measure. Journal of Orthopaedics and Sports Physical Therapy 1998;28(2):88-96.

Roush 2012

Roush JR, Curtis Bay R. Prevalence of anterior knee pain in 18-35 year-old females. International Journal of Sports Physical Therapy 2012;7(4):396-401.

\section{Schünemann 2011}

Schünemann HJ, Oxman AD, Vist GE, Higgins JPT, Deeks JJ, Glasziou P, Guyatt GH. Chapter 12: Interpreting results and drawing conclusions. In: Higgins JPT, Green $S$ (editors), Cochrane Handbook for Systematic Reviews of Interventions Version 5.1.0 (updated March 2011). The Cochrane Collaboration, 2011. Available from www.cochrane-handbook.org.

\section{Shellock 1994}

Shellock FG, Mink JH, Deutsch AL, Fox J, Molnar T, Kvitne R, et al. Effect of a patellar realignment brace on patellofemoral relationships: evaluation with kinematic MR imaging. Journal of Magnetic Resonance Imaging 1994;4(4): $590-4$.

\section{Shellock 1995}

Shellock FG, Mink JH, Deutsch AL, Molnar T. Effect of a newly designed patellar realignment brace on patellofemoral relationships. Medicine and Science in Sports and Exercise 1995;27(4):469-72.

\section{Shellock 2000}

Shellock FG, Mullin M, Stone KR, Coleman M, Crues JV. Kinematic magnetic resonance imaging of the effect of bracing on patellar position: qualitative assessment using an extremity magnetic resonance system. Journal of Athletic Training 2000;35(1):44-9.

\section{Song 2011}

Song CY, Lin JJ, Jan MH, Lin YF. The role of patellar alignment and tracking in vivo: the potential mechanism of patellofemoral pain syndrome. Physical Therapy in Sport 2011;12(3):140-7.

\section{Stathopulu 2003}

Stathopulu E, Baildam E. Anterior knee pain: a long-term follow-up. Rheumatology 2003;42(2):380-2.

\section{Sterne 2011}

Sterne JAC, Egger M, Moher D (editors). Chapter 10: Addressing reporting biases. In: Higgins JPT, Green S (editors). Cochrane Handbook for Systematic Reviews of Intervention. Version 5.1.0 (updated March 2011). 
The Cochrane Collaboration, 2011. Available from www.cochrane-handbook.org.

\section{Swart 2012}

Swart NM, Van Linschoten R, Bierma-Zeinstra SM, Van Middelkoop M. The additional effect of orthotic devices on exercise therapy for patients with patellofemoral pain syndrome: a systematic review. British Journal of Sports Medicine 2012;46(8):570-7.

Thomas 2010

Thomas MJ, Wood L, Selfe J, Peat G. Anterior knee pain in younger adults as a precursor to subsequent patellofemoral osteoarthritis: a systematic review. BMC Musculoskeletal Disorders 2010;11:201.

\section{Turba 1979}

Turba JE, Walsh WM, McLeod WD. Long-term results of extensor mechanism reconstruction. A standard for evaluation. American Journal of Sports Medicine 1979;7(2): $91-4$.

Utting 2005

Utting MR, Davies G, Newman JH. Is anterior knee pain a predisposing factor to patellofemoral osteoarthritis?. Knee 2005;12(5):362-5.

\section{Van der Heijden 2015}

Van der Heijden RA, Lankhorst NE, Van Linschoten R, Bierma-Zeinstra SMA, Van Middelkoop M. Exercise for treating patellofemoral pain syndrome. Cochrane Database of Systematic Reviews 2005, Issue 1. [DOI: 10.1002/ 14651858.CD010387.pub2]

\section{Van Linschoten 2009}

Van Linschoten R, Van Middelkoop M, Berger MY, Heintjes EM, Verhaar JAN, Willemsen SP, et al. Supervised exercise therapy versus usual care for patellofemoral pain syndrome: an open label randomised controlled trial. $B M J$ 2009;339:b4074.

\section{Warden 2008}

Warden SJ, Hinman RS, Watson MA, Avin KG,

Bialocerkowski AE, Crossley KM. Patellar taping and bracing for the treatment of chronic knee pain: a systematic review and meta-analysis. Arthritis and Rheumatology 2008; 59(1):73-83.

\section{Ware 1996}

Ware J, Kosinski M, Keller SD. A 12-Item short-form health survey: construction of scales and preliminary tests of reliability and validity. Medical Care 1996;34(3):220-33.

\section{Waryasz 2008}

Waryasz GR, McDermott AY. Patellofemoral pain syndrome (PFPS): a systematic review of anatomy and potential risk factors. Dynamic Medicine 2008;7(1):9.

\section{Werner 1993}

Werner S, Arvidsson I, Arvidsson I, Eriksson E. Electrical stimulation of vastus medialis and stretching of lateral thigh muscles in patients with patello-femoral symptoms. Knee Surgery, Sports Traumatology, Arthroscopy 1993;1(2):85-92.

Witvrouw 2014

Witvrouw E, Callaghan MJ, Stefanik JJ, Noehren B, Bazett-Jones DM, Willson JD, et al. Patellofemoral pain: consensus statement from the 3rd International Patellofemoral Pain Research Retreat held in Vancouver, September 2013. British Journal of Sports Medicine 2014;48 (6):411-4.

\section{References to other published versions of this review}

\section{Smith 2013}

Smith TO, Drew BT, Meek TH, Clark AB. Knee orthoses for treating patellofemoral pain syndrome. Cochrane Database of Systematic Reviews 2013, Issue 5. [DOI: 10.1002/14651858.CD010513]

* Indicates the major publication for the study 


\title{
CHARACTERISTICS OFSTUDIES
}

\author{
Characteristics of included studies [ordered by study ID]
}

\section{Evcik 2010}

Methods

Participants
Prospective, single-centre, single-blinded, randomised controlled trial

Based in Turkey. No recruitment/study dates documented.

We assume participants are 'mixed civilian' but this is not actually stated

86 participants were recruited ( 72 female, 14 male; mean age 42 years, range 17 to 80 years) diagnosed with patellofemoral pain syndrome by physicians and an orthopaedic surgeon

Two groups:

Knee sleeve group: $\mathrm{n}=41$ (female 35, male 6; age 42.2 years (SD 15.3, range 17 to 80 ) ; mean duration of symptoms 24.2 months (SD 13.6, range 1 to 80))

Control group: $\mathrm{n}=45$ (female 37 , male 8 ; age 41.0 years (SD 9.3, range 20 to 59); mean duration of symptoms 18.2 months (SD 13.2, range 1 to 72))

Inclusion criteria: Anterior or retropatellar knee pain when walking up and down stairs, squatting, kneeling or prolonged sitting for at least 4 weeks were enrolled in this study. In addition, they should have pain in at least 2 of the following physical tests: patellar compression test, in which pressure is applied over the patella while the knee is fully extended, Clarke's test (physician places his/her hand over the patient's patella, presses gently downwards, as the patient contracts the quadriceps muscle and the test is positive if pain occurs, which indicates patellofemoral joint problems), patellar apprehension test (the physician should be aware that patients with a history of subluxation or dislocation of the patella might feel very uncomfortable at this point and try to stop the physician from completing the test) and palpation of the posterior medial-lateral borders of the patella. Hypermobility, measurement of Q-angle and patellar tilt test were also applied. All participants underwent weight-bearing anteroposterior telemetric X-ray evaluation and tangential knee radiography in 30 and 45 degrees of flexion. Patellar subluxation (which was demonstrated by measuring the lateral PF angle), subchondral sclerosis and presence of degenerative changes were determined from these radiographs. All participants were diagnosed as having PFPS based on history, physical examination, and radiological evaluation

Exclusion criteria: People with tibiofemoral compartment osteoarthritis, knee effusion, inflammatory joint pathology, infection, previous knee arthroplasty, lower extremity fracture history and severe cardiovascular diseases were excluded from the study. After the physical examination, full blood count, erythrocyte sedimentation rate (ESR), Creactive protein $(\mathrm{CRP})$ and biochemical markers were evaluated in order to determine the presence of other systemic inflammatory diseases

Interventions

Knee sleeve group: Received the control group's exercise programme in addition to an Altex Patellar Knee support (Altex Patellar knee support AL-2285C), which is a neoprene sleeve with a patella cut-out. This was worn whilst performing the exercises as well as during the day for the six-week study period. The knee support was only removed at night for sleeping

Control group: A home-based exercise therapy including a standardised protocol developed by a physiotherapist. This consisted of isometric and isotonic programmes for quadriceps muscles, performed five times per week. All participants performed 10 repe- 
Evcik 2010 (Continued)

titions per day for six weeks. All participants provided with an exercise sheet, outlining the programme

All participants were reviewed at 2-weekly intervals to monitor compliance to allocated treatment

Outcomes

Outcomes assessed at baseline and at 6 weeks post-commencement of the sleeve and exercise interventions

Outcomes evaluated included:

1. VAS pain score

2. Western Ontario McMaster Osteoarthritis Index (WOMAC) pain and

functional capacity scales

3. Fulkerson-Shea Patellofemoral Evaluation (FSPES) scores

Notes

Risk of bias

Bias Authors' judgement $\quad$ Support for judgement

Random sequence generation (selection High risk bias)

Consecutive admission to the outpatient clinic. Materials and Methods (Page 101) participants were "randomly allocated to either" group, with "randomisation made according to the consecutive admissions of the patients to the outpatient clinic" This appears to be quasi-randomised

Allocation concealment (selection bias) High risk

Not documented whether allocation was concealed but this seems unlikely

Blinding of participants and personnel High risk (performance bias)

No blinding of physiotherapist: MateriAll outcomes als and Methods section (page 101): "only the therapist who applied the therapy was aware of the therapy"

Although it would be logistically difficult to blind the participants or study personnel to the intervention, the standardisation of the intervention with the exercise sheet detailing the home-exercise programme attempted to reduce physiotherapist's potential bias

Blinding of outcome assessment (detection Unclear risk bias)

All outcomes
The assessor was blinded to group allocation. Methods section (page 101): "the physician was blinded to the treatment program". However, no safeguards were described and subjective outcomes reported by the patients were not blinded 
Evcik 2010 (Continued)

\begin{tabular}{|c|c|c|}
\hline $\begin{array}{l}\text { Incomplete outcome data (attrition bias) } \\
\text { All outcomes }\end{array}$ & Low risk & $\begin{array}{l}\text { Results section (page 102): "all patients } \\
\text { completed the regular exercise program", } \\
\text { therefore none appeared lost to follow-up }\end{array}$ \\
\hline
\end{tabular}

Selective reporting (reporting bias) Unclear risk

No protocol available. However, all outcomes presented within the Results section (page 103) and Table 2, as previously discussed in the Methods section

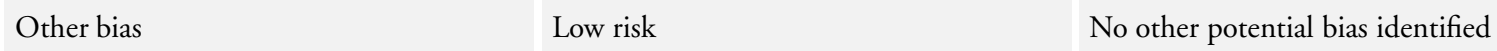

Finestone 1993

Methods Prospective, single-centre, non-blinded, randomised controlled trial

Participants Based in Israel. Participants recruited in the summer of 1990

All participants were male Israeli army recruits and were diagnosed and reviewed by a team that comprised an army physician and an orthopaedic surgeon. Review took place every two weeks during 14 weeks of basic military training

59 participants (all males) with 84 affected and eligible knees were recruited

Three groups:

Genutrain knee sleeve group: $\mathrm{n}=22$ knees (all male, age: not reported, duration not stated but was up to 2 weeks)

Simple elastic sleeve group: $\mathrm{n}=22$ knees (all male, age: not reported, duration not stated but was up to 2 weeks)

Control group: $\mathrm{n}=40$ knees (all male, age: not reported, duration not stated but was up to 2 weeks)

No further details of the participants' characteristics were included in the text

Eligibility criteria: All participants presented with both subjective and objective findings indicative of patellofemoral pain syndrome, but with no history of knee trauma or symptoms of patellofemoral pain syndrome prior to joining the miliary services.

Interventions

Simple elastic sleeve group: Received same basic military training as the control group in addition to receiving a simple elastic knee sleeve

Genutrain knee sleeve group: Received same basic military training as the control group in addition to receiving an elastic knee sleeve with silicone plastic ring (Genutrain, Bauerfeind GmbH, Kempen, Germany)

The paper does not clearly define when and for how long the knee sleeves were worn by participants in the two knee sleeve groups

Control group: received no treatment but standard 14 weeks of basic military training

Outcomes

Outcomes were evaluated every 2 weeks for a total of 14 weeks during basic military training and then 2 months following the completion of basic military training

The outcomes assessed were:

1. Pain subjectively rated using a 1 to 4 Likert system where: $1=$ discomfort, $2=$ moderate pain, 3 = significant pain but continue to train, $4=$ severe pain and stop training 2. Participant satisfaction with their brace/treatment was rated on a 1 to 4 Likert system. The definitions of each criterion were not provided 
Finestone 1993 (Continued)

3. Complications from wearing the interventions were evaluated through questioning participants about their experiences. Complications such as the sleeve rubbing or skin abrasions were recorded

Notes

The imbalance in the numbers in the treatment groups was not explained. It is possible that random allocation applied to treatment (knee orthosis) versus no treatment groups and not the two knee orthosis groups

Risk of bias

\begin{tabular}{|c|c|c|}
\hline Bias & Authors' judgement & Support for judgement \\
\hline $\begin{array}{l}\text { Random sequence generation (selection } \\
\text { bias) }\end{array}$ & High risk & $\begin{array}{l}\text { Methods not stated, only that the par- } \\
\text { ticipants were randomised. Materials and } \\
\text { Methods (page 209): "Recruits with } \\
\text { overuse patellofemoral pain were divided } \\
\text { randomly into treatment (Groups } 1 \text { and 2) } \\
\text { and nontreatment groups (Group 3)." } \\
\text { Note it is not clear whether any randomisa- } \\
\text { tion occurred for allocation of the different } \\
\text { knee sleeves }\end{array}$ \\
\hline Allocation concealment (selection bias) & Unclear risk & $\begin{array}{l}\text { No information provided to indicate } \\
\text { whether participant allocation was con- } \\
\text { cealed }\end{array}$ \\
\hline
\end{tabular}

Blinding of participants and personnel High risk (performance bias)

All outcomes
No information provided in the paper regarding blinding of participants or study personnel and clinicians to group allocation. However, this would have been logistically difficult to achieve due to the nature of the intervention

No information was provided in the paper indicating whether the assessor was blinded to group allocation during the data collection phases

Blinding of outcome assessment (detection High risk bias)

All outcomes

Unclear risk

Incomplete outcome data (attrition bias)

All outcomes

High risk
All participants appear to be accounted for at end of the trial. However, group allocation statistics were available only for knees not participants. See also 'Other bias'

No protocol available. Pain scores were only reported for baseline and at two months after completion of their basic military training. No data presented on participant satisfaction 
Finestone 1993 (Continued)

Other bias

High risk
It was not explicitly stated how many participants in each group presented with bilateral knee symptoms. Results (page 209) : "59 recruits were diagnosed as having anterior knee pain in 84 affected knees”. Unresolvable unit of analyses problems

Lun 2005

Methods

Participants
Prospective, single-centre, single-blinded, randomised controlled trial

Based in Canada. No recruitment/study dates documented.

We assume participants are 'mixed civilian' but the details of actual composition of population are not given. The population was drawn from an university sports centre, university campus community and city fitness facilities, and family physician clientele 152 participants met the inclusion criteria 21 withdrew and 2 crossed over. Data were reported for 129 participants (76 females, 53 males) with 186 affected knees: diagnosed and eligibility determined by two sport medicine physicians

Four groups:

Knee brace group: $\mathrm{n}=32$ (gender not specified; mean age 34 years (SD 11); symptom duration 8 months (SD 6 months)); 47 knees

Exercise group: $\mathrm{n}=34$ (gender not specified; mean age 35 years (SD 11); symptom duration 11 months (SD 8 months)); 50 knees

Exercise and knee brace group: $\mathrm{n}=32$ (gender not specified; mean age 35 years (SD 11); symptom duration 10 months (SD 7 months)); 45 knees

Exercise and knee sleeve group: $\mathrm{n}=31$ (gender not specified; mean age 35 years (SD 9); symptom duration 7 months (SD 5 months)); 44 knees

Eligibility criteria: listed under 3 categories in the trial report.

\section{History}

- Atraumatic unilateral and/or bilateral peripatellar or retropatellar knee pain for at least three weeks but not greater than two years

- Patellofemoral knee pain with and/or after activity

- Inactivity patellofemoral pain and/or stiffness, especially with sitting with knees in

a

fl exed position

- No prior history of any significant knee injury (including but not limited to patellar subluxations/dislocations/fractures and ligament or meniscal injuries, and so forth) or knee surgery

- No previous treatment with physiotherapy

Physical examination

- No or minimal articular or soft-tissue periarticular effusion or bursitis

- No significant joint line tenderness

- No intra-articular ligamentous instability

- Peripatellar tenderness

- Mild inferior patellar pole tenderness

$X$-ray examination

- Participants with any bony abnormalities including bony fracture, osteochondritis 
dissecans, bipartite patella, or osteoarthritis were excluded from participating in the study

- Mild inferior patellar pole spurring was acceptable

Interventions

Outcomes
Knee brace group: Participants wore a knee brace only. The brace was a Special FX Knee Brace (Generation II Orthotics, Inc, Richmond, BC). It has a Y-shaped inferior patellar buttress pad and an external stabilisation strap to help control patellar movement

Exercise group: Participants received a structured home rehabilitation programme only. This structured home-rehabilitation programme consisted of a strengthening component, consisting of a 6-stage progression of 2-leg eccentric drop squats, then single leg lunges, and finally 1-leg eccentric drop squats. The stretching component of the rehabilitation programme consisted of seated spinal rotations, supine hip external rotation, standing quadriceps stretch, and sitting hamstring stretch. Stretches were performed daily prior to and after the strengthening component of the programme. Each stretch was performed passively 3 times, with each stretch held for 30 seconds

Exercise and knee brace group: Participants received the exercise group's structured home-rehabilitation and were prescribed and fitted with the Special FX Knee Brace (Generation II Orthotics, Inc, Richmond, BC) as described above

Exercise and knee sleeve group: Participants received the exercise group's structured home-rehabilitation programme and were prescribed and fitted with a knee sleeve constructed with same sleeve material as the patella brace. No hole was made in the sleeve over the patella

The knee braces and knee sleeves were fitted by the second research assistant. In those diagnosed with bilateral PFPS, both knees were fitted with a knee brace or knee sleeve. Participants in the brace group, exercise and brace group or exercise and knee sleeve group were encouraged to wear their braces or sleeves at all times except whilst sleeping

The outcome measurements were performed at baseline and at 3, 6 and 12 weeks Outcomes evaluated were:

1. VAS knee pain rating. This was evaluated in three different situations: during sport activity; 1 hour after sport activity; and following 30 minutes of sitting with knees fl exed

2. Knee Function Scale. For the purpose of this study, the scale was modified. A 'no pain' response was added to the occurrence of pain category, with a corresponding score of 18. The maximum score of the knee function scale was therefore increased to 53, which equated to normal function

Notes

Risk of bias

\begin{tabular}{|c|}
\hline Bias \\
\hline
\end{tabular}

Random sequence generation (selection Low risk bias)
Participants were randomised to interventions. Methods, Study Procedure (page 236): "random number generator with block design" 
Allocation concealment (selection bias) Low risk

Blinding of participants and personnel High risk (performance bias)

All outcomes
Randomisation was through concealed allocation through a second researcher. Methods, Study Procedure (Page 236): "a second research assistant used a random number generator with block design to assign subjects to 1 of 4 treatment group."

No information provided regarding the blinding of researchers or clinical personnel. No information provided regarding the blinding of study participants; however, participants or clinician blinding would be logistically difficult due to the nature of the study interventions

Blinding of outcome assessment (detection Unclear risk bias)

All outcomes

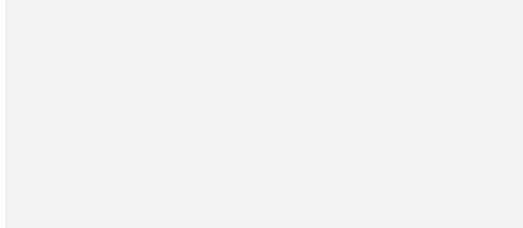

Incomplete outcome data (attrition bias) High risk

All outcomes

\section{Hish risk}

Selective reporting (reporting bias)

Unclear risk

Other bias

High risk
Study was described as 'single-blinded' in the abstract of the trial report, which also stated "The investigators were blinded to the treatment group of each subject." However, no information was provided in the text of the trial report including measures taken to avoid unblinding of group allocation. Moreover, subjective outcomes reported by the patients were not blinded

Separate participant flow not provided for individual groups. Thus group allocation of the 21 withdrawals and 2 cross-overs excluded from the analyses. See also 'Other bias'

Data inconsistencies and potential labelling errors between table 3 and figures in the article

No protocol available. However, all outcomes reported in the Methods section were reported in the Results section (pages 237 to 239 )

In the Analysis ( $\mathrm{p}$ 237) it is stated that "If a subject had bilateral symptoms, each knee was individually included in the analysis." Unresolvable unit of analysis issues 
Methods

Participants
Prospective, single-centre, non-blinded, randomised controlled trial

Based in USA. No recruitment/study dates documented.

59 participants (data for 51: 13 females, 38 males). All participants were military cadets. Unclear who diagnosed and determined eligibility

Three groups:

Palumbo sleeve group: $\mathrm{n}=18$ ( 3 female, 15 male; age not reported; duration of symptoms within 3 weeks of starting training)

Cho-Pat knee strap group: $\mathrm{n}=13$ (2 female, 11 male; age not reported; duration of symptoms within 3 weeks of starting training)

Control group: $\mathrm{n}=20$ ( 8 female, 12 male; age not reported; duration of symptoms within 3 weeks of starting training)

No further information on baseline characteristics available

Inclusion criteria: Complaint of anterior knee pain within first three weeks of military training

Exclusion criteria: Lack of desire to remain in basic training; previous surgery; history patellar dislocation; previously known knee disorders; abnormalities on physical examination; abnormal radiographs

Palumbo sleeve group: Participants received all interventions provided in the control group in addition to the provision, fitting and instruction to wear the Palumbo Brace throughout all military training activities

Cho-Pat knee strap group: Participants received all interventions provided in the control group in addition to the provision, fitting and instruction to wear the Cho-Pat Knee Strap throughout all military training activities

'Brace wear was monitored throughout the study to ensure compliance." (p11 of article) Control group: Enrolled in physical therapy consisting of an exercise programme of closed-chain quadriceps strengthening exercises and a lower limb tissue flexibility (stretching) programme; ibuprofen prescribed (800 milligrams) 3 times daily; and completion of basic military physical training

The trainees were allowed to substantially modify their activities at the risk of being 'disenrolled' from their 2 months training

Outcomes

Participants were evaluated weekly from baseline to 8 weeks post-randomisation The main outcome assessed was the Patient Pain Profile Questionnaire, which incorporates a VAS score, a measure of participant's desire to remain in training and a measure of their desire to remain in training if their knee pain resolves

Notes

The total number of recruits able to complete the training was also documented and the relevant reasons for attrition explained

Risk of bias

Bias

Authors' judgement

Support for judgement

Random sequence generation (selection Unclear risk bias)

Knee orthoses for treating patellofemoral pain syndrome (Review)
Method of sequence generation not clearly documented. Materials and Methods (page 11): participants "were then randomised into the groups" 
Miller 1997 (Continued)

\begin{tabular}{|c|c|c|}
\hline Allocation concealment (selection bias) & Unclear risk & $\begin{array}{l}\text { No clear documentation as to whether } \\
\text { randomisation was performed through a } \\
\text { concealed method. Materials and Meth- } \\
\text { ods (page 11): participants "were then ran- } \\
\text { domised into the groups" }\end{array}$ \\
\hline
\end{tabular}

Blinding of participants and personnel High risk (performance bias)

No information was provided regarding All outcomes whether participants or study personnel/ clinicians were blinded to group allocation. Due to the nature of the intervention, it would have been logistically difficult to blind participants to the bracing interventions

Blinding of outcome assessment (detection High risk bias)

The paper did not detail whether assessors were blinded to group allocation

All outcomes

Incomplete outcome data (attrition bias) Unclear risk All outcomes
Participant attrition was documented with all participants accounted for. Materials and methods page 12: "four participants were excluded from the study due to insufficient follow-up. Four additional patients failed to complete basic training leaving 51 patients in the study cohort". While the \% losses were similar in the three groups $(13 \%$ to $14 \%$ ), some bias could result from differing reasons for missing data

The Materials and Methods section states a number of outcome measurements were collected (Page 11). These included: "thigh circumference, effusion, popliteal angle, compression test, localised tenderness, apprehension test, Q-Angle, range of motion, Lachmann test, anterior drawer, varus/ valgus instability and McMurray's tests." However, these were not reported

The paper also only reported findings from the initial 3-week follow-up period, neglecting to provide data from weeks 4 to 8 . No explanation was provided for this discrepancy in reporting

Other bias

Unclear risk
Baseline characteristics not provided for all randomised participants 
Methods

Participants

Interventions

Outcomes
Prospective, single-centre, non-blinded, randomised controlled trial

Based in Denmark. No recruitment/study dates documented

We assume participants are 'mixed civilian' but this is not actually stated. Unclear who diagnosed and determined eligibility

35 participants ( 35 unilateral knees) ( 25 female, 10 male; mean age 23 years (range 18 to 35 ); mean duration of symptoms 21 months (3 to 120 months))

Two groups:

Knee brace group: $\mathrm{n}=17$ (gender, age and duration of symptoms not specified; 10 participants had a history of patellar subluxation and 7 participants had a history of idiopathic chondromalacia patellae)

Control group: $\mathrm{n}=18$ (gender, age and duration of symptoms not specified; 7 participants had a history of patellar subluxation; and 11 participants had a history of idiopathic chondromalacia patellae)

Inclusion criteria: Arthroscopy was done on all knees and revealed different stages of diseased articular cartilage. The knees were initially evaluated subjectively and objectively according to the numerical rating system described by Turba 1979, assessing swelling, pain, symptoms of instability, and limitation of activity. Objectively, the evaluation included motion, pain effusion, quadriceps atrophy, and patellar hypermobility

Exclusion criteria: Patients with obvious signs of meniscus tears, joint laxity, radiological osteoarthritis, former surgery of the knee, or recurrent subluxation of the patella

Knee brace group: In addition to the exercise programme, participants in this group wore a knee brace made of orthoplast. The brace only allowed a knee range of motion from 0 to 30 degrees of flexion. The brace was worn for a 6 -week period. No details provided with regards to whether the brace was worn at night or not

Control group: An isometric quadriceps and hamstrings exercise programme. This was performed for at least 15 minutes, 4 times daily. Participants were asked to exercise within the limits of their pain
A follow-up was performed after 6 weeks and 3 and 12 months

Outcome measures included:

1. The Turba 1979 rating system. This is a numerical rating outcome measure to assess the extensor mechanism of the knee in respect to swelling, pain, symptoms of instability, and limitation of activity. Results were categorised as excellent, good, fair, and poor. The knees were rated as improved only if the results were excellent or good both objectively and subjectively

2. Mean quadriceps circumference

3. Likert scale based on subjective improvement

4. Return to activity

Five participants subsequently underwent surgery; 4 for correction of patellar malalignment

Risk of bias

Bias

Authors' judgement
Support for judgement 
Moller 1986 (Continued)

\begin{tabular}{|c|c|c|}
\hline $\begin{array}{l}\text { Random sequence generation (selection } \\
\text { bias) }\end{array}$ & Unclear risk & $\begin{array}{l}\text { No mention of randomisation procedure. } \\
\text { No detail provided regarding sequence } \\
\text { generation. Patients and Methods section } \\
\text { (page 377) "seventeen patients were ran- } \\
\text { domised to a knee brace made of ortho- } \\
\text { plast" }\end{array}$ \\
\hline Allocation concealment (selection bias) & Unclear risk & $\begin{array}{l}\text { No mention of randomisation procedure, } \\
\text { with the methods of allocation conceal- } \\
\text { ment not described }\end{array}$ \\
\hline $\begin{array}{l}\text { Blinding of participants and personnel } \\
\text { (performance bias) } \\
\text { All outcomes }\end{array}$ & High risk & $\begin{array}{l}\text { This was not described in the paper. It was } \\
\text { unclear from information presented in the } \\
\text { paper which personnel were involved in } \\
\text { the trial and whether they were blinded to } \\
\text { group allocation. Given the nature of this } \\
\text { intervention, it would be logistically diffi- } \\
\text { cult to blind participants or personnel to } \\
\text { group allocation }\end{array}$ \\
\hline
\end{tabular}

Blinding of outcome assessment (detection High risk bias)

All outcomes

Incomplete outcome data (attrition bias) Unclear risk

All outcomes

Selective reporting (reporting bias)

High risk

Other bias

High risk
There was insufficient information detailing potential assessor blinding, and data collection of the outcome measures

All participants seem to be accounted in the Results section (page 378) but incomplete reporting of data (see next item)

All outcome measures discussed in the Patients and Methods sections were presented in the Results section (page 387). However, no raw data were available and no numerical values were provided for the Turba scale. The paper only presented the frequency of 'excellent' and 'good' results as a combined number. It was therefore difficult to interpret the Results (Page 378 and Table 1)

The Patients and Methods section was not clear, particularly in relation to the data collection procedure, which was not described.

No separate baseline characteristics (sex, age, duration of symptoms) provided

Outcomes in bold are those that are relevant for this review. 
Characteristics of excluded studies [ordered by study ID]

\begin{tabular}{|c|c|}
\hline Study & Reason for exclusion \\
\hline Antich 1986 & No orthosis examined \\
\hline Avraham 2007 & No orthosis examined \\
\hline BenGal 1997 & Examined the use of orthosis as a 'preventative' rather than 'treatment' intervention \\
\hline Denton 2005 & The intervention under investigation was a resistance exercise device rather than a brace or orthosis \\
\hline Draper 2009 & Not a randomised controlled trial \\
\hline Farkas 1997 & Not a randomised controlled trial \\
\hline Fukuschima 1992 & Not a randomised controlled trial \\
\hline Greenwald 1996 & Not a randomised controlled trial \\
\hline Gulling 1996 & Not a randomised controlled trial \\
\hline IRCT138810293101N1 & Not a randomised controlled trial \\
\hline Lindberg 1988 & Not a randomised controlled trial \\
\hline Lysholm 1984 & Not a randomised controlled trial \\
\hline McCrory 2004 & Not a randomised controlled trial \\
\hline McCrory 2007 & Not a randomised controlled trial \\
\hline Palumbo 1981 & Not a randomised controlled trial \\
\hline Powers 1999 & Not a randomised controlled trial \\
\hline Powers 2004 & Not a randomised controlled trial \\
\hline Roostayi 2009 & Not a randomised controlled trial \\
\hline Sathe 2002 & Not a randomised controlled trial \\
\hline Selfe 2008 & None of the participants presented with patellofemoral pain syndrome; all had pain-free knees \\
\hline Selfe 2011 & $\begin{array}{l}\text { Randomisation was used to allocate the order of treatment within individual participants but not the } \\
\text { allocation of interventions among participants }\end{array}$ \\
\hline Straub 2012 & $\begin{array}{l}\text { Randomisation was used to allocate the order of treatment within individual participants but not the } \\
\text { allocation of interventions among participants. None of the participants presented with patellofemoral } \\
\text { pain syndrome }\end{array}$ \\
\hline
\end{tabular}


(Continued)

\begin{tabular}{l|l} 
Timm 1998 & The intervention under investigation was a resistance exercise device rather than a brace or orthosis \\
\hline Van Tiggelen 2004 & $\begin{array}{l}\text { Recruited participants who did not have patellofemoral pain syndrome. Outcome measurement of interest } \\
\text { was the 'prevention' not the 'treatment' of patellofemoral pain syndrome }\end{array}$ \\
\hline
\end{tabular}

Van Tiggelen $2011 \quad$ Paper solely reported concentric isokinetic test results. This outcome was not a pre-specified outcome measure of interest in this review

Wijnen 1996

A comparison of two taping techniques with no investigation of orthosis interventions

Worrell $1998 \quad$ Not a randomised controlled trial

\section{Characteristics of ongoing studies [ordered by study ID]}

\section{DRKS00003291}

\begin{tabular}{|c|c|}
\hline Trial name or title & $\begin{array}{l}\text { "Therapy of the patellofemoral pain syndrome: A prospective randomised study with two treatment groups: } \\
\text { Physiotherapy and } 2 \text {. Recentering orthosis plus physiotherapy" }\end{array}$ \\
\hline Methods & Open, randomised controlled trial \\
\hline Participants & $\begin{array}{l}135 \text { male and females aged between } 18 \text { and } 50 \text { (target recruitment) } \\
\text { Inclusion criteria: patient's suffering longer than } 2 \text { months but not longer than } 2 \text { years with any } 3 \text { of the } \\
\text { following symptoms: anterior knee pain while running; anterior knee pain while climbing stairs; anterior knee } \\
\text { pain while bicycling; anterior knee pain while sitting with flexed knees; anterior knee pain while squatting } \\
\text { Exclusion criteria: osteoarthritis } 3^{\circ} \text { to } 4^{\circ} \text {; local cartilage damage } 3^{\circ} \text { to } 4^{\circ} \text {; subluxation of the patella; previous } \\
\text { knee injuries (ACL ruptures); tendinosis of the patella tendon; Osgood Schlatter; pathological damage of the } \\
\text { knee joint (osteochondrosis dissecans); valgus knee with more than } 3 \text { fingers between the malleoli; varus knee } \\
\text { with more than } 2 \text { fingers between the femoral condyles }\end{array}$ \\
\hline Interventions & $\begin{array}{l}\text { Group 1: prescription of physiotherapy: } 12 \times 30 \text {-minute physiotherapy sessions (to be delivered } \mathrm{x} 2 \text { weekly } \\
\text { sessions over a } 6 \text {-week period) } \\
\text { Group 2: a Patella Pro Orthosis and a prescription of physiotherapy ( } 12 \times \text { physiotherapy for } 30 \text { minutes). } \\
\text { The patients should wear the Patella Pro Orthosis for } 6 \text { hours even during physiotherapy }\end{array}$ \\
\hline Outcomes & $\begin{array}{l}\text { 1. A 'healing' score ( } 7 \text { points Likert scale) } \\
\text { 2. The Kujala Patellofemoral Disorder Score } \\
\text { 3. The Knee Pain and Osteoarthritis Outcome Score (KOOS) } \\
\text { 4. Severity of pain at several activities measured on a numerical analogue scale ( } 0 \text { to 100) } \\
\text { Outcomes will be measured at the initial visit, } 6 \text { weeks, } 3 \text { months and } 12 \text { months }\end{array}$ \\
\hline Starting date & 01.03 .2012 \\
\hline Contact information & n, Caspar Theyys Strasse 27-31, 14193, Berlin, Germany, w.petersen@mlk-berlin.de \\
\hline
\end{tabular}

Knee orthoses for treating patellofemoral pain syndrome (Review) 
DRKS00003291 (Continued)

Notes

Commercial source of funding: Otto Bock Health Care GmbH Abt. Medical Affairs, Germany

Knee orthoses for treating patellofemoral pain syndrome (Review)

Copyright $\odot 2015$ The Cochrane Collaboration. Published by John Wiley \& Sons, Ltd. 
DATA AND ANALYSES

Comparison 1. Knee orthosis and non-operative intervention (exercises) versus non-operative intervention (exercises) alone

\begin{tabular}{|c|c|c|c|c|}
\hline Outcome or subgroup title & $\begin{array}{l}\text { No. of } \\
\text { studies }\end{array}$ & $\begin{array}{c}\text { No. of } \\
\text { participants }\end{array}$ & Statistical method & Effect size \\
\hline $\begin{array}{l}1 \text { Pain during activity ( } 0 \text { to } 10 \text {; } \\
\text { higher score means worse pain) }\end{array}$ & 3 & 234 & Mean Difference (IV, Fixed, 95\% CI) & $-0.46[-1.16,0.24]$ \\
\hline 1.1 Knee sleeve & 3 & 162 & Mean Difference (IV, Fixed, 95\% CI) & $-0.48[-1.31,0.35]$ \\
\hline 1.2 Patellar strap & 1 & 23 & Mean Difference (IV, Fixed, 95\% CI) & $-1.09[-3.71,1.53]$ \\
\hline 1.3 Knee brace & 1 & 49 & Mean Difference (IV, Fixed, 95\% CI) & $-0.20[-1.68,1.28]$ \\
\hline $\begin{array}{l}2 \text { Pain scores ( } 0 \text { to } 10 \text {; higher score } \\
\text { means worse pain) }\end{array}$ & 3 & & Mean Difference (IV, Fixed, 95\% CI) & Subtotals only \\
\hline 2.1 Knee orthosis (any) & 3 & 234 & Mean Difference (IV, Fixed, 95\% CI) & $-0.46[-1.16,0.24]$ \\
\hline $\begin{array}{l}\text { 2.2 Sensitivity analysis } \\
\text { (knees). Knee orthosis (any) }\end{array}$ & 3 & 276 & Mean Difference (IV, Fixed, 95\% CI) & $-0.41[-1.04,0.23]$ \\
\hline $\begin{array}{l}3 \text { Different pain scores ( } 0 \text { to } 10 \text {; } \\
\text { higher score means worse pain) } \\
\text { at } 12 \text { weeks }\end{array}$ & 1 & & Mean Difference (IV, Fixed, 95\% CI) & Subtotals only \\
\hline 3.1 Pain during activity & 1 & 97 & Mean Difference (IV, Fixed, 95\% CI) & $-0.15[-1.20,0.90]$ \\
\hline $\begin{array}{l}3.2 \text { Sensitivity analysis } \\
\text { (knees). Pain during activity }\end{array}$ & 1 & 139 & Mean Difference (IV, Fixed, 95\% CI) & $-0.15[-1.02,0.72]$ \\
\hline $\begin{array}{l}3.3 \text { Pain } 1 \text { hour after sporting } \\
\text { activity }\end{array}$ & 1 & 97 & Mean Difference (IV, Fixed, 95\% CI) & $0.75[-0.19,1.69]$ \\
\hline $\begin{array}{l}3.4 \text { Sensitivity analysis } \\
\text { (knees). Pain } 1 \text { hour after } \\
\text { sporting activity }\end{array}$ & 1 & 139 & Mean Difference (IV, Fixed, 95\% CI) & $0.75[-0.04,1.53]$ \\
\hline $\begin{array}{l}\text { 3.5 Pain after } 30 \text { minutes } \\
\text { sitting with knees flexed }\end{array}$ & 1 & 97 & Mean Difference (IV, Fixed, 95\% CI) & $0.25[-0.82,1.32]$ \\
\hline $\begin{array}{l}\text { 3.6 Sensitivity analysis } \\
\text { (knees). Pain after sitting with } \\
\text { knees flexed }\end{array}$ & 1 & 139 & Mean Difference (IV, Fixed, 95\% CI) & $0.25[-0.64,1.14]$ \\
\hline $\begin{array}{l}4 \text { Excellent or good results in terms } \\
\text { of reduction in symptoms }\end{array}$ & 1 & & Risk Ratio (M-H, Fixed, 95\% CI) & Totals not selected \\
\hline 4.1 At 12 weeks & 1 & & Risk Ratio (M-H, Fixed, 95\% CI) & $0.0[0.0,0.0]$ \\
\hline 4.2 At 12 months & 1 & & Risk Ratio (M-H, Fixed, 95\% CI) & $0.0[0.0,0.0]$ \\
\hline $\begin{array}{l}5 \text { Functional scores (higher score } \\
\text { means higher function) }\end{array}$ & 2 & & Std. Mean Difference (IV, Fixed, 95\% CI) & Subtotals only \\
\hline 5.1 Knee orthosis (any) & 2 & 183 & Std. Mean Difference (IV, Fixed, 95\% CI) & $-0.25[-0.55,0.05]$ \\
\hline $\begin{array}{l}5.2 \text { Sensitivity analysis } \\
\text { (knees): Knee orthosis (any) }\end{array}$ & 2 & 225 & Std. Mean Difference (IV, Fixed, 95\% CI) & $-0.28[-0.55,-0.01]$ \\
\hline $\begin{array}{l}6 \text { Discontinuation of a basic } \\
\text { military training programme }\end{array}$ & 1 & & Risk Ratio (M-H, Fixed, 95\% CI) & Totals not selected \\
\hline
\end{tabular}




\begin{tabular}{|c|c|c|c|c|}
\hline Outcome or subgroup title & $\begin{array}{l}\text { No. of } \\
\text { studies }\end{array}$ & $\begin{array}{c}\text { No. of } \\
\text { participants }\end{array}$ & Statistical method & Effect size \\
\hline $\begin{array}{l}1 \text { Pain score (0 to } 10 \text { : higher score } \\
\text { means worse pain) }\end{array}$ & 2 & & Mean Difference (IV, Fixed, 95\% CI) & Totals not selected \\
\hline $\begin{array}{l}\text { 1.1 Patellar strap versus knee } \\
\text { sleeve }\end{array}$ & 1 & & Mean Difference (IV, Fixed, 95\% CI) & $0.0[0.0,0.0]$ \\
\hline $\begin{array}{l}1.2 \text { Knee brace versus knee } \\
\text { sleeve }\end{array}$ & 1 & & Mean Difference (IV, Fixed, 95\% CI) & $0.0[0.0,0.0]$ \\
\hline $\begin{array}{l}1.3 \text { Knee brace versus knee } \\
\text { sleeve (sensitivity analysis: } \\
\text { knees) }\end{array}$ & 1 & & Mean Difference (IV, Fixed, 95\% CI) & $0.0[0.0,0.0]$ \\
\hline $\begin{array}{l}1.4 \text { Knee brace versus knee } \\
\text { sleeve }\end{array}$ & 1 & & Mean Difference (IV, Fixed, 95\% CI) & $0.0[0.0,0.0]$ \\
\hline $\begin{array}{l}1.5 \text { Knee brace versus knee } \\
\text { sleeve (sensitivity analysis: } \\
\text { knees) }\end{array}$ & 1 & & Mean Difference (IV, Fixed, 95\% CI) & $0.0[0.0,0.0]$ \\
\hline $\begin{array}{l}2 \text { Functional score (0 to } 53 \text { : higher } \\
\text { scores means greater function) }\end{array}$ & 1 & & Mean Difference (IV, Fixed, 95\% CI) & Totals not selected \\
\hline $\begin{array}{l}2.1 \text { Knee brace versus knee } \\
\text { sleeve }\end{array}$ & 1 & & Mean Difference (IV, Fixed, 95\% CI) & $0.0[0.0,0.0]$ \\
\hline $\begin{array}{l}2.2 \text { Knee brace versus knee } \\
\text { sleeve (sensitivity analysis: } \\
\text { knees) }\end{array}$ & 1 & & Mean Difference (IV, Fixed, 95\% CI) & $0.0[0.0,0.0]$ \\
\hline $\begin{array}{l}3 \text { Discontinuation of a basic } \\
\text { military training programme }\end{array}$ & 1 & & Risk Ratio (M-H, Fixed, 95\% CI) & Totals not selected \\
\hline $\begin{array}{l}\text { 3.1 Patellar strap versus knee } \\
\text { sleeve }\end{array}$ & 1 & & Risk Ratio (M-H, Fixed, 95\% CI) & $0.0[0.0,0.0]$ \\
\hline 4 Complications & 1 & & Risk Ratio (M-H, Fixed, 95\% CI) & Totals not selected \\
\hline $\begin{array}{l}4.1 \text { Knee sleeve and patella } \\
\text { ring versus knee sleeve without } \\
\text { patellar ring }\end{array}$ & 1 & & Risk Ratio (M-H, Fixed, 95\% CI) & $0.0[0.0,0.0]$ \\
\hline
\end{tabular}

\section{Comparison 3. Orthosis versus exercise}

\begin{tabular}{lccc} 
Outcome or subgroup title & $\begin{array}{c}\text { No. of } \\
\text { studies }\end{array}$ & $\begin{array}{c}\text { No. of } \\
\text { participants }\end{array}$ & Statistical method \\
\hline $\begin{array}{c}\text { 1 Pain during activity (0 to 10: } \\
\text { higher score means worse pain) }\end{array}$ & 1 & Mean Difference (IV, Fixed, 95\% CI) & Totals not selected \\
$\begin{array}{l}\text { 1.1 Pain score during sporting } \\
\text { activity }\end{array}$ & 1 & Mean Difference (IV, Fixed, 95\% CI) & $0.0[0.0,0.0]$ \\
$\begin{array}{l}1.2 \text { Pain score 1 hour after } \\
\text { sporting activity }\end{array}$ & 1 & Mean Difference (IV, Fixed, 95\% CI) & $0.0[0.0,0.0]$ \\
\hline
\end{tabular}

Knee orthoses for treating patellofemoral pain syndrome (Review) 
2.1 Pain score during sporting activity

2.2 Pain score 1 hour after sporting activity 2.3 Pain score following 30 minutes of sitting with knees flexed

3 Functional scores (0 to 53: higher scores means greater function)

\begin{abstract}
Analysis I.I. Comparison I Knee orthosis and non-operative intervention (exercises) versus non-operative intervention (exercises) alone, Outcome I Pain during activity (0 to I0; higher score means worse pain).

Review: Knee orthoses for treating patellofemoral pain syndrome

Comparison: I Knee orthosis and non-operative intervention (exercises) versus non-operative intervention (exercises) alone

Outcome: I Pain during activity (0 to I0; higher score means worse pain)

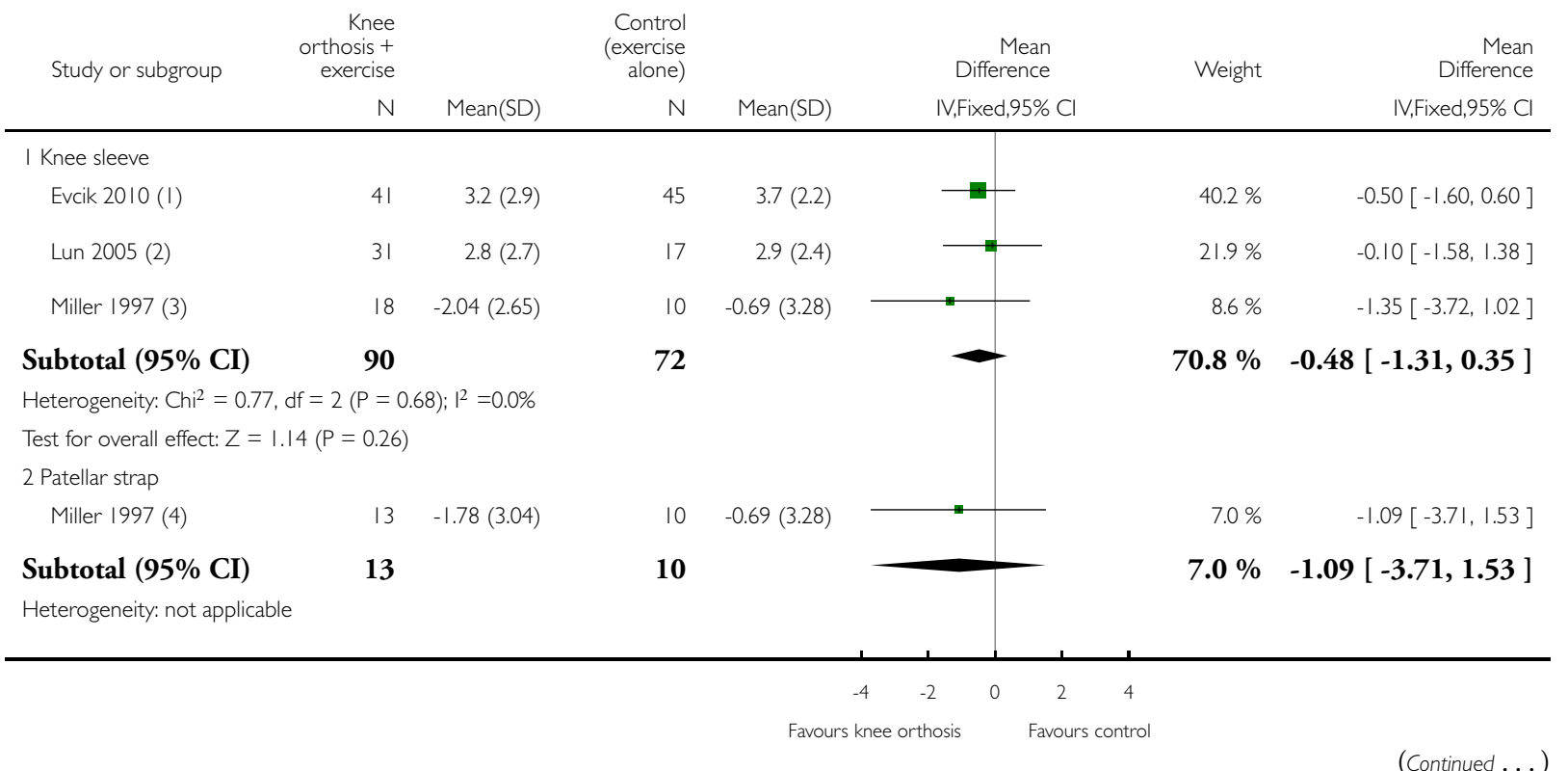




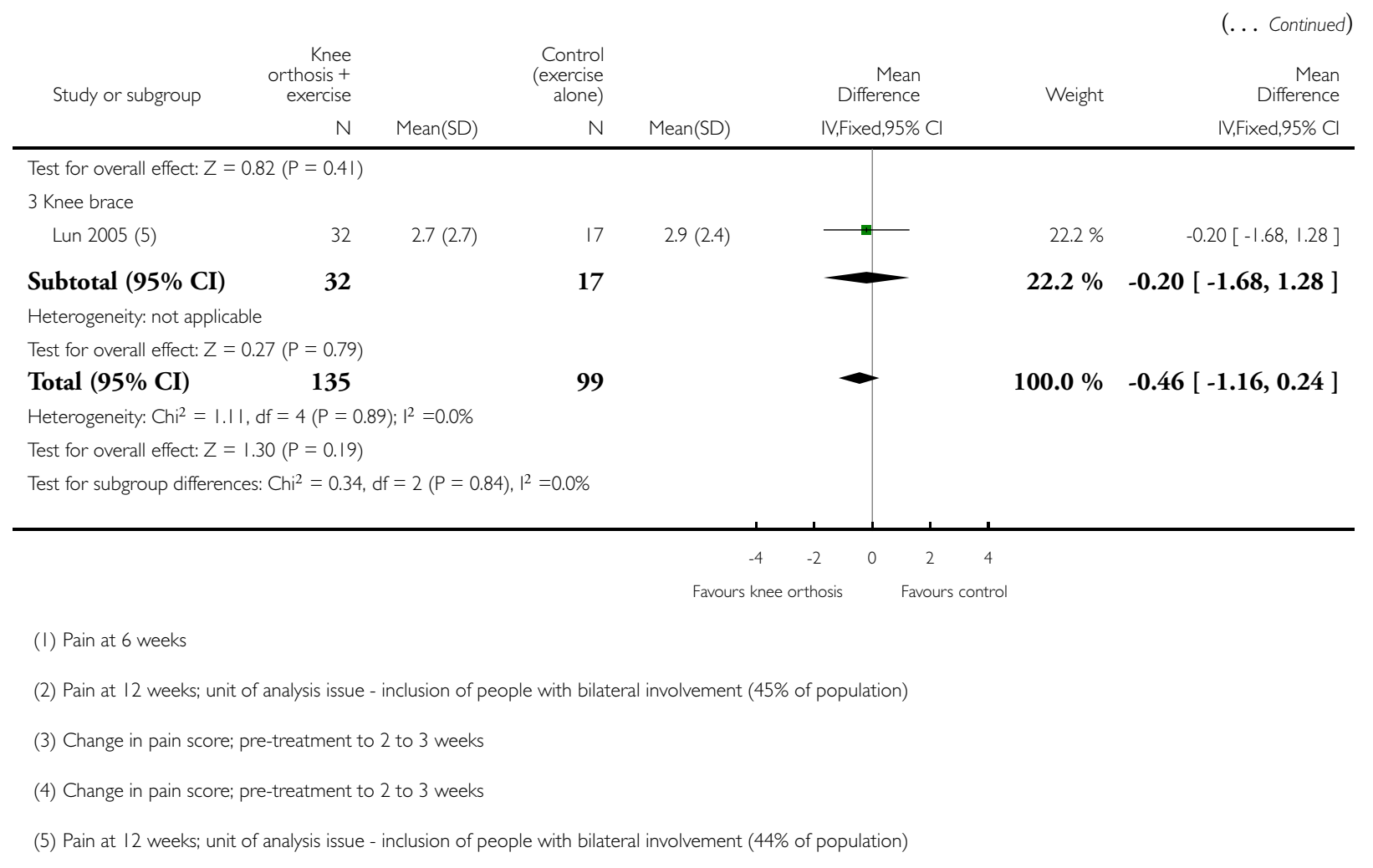


Analysis I.2. Comparison I Knee orthosis and non-operative intervention (exercises) versus non-operative intervention (exercises) alone, Outcome 2 Pain scores (0 to 10; higher score means worse pain).

Review: Knee orthoses for treating patellofemoral pain syndrome

Comparison: I Knee orthosis and non-operative intervention (exercises) versus non-operative intervention (exercises) alone

Outcome: 2 Pain scores (0 to I0; higher score means worse pain)

\begin{tabular}{|c|c|c|c|c|c|c|c|}
\hline Study or subgroup & $\begin{array}{r}\text { Knee } \\
\text { orthosis + } \\
\text { exercise }\end{array}$ & & $\begin{array}{r}\text { Control } \\
\text { (exercise } \\
\text { alone) }\end{array}$ & & $\begin{array}{r}\text { Mean } \\
\text { Difference }\end{array}$ & Weight & $\begin{array}{r}\text { Mean } \\
\text { Difference }\end{array}$ \\
\hline & $\mathrm{N}$ & Mean(SD) & $N$ & Mean(SD) & IV,Fixed,95\% Cl & & IV,Fixed,95\% Cl \\
\hline
\end{tabular}

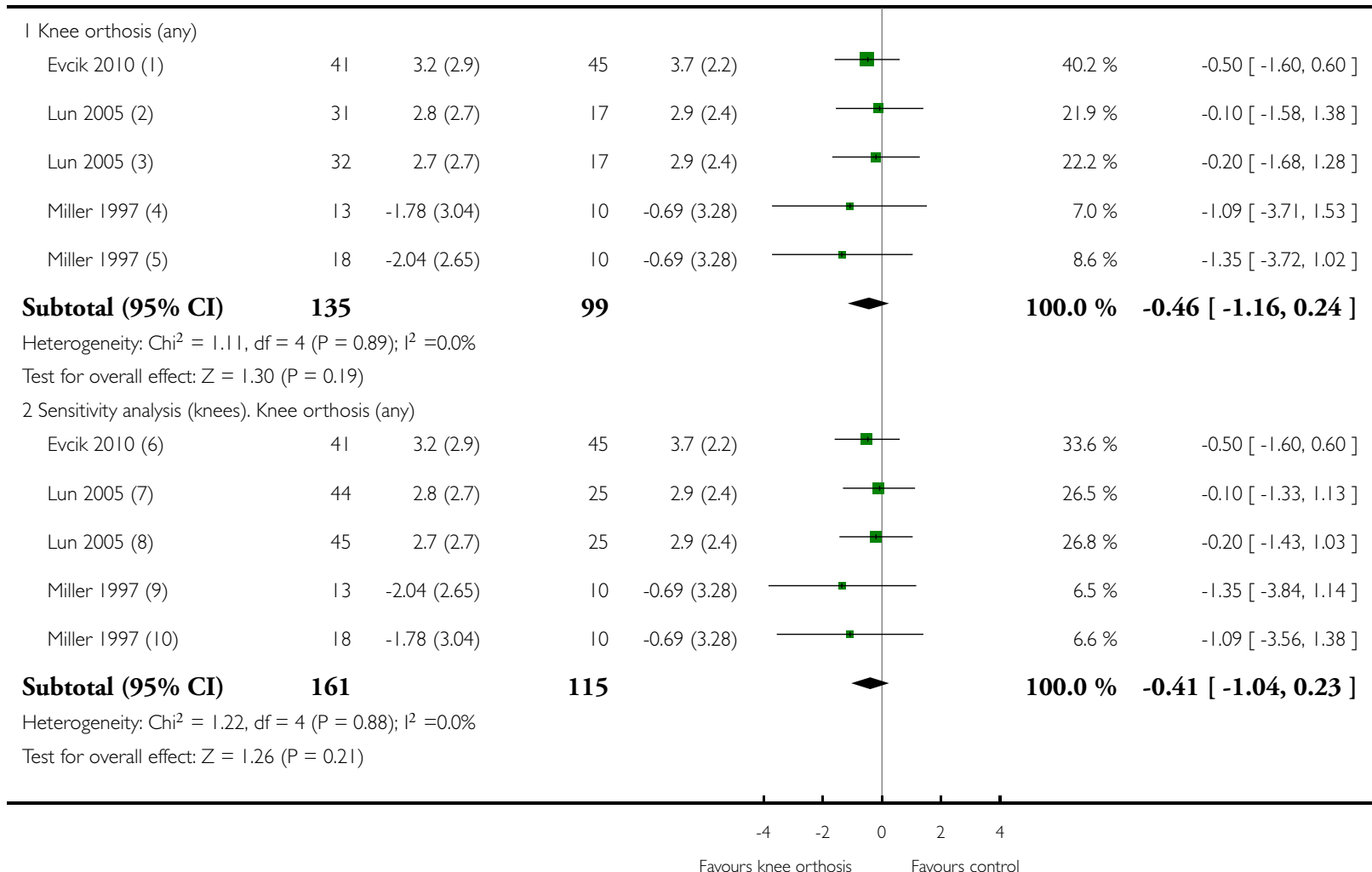

(I) Knee brace. Pain at 6 weeks

(2) Knee sleeve. Pain during activity at 12 weeks

(3) Knee brace. Pain during activity at 12 weeks

(4) Patellar strap. Change in pain score; pre-treatment to 2 to 3 weeks

(5) Knee sleeve. Change in pain score; pre-treatment to 2 to 3 weeks

(6) Knee brace. Pain at 6 weeks

(7) Knee sleeve. Pain during activity at 12 weeks

(8) Knee brace. Pain during activity at 12 weeks

(9) Patellar strap. Change in pain score; pre-treatment to 2 to 3 weeks

(10) Knee sleeve. Change in pain score; pre-treatment to 2 to 3 weeks 
Analysis I.3. Comparison I Knee orthosis and non-operative intervention (exercises) versus non-operative intervention (exercises) alone, Outcome 3 Different pain scores (0 to I0; higher score means worse pain) at 12 weeks.

Review: Knee orthoses for treating patellofemoral pain syndrome

Comparison: I Knee orthosis and non-operative intervention (exercises) versus non-operative intervention (exercises) alone

Outcome: 3 Different pain scores ( 0 to 10; higher score means worse pain) at 12 weeks

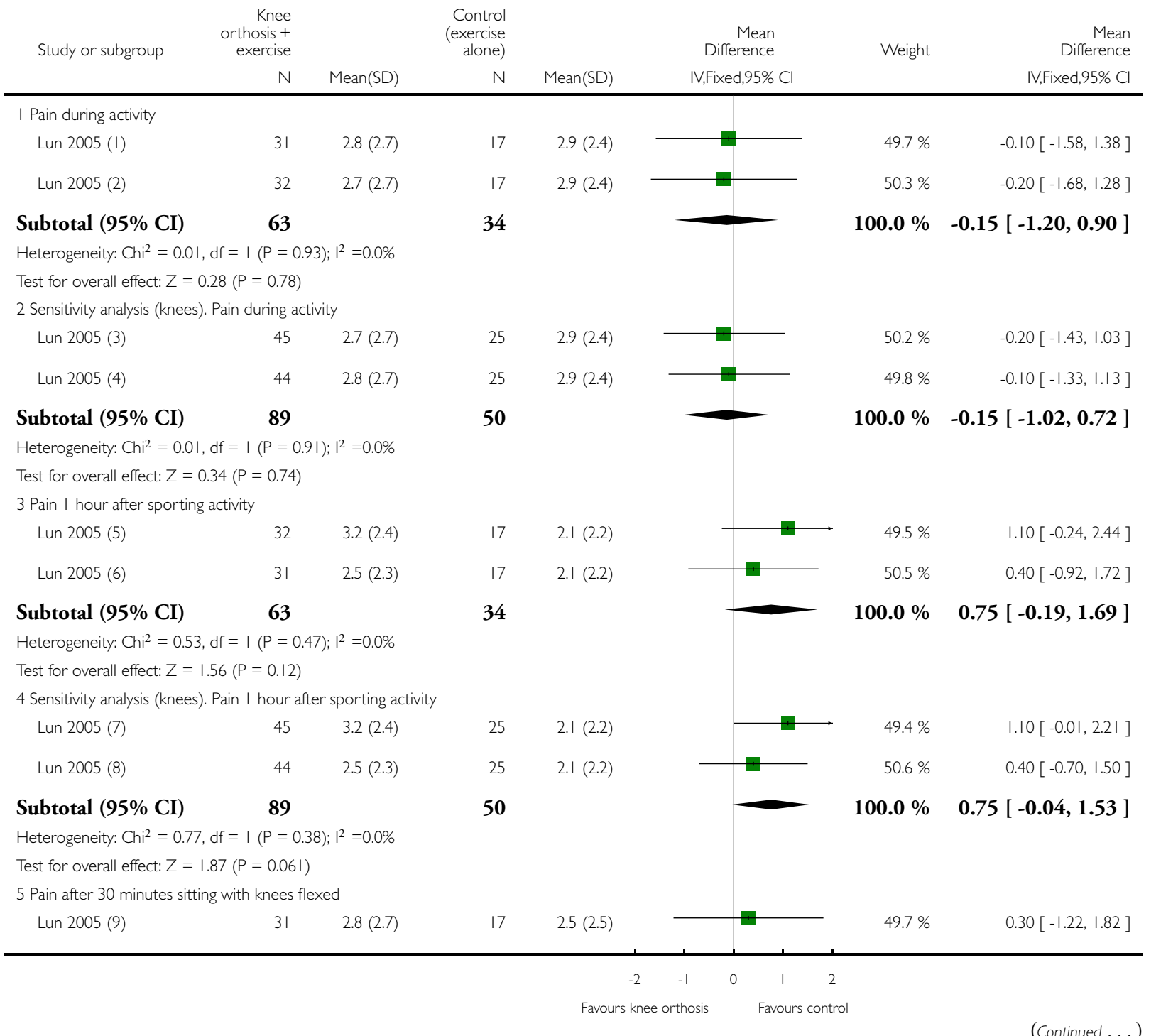

Knee orthoses for treating patellofemoral pain syndrome (Review) 


\begin{tabular}{|c|c|c|c|c|c|c|c|}
\hline \multirow[t]{2}{*}{ Study or subgroup } & $\begin{array}{r}\text { Knee } \\
\text { orthosis + } \\
\text { exercise }\end{array}$ & & $\begin{array}{r}\text { Control } \\
\text { (exercise } \\
\text { alone) }\end{array}$ & & \multirow{2}{*}{$\begin{array}{c}\text { Mean } \\
\text { Difference } \\
\text { IV,Fixed,95\% Cl }\end{array}$} & \multirow[t]{2}{*}{ Weight } & \multirow{2}{*}{$\begin{array}{r}\text { (... Continued) } \\
\text { Mean } \\
\text { Difference } \\
\text { IV,Fixed,95\% Cl }\end{array}$} \\
\hline & $\mathrm{N}$ & Mean(SD) & $\mathrm{N}$ & Mean(SD) & & & \\
\hline Lun 2005 (10) & 32 & $2.7(2.7)$ & 17 & $2.5(2.5)$ & +1 & $50.3 \%$ & $0.20[-1.31,1.71]$ \\
\hline Subtotal $(95 \% \mathrm{CI})$ & 63 & & 34 & & 1 & $100.0 \%$ & $0.25[-0.82,1.32]$ \\
\hline \multicolumn{8}{|c|}{ Heterogeneity: $\mathrm{Chi}^{2}=0.01, \mathrm{df}=\mathrm{I}(\mathrm{P}=0.93) ; \mathrm{I}^{2}=0.0 \%$} \\
\hline \multicolumn{8}{|c|}{ Test for overall effect: $Z=0.46(P=0.65)$} \\
\hline \multicolumn{8}{|c|}{6 Sensitivity analysis (knees). Pain after sitting with knees flexed } \\
\hline Lun 2005 (II) & 44 & $2.8(2.7)$ & 25 & $2.5(2.5)$ & + & $49.8 \%$ & $0.30[-0.96,1.56]$ \\
\hline Lun 2005 (12) & 45 & $2.7(2.7)$ & 25 & $2.5(2.5)$ & +1 & $50.2 \%$ & $0.20[-1.06,1.46]$ \\
\hline Subtotal $(95 \% \mathrm{CI})$ & 89 & & 50 & & & $100.0 \%$ & $0.25[-0.64,1.14]$ \\
\hline \multicolumn{8}{|c|}{ Heterogeneity: $\mathrm{Ch}^{2}=0.01, \mathrm{df}=\mathrm{I}(\mathrm{P}=0.91) ; \mathrm{I}^{2}=0.0 \%$} \\
\hline \multicolumn{8}{|c|}{ Test for overall effect: $Z=0.55(P=0.58)$} \\
\hline & & & & & 0 & & \\
\hline
\end{tabular}
( I) Knee sleeve.
(2) Knee brace.
(3) Knee brace.
(4) Knee sleeve.
(5) Knee brace
(6) Knee sleeve
(7) Knee brace.
(8) Knee sleeve.
(9) Knee sleeve
(10) Knee brace
(II) Knee sleeve
(12) Knee brace 
Analysis I.4. Comparison I Knee orthosis and non-operative intervention (exercises) versus non-operative intervention (exercises) alone, Outcome 4 Excellent or good results in terms of reduction in symptoms.

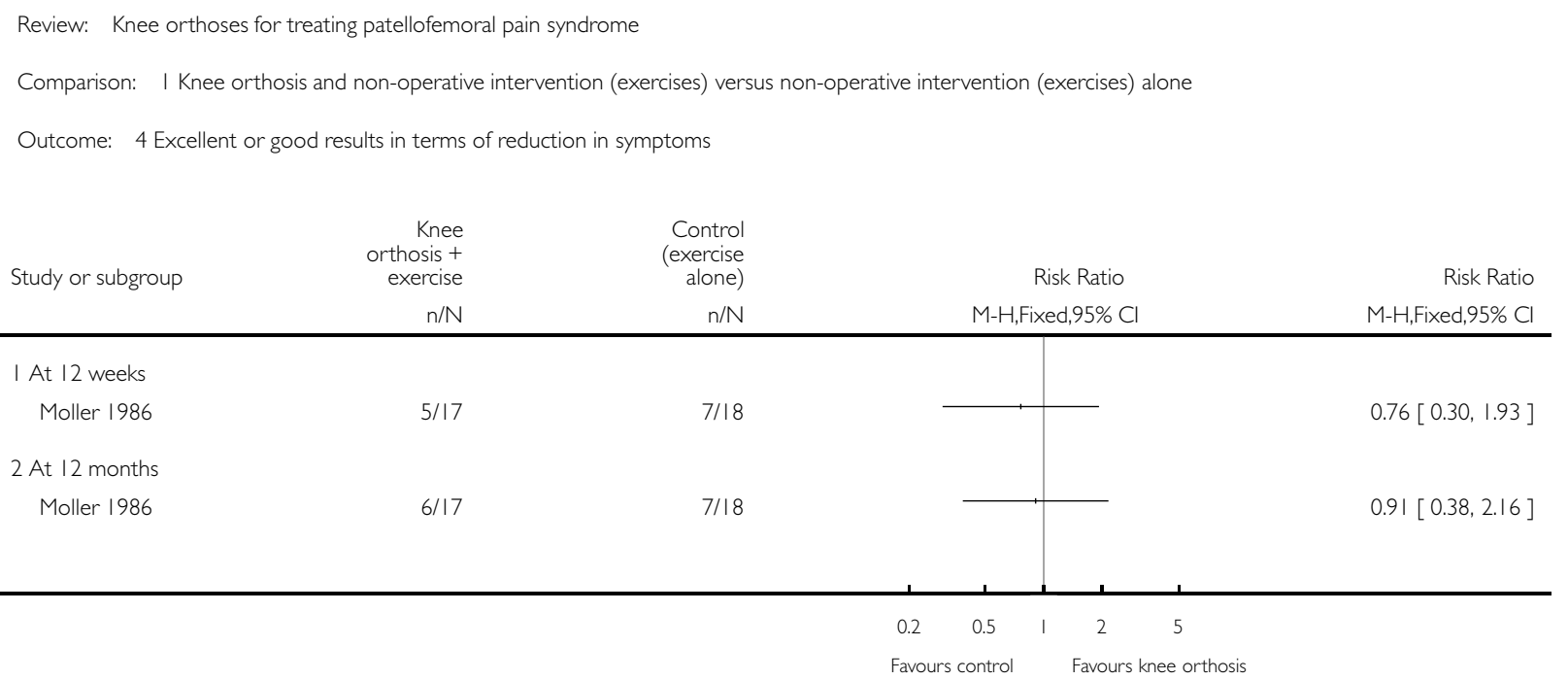


Analysis I.5. Comparison I Knee orthosis and non-operative intervention (exercises) versus non-operative intervention (exercises) alone, Outcome 5 Functional scores (higher score means higher function).

Review: Knee orthoses for treating patellofemoral pain syndrome

Comparison: I Knee orthosis and non-operative intervention (exercises) versus non-operative intervention (exercises) alone

Outcome: 5 Functional scores (higher score means higher function)

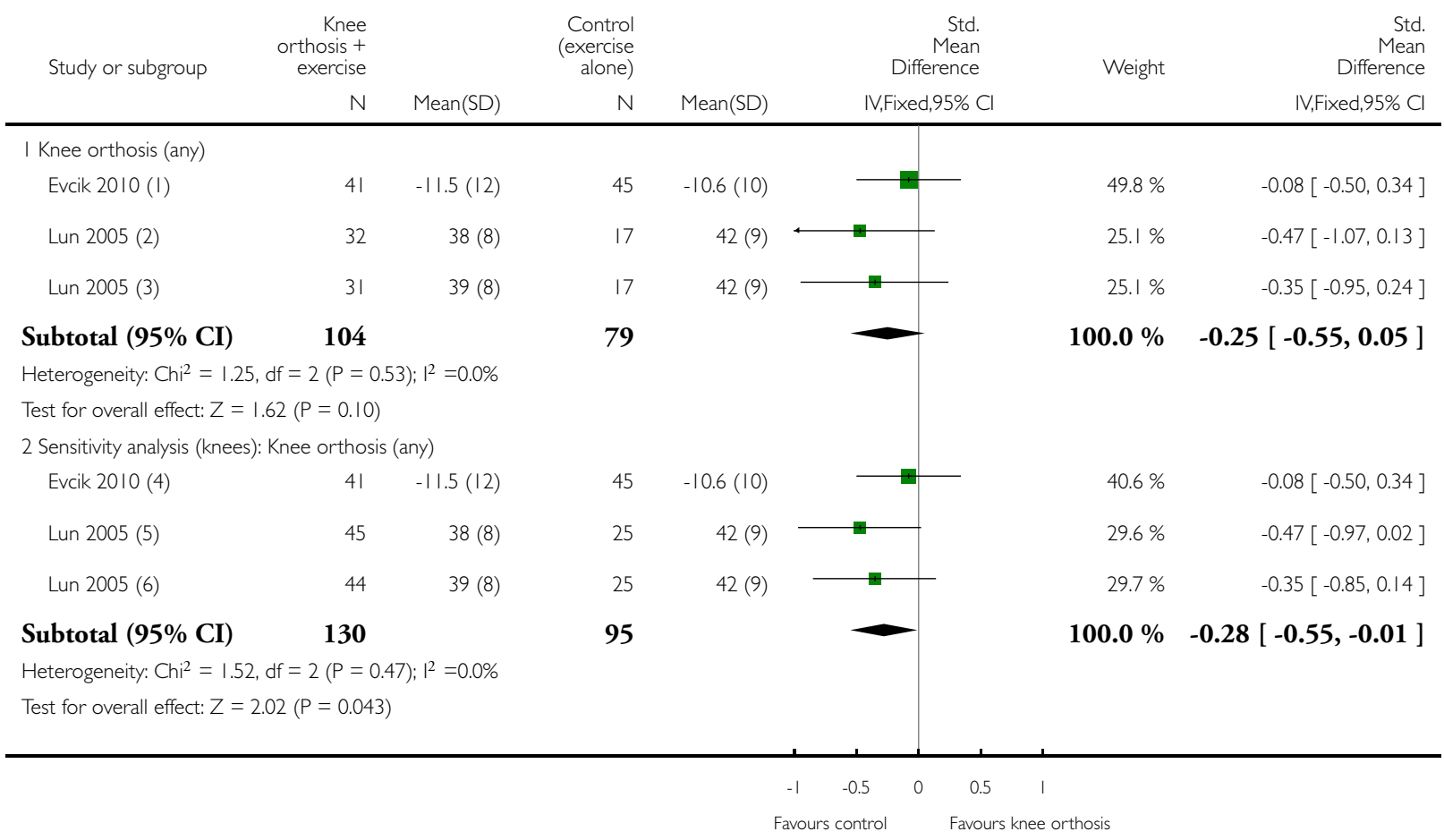

(I) Knee brace. WOMAC functional score measured at 6 weeks

(2) Knee sleeve: Modified version of the Knee Function Scale at 12 weeks

(3) Knee brace: Modified version of the Knee Function Scale at 12 weeks

(4) Knee brace. WOMAC functional score measured at 6 weeks

(5) Knee sleeve: Modified version of the Knee Function Scale at 12 weeks

(6) Knee brace: Modified version of the Knee Function Scale at 12 weeks 
Analysis I.6. Comparison I Knee orthosis and non-operative intervention (exercises) versus non-operative intervention (exercises) alone, Outcome 6 Discontinuation of a basic military training programme.

Review: Knee orthoses for treating patellofemoral pain syndrome

Comparison: I Knee orthosis and non-operative intervention (exercises) versus non-operative intervention (exercises) alone

Outcome: 6 Discontinuation of a basic military training programme

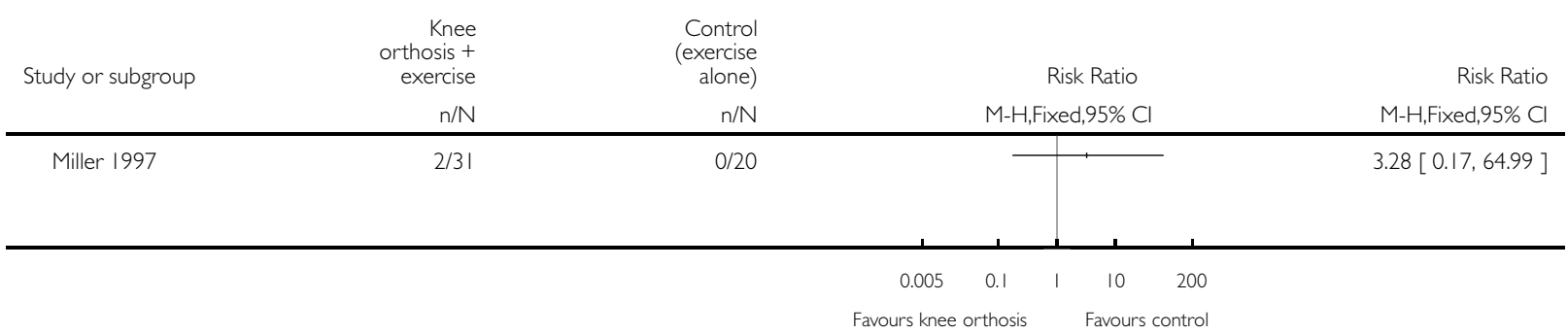

Analysis 2.I. Comparison 2 One type of orthosis versus another type, Outcome I Pain score (0 to I0: higher score means worse pain).

Review: Knee orthoses for treating patellofemoral pain syndrome

Comparison: 2 One type of orthosis versus another type

Outcome: I Pain score (0 to 10: higher score means worse pain)

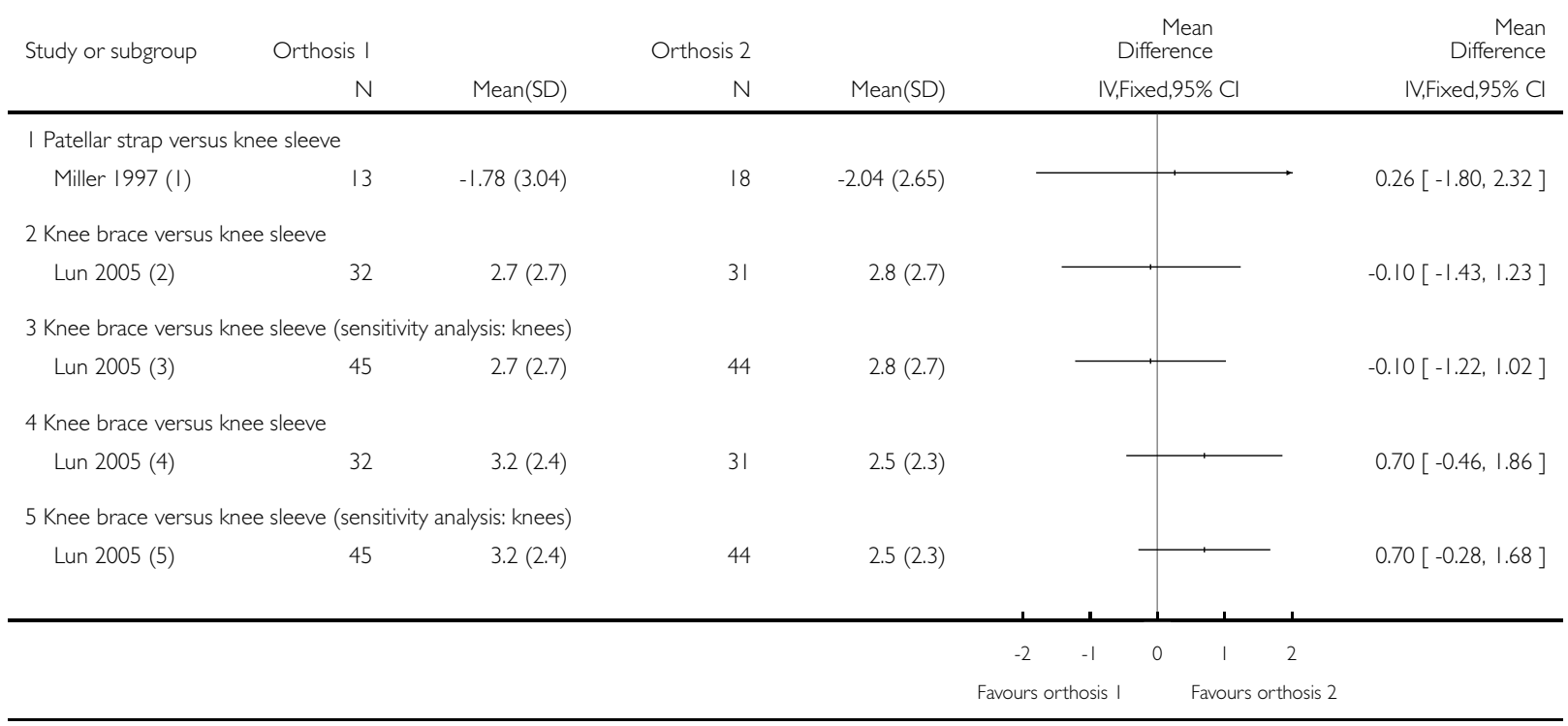

Knee orthoses for treating patellofemoral pain syndrome (Review)

Copyright $\odot 2015$ The Cochrane Collaboration. Published by John Wiley \& Sons, Ltd. 
(I) Change in pain score; pre-treatment to 2 to 3 weeks

(2) Pain during sporting activity at 12 weeks

(3) Pain during sporting activity at 12 weeks

(4) Pain I hour after sporting activity at 12 weeks

(5) Pain I hour after sporting activity at 12 weeks

\section{Analysis 2.2. Comparison 2 One type of orthosis versus another type, Outcome 2 Functional score (0 to 53 :} higher scores means greater function).

Review: Knee orthoses for treating patellofemoral pain syndrome

Comparison: 2 One type of orthosis versus another type

Outcome: 2 Functional score (0 to 53: higher scores means greater function)

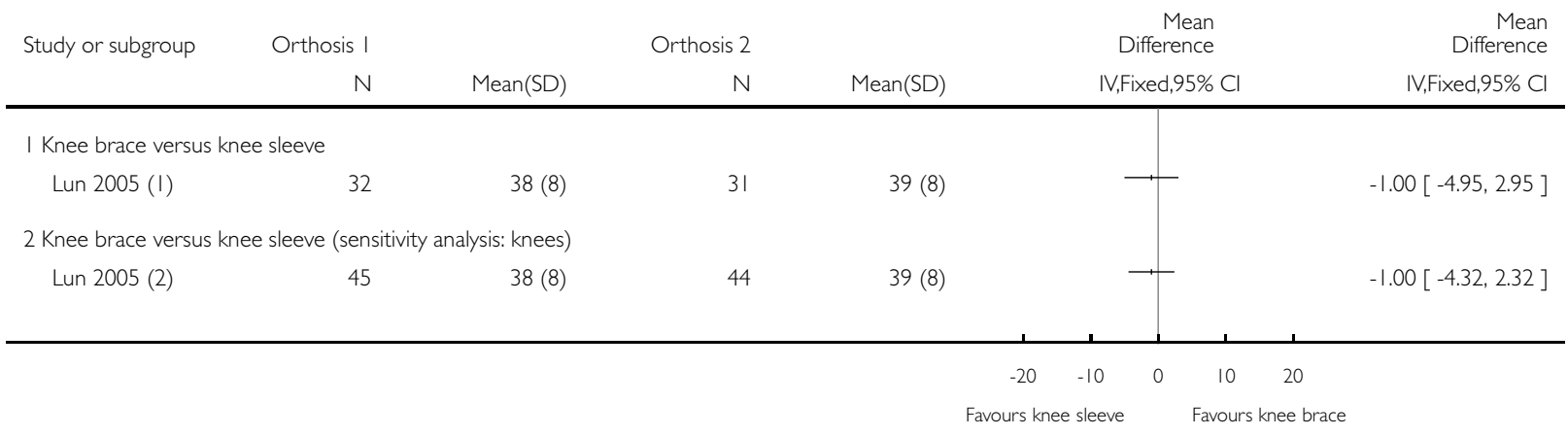

( I) Modified version of the Knee Function Scale at 12 weeks; unit of analysis issue - inclusion of people with bilateral involvement (44\% of population)

(2) Modified version of the Knee Function Scale at 12 weeks; unit of analysis issue - inclusion of people with bilateral involvement (44\% of population) 
Analysis 2.3. Comparison 2 One type of orthosis versus another type, Outcome 3 Discontinuation of a basic military training programme.

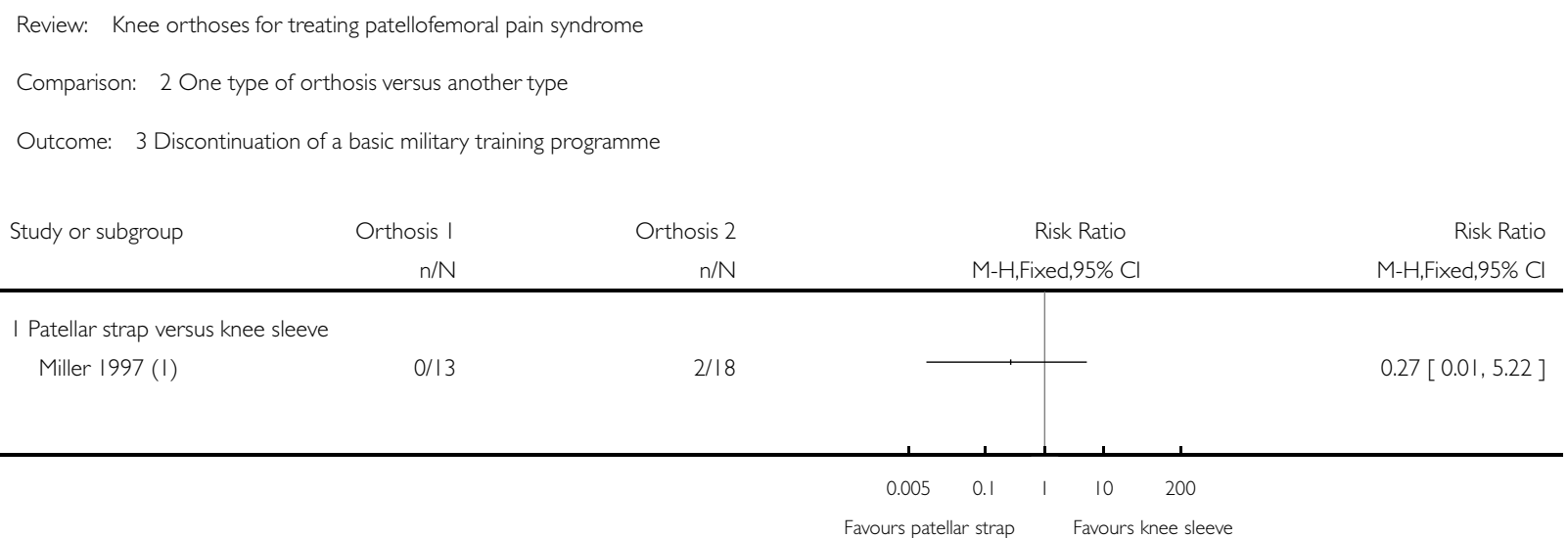

(I) Continuation of basic military training at 8 weeks after study initiation.

Analysis 2.4. Comparison 2 One type of orthosis versus another type, Outcome 4 Complications.

Review: Knee orthoses for treating patellofemoral pain syndrome

Comparison: 2 One type of orthosis versus another type

Outcome: 4 Complications

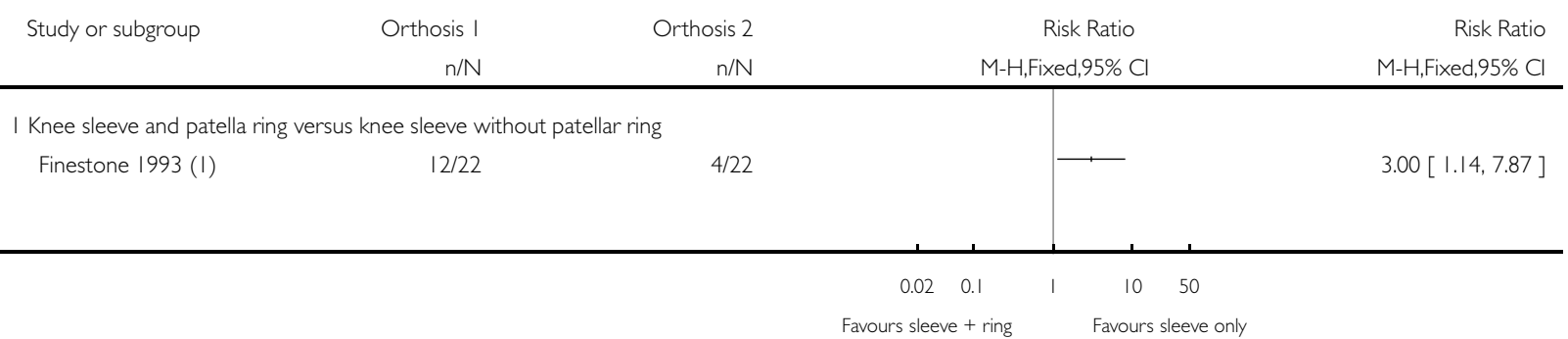

(I) Complications at 14 weeks. 
Analysis 3.I. Comparison 3 Orthosis versus exercise, Outcome I Pain during activity (0 to I0: higher score means worse pain).

\begin{tabular}{|c|c|c|c|c|c|c|}
\hline \multicolumn{7}{|c|}{ Comparison: 3 Orthosis versus exercise } \\
\hline \multicolumn{7}{|c|}{ Outcome: I Pain during activity (0 to 10: higher score means worse pain) } \\
\hline \multirow[t]{2}{*}{ Study or subgroup } & \multirow{2}{*}{$\begin{array}{r}\text { Knee brace } \\
\mathrm{N}\end{array}$} & \multicolumn{3}{|c|}{ Exercise } & \multirow{2}{*}{$\begin{array}{c}\text { Mean } \\
\text { Difference } \\
\text { IV,Fixed,95\% Cl }\end{array}$} & $\begin{array}{r}\text { Mean } \\
\text { Difference }\end{array}$ \\
\hline & & Mean(SD) & $\mathrm{N}$ & Mean(SD) & & IV,Fixed,95\% Cl \\
\hline \multicolumn{7}{|c|}{ I Pain score during sporting activity } \\
\hline Lun 2005 & 32 & $2.7(1.8)$ & 34 & $2.9(2.4)$ & - & $-0.20[-1.22,0.82]$ \\
\hline \multicolumn{7}{|c|}{2 Pain score I hour after sporting activity } \\
\hline Lun 2005 & 32 & $2.5(1.8)$ & 34 & $2.1(2.2)$ & - & $0.40[-0.57,1.37]$ \\
\hline \multicolumn{7}{|c|}{3 Pain score following 30 minutes of sitting with knees flexed } \\
\hline Lun 2005 & 32 & $2.9(2.3)$ & 34 & $2.5(2.5)$ & - & $0.40[-0.76,1.56]$ \\
\hline
\end{tabular}


Analysis 3.2. Comparison 3 Orthosis versus exercise, Outcome 2 Sensitivity analyses (knees): Pain during activity (0 to 10: higher score means worse pain).

Review: Knee orthoses for treating patellofemoral pain syndrome

Comparison: 3 Orthosis versus exercise

Outcome: 2 Sensitivity analyses (knees): Pain during activity (0 to I 0 : higher score means worse pain)

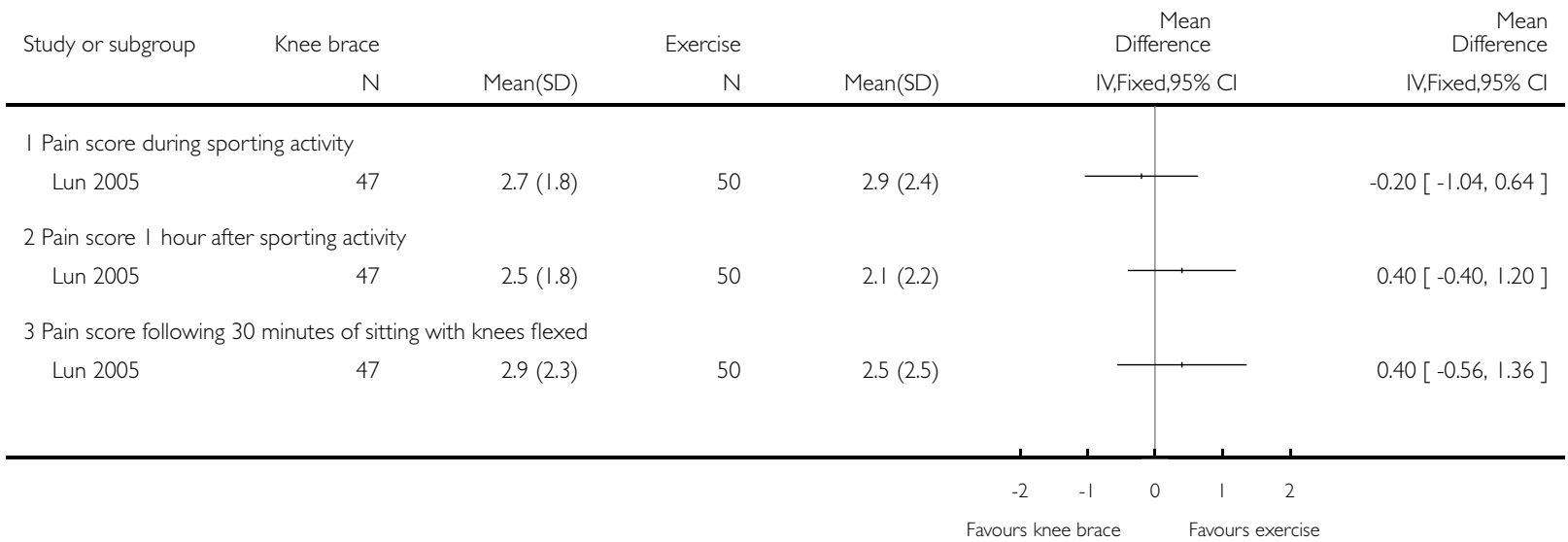

Analysis 3.3. Comparison 3 Orthosis versus exercise, Outcome 3 Functional scores (0 to 53: higher scores means greater function).

Review: Knee orthoses for treating patellofemoral pain syndrome

Comparison: 3 Orthosis versus exercise

Outcome: 3 Functional scores (0 to 53: higher scores means greater function)

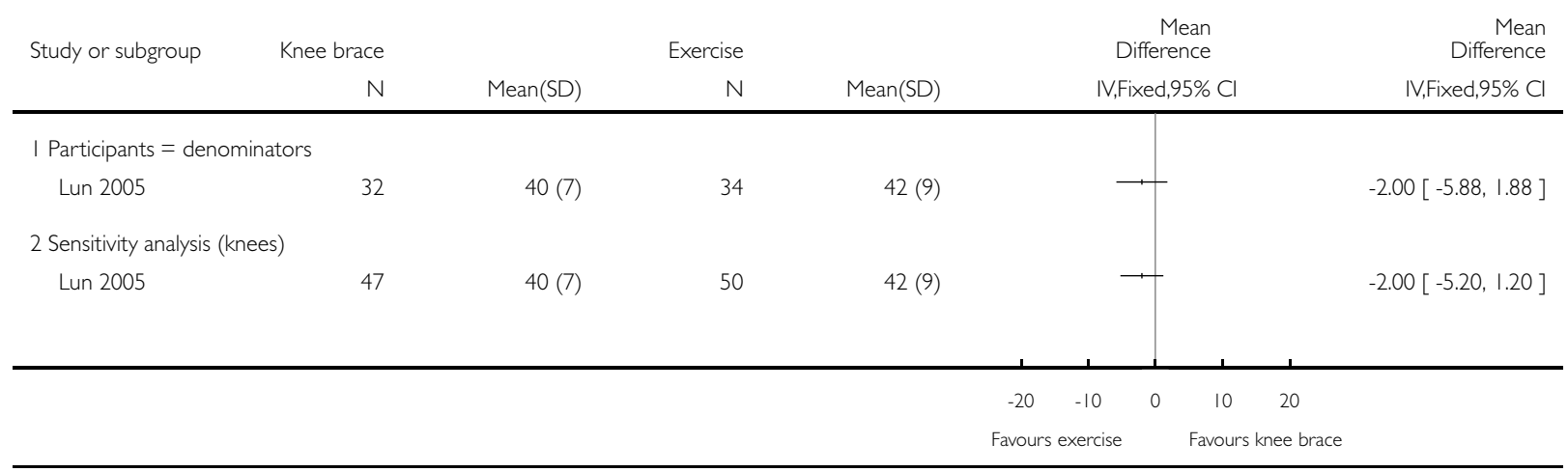

Knee orthoses for treating patellofemoral pain syndrome (Review)

Copyright @ 2015 The Cochrane Collaboration. Published by John Wiley \& Sons, Ltd. 


\section{A P P E N D I C E S}

\section{Appendix I. Search strategies}

\section{CENTRAL (Wiley Online Library)}

\#1 MeSH descriptor: [Patellofemoral Pain Syndrome] this term only (72)

\#2 [mh Knee] or [mh “"Knee Injuries"] or [mh “"Knee Joint”] or [mh Patella] (3341)

\#3 [mh Ârthralgia] or [mh ^Pain] (10158)

\#4 \#2 and \#3 (365)

\#5 "anterior knee pain":ti,ab,kw (Word variations have been searched) (156)

\#6 PFPS:ti,ab,kw (Word variations have been searched) (56)

\#7 ((patell ${ }^{*}$ or femoropatell ${ }^{*}$ or femoro-patell ${ }^{*}$ or retropatell* ${ }^{*}$ retro-patell*) near/2 (pain or syndrome or dysfunction or sublux or malalign* or realign*)):ti,ab,kw (Word variations have been searched) (319)

\#8 MeSH descriptor: [Chondromalacia Patellae] this term only (5)

\#9 ((chondromalac* or chondropath*) near/2 (knee* or patell* or femoropatell* or femoro-patell* or retropatell* or retro-patell*)): ti,ab,kw (Word variations have been searched) (32)

\#10 ((lateral compression or lateral facet or lateral pressure or odd facet) near syndrome):ti,ab,kw (Word variations have been searched) (1)

\#11 or \#5-\#10\} (451)

\#12 \#1 or \#4 or \#11 (742)

\#13 MeSH descriptor: [Rehabilitation] explode all trees (15765)

\#14 MeSH descriptor: [Physical Therapy Modalities] explode all trees (16415)

\#15 MeSH descriptor: [Physical Therapy Specialty] this term only (114)

\#16 MeSH descriptor: [Orthotic Devices] explode all trees (927)

\#17 (brace* or sleeve* or strap* or orthotic* or orthosis or orthoses or bandage*):ti,ab,kw (Word variations have been searched) 4467

\#18 "realign":ti,ab,kw (Word variations have been searched) (21)

\#19 (physiotherapy or physical therapy):ti,ab,kw (Word variations have been searched) (17257)

\#20 rehabilitat*:ti,ab,kw (Word variations have been searched) (14093)

\#21 Any MeSH descriptor with qualifier(s): [Rehabilitation - RH] (13927)

\#22 (non-surg* or nonsurg* or non-operat* or nonoperat* or conserv*):ti,ab,kw (Word variations have been searched) (9270)

\#23 \{or \#13-\#22\} (61513)

$\# 24 \# 12$ and \#23 (319)

\section{MEDLINE (Ovid Online)}

1 Patellofemoral Pain Syndrome/ (510)

2 exp Knee/ or Knee Injuries/ or Knee Joint/ or exp Patella/ (65152)

3 Arthralgia/ or Pain/ (116321)

42 and 3 (3557)

5 anterior knee pain.tw. (1123)

6 pfps.tw. (297)

7 ((patell\$ or femoropatell\$ or femoro-patell\$ or retropatell\$ or retro-patell\$) adj2 (pain or syndrome or dysfunction or sublux or malalign $\$$ or realign\$)).tw. (2083)

Knee orthoses for treating patellofemoral pain syndrome (Review)

Copyright @ 2015 The Cochrane Collaboration. Published by John Wiley \& Sons, Ltd. 
8 ((lateral compression or lateral facet or lateral pressure or odd facet) adj syndrome).tw. (21)

9 Chondromalacia Patellae/ (62)

10 ((chondromalac\$ or chondropath\$) adj2 (knee\$1 or patell\$ or femoropatell\$ or femoro-patell\$ or retropatell\$ or retro-patell\$)).tw. (512)

11 or/5-10 (3483)

121 or 4 or $11(6408)$

13 exp Rehabilitation/ (155245)

14 exp Physical Therapy Modalities/ (129434)

15 Physical Therapy Specialty/ (2236)

16 exp Orthotic Devices/ (9782)

17 (brace\$ or sleeve\$ or strap\$ or orthotic* or orthos\#s or bandage\$).tw. (22186)

18 realign\$.tw. (3331)

19 (physiotherapy or physical therapy).tw. (23363)

20 rehabilitat*.tw. (113902)

21 rh.fs. (169770)

22 (non-surg\$ or nonsurg $\$$ or non-operat $\$$ or nonoperat $\$$ or conserv $\$$ ).tw. (359633)

23 or/13-22 (799951)

2412 and 23 (1614)

25 Randomized controlled trial.pt. (394854)

26 Controlled clinical trial.pt. (89435)

27 randomized.ab. (320090)

28 placebo.ab. (162328)

29 Drug therapy.fs. (1771045)

30 randomly.ab. (230447)

31 trial.ab. (331205)

32 groups.ab. (1449538)

33 or/25-32 (3528365)

34 exp Animals/ not Humans/ (4037832)

3533 not 34 (3031597)

3624 and $35(452)$

\section{EMBASE (Ovid Online)}

1 Patellofemoral Pain Syndrome/ (791)

2 Knee/ or Knee Injury/ or Patella/ (59862)

3 Arthralgia/ or Pain/ (255225)

42 and 3 (6247)

5 anterior knee pain.tw. (1339)

6 PFPS.tw. (351)

7 ((patell\$ or femoropatell\$ or femoro-patell\$ or retropatell\$ or retro-patell\$) adj2 (pain or syndrome or dysfunction or sublux or malalign \$ or realign\$)).tw. (2424)

8 ((lateral compression or lateral facet or lateral pressure or odd facet) adj syndrome).tw. (25)

9 Patella Chondromalacia/ (597)

10 ((chondromalac\$ or chondropath\$) adj2 (knee\$1 or patell\$ or femoropatell\$ or femoro-patell\$ or retropatell\$ or retro-patell\$)).tw. (608)

11 or/5-10 (4280)

121 or 4 or $11(10233)$

13 exp Rehabilitation/ (248682)

14 Physiotherapy/ (55685)

15 Orthotics/ (3013)

16 (brace\$ or sleeve\$ or strap\$ or orthotic* or orthos\#s or bandage\$).tw. (29461)

17 realign\$.tw. (3918)

18 (physiotherapy or physical therapy).tw. (33422)

Knee orthoses for treating patellofemoral pain syndrome (Review)

Copyright () 2015 The Cochrane Collaboration. Published by John Wiley \& Sons, Ltd. 
19 rehabilitat\$.tw. (153896)

20 (non-surg $\$$ or nonsurg $\$$ or non-operat $\$$ or nonoperat $\$$ or conserv\$).tw. (400593)

21 or/13-20 (811654)

2212 and 21 (2533)

23 exp Randomized Controlled Trial/ or exp Single Blind Procedure/ or exp Double Blind Procedure/ or Crossover Procedure/ (416387)

24 (random\$ or RCT or placebo or allocat\$ or crossover \$ or 'cross over' or trial or (doubl\$ adj1 blind\$) or (singl\$ adj1 blind\$)).ti,ab.

(1362815)

2523 or 24 (1438687)

26 (exp Animal/ or animal.hw. or Nonhuman/) not (exp Human/ or Human Cell/ or (human or humans).ti.) (5260646)

2725 not $26(1266421)$

2822 and 27 (500)

\section{AMED (Ovid Online)}

1 Patellofemoral Pain Syndrome/ (75)

2 Knee/ or Knee Injuries/ or Knee Joint/ or Patella/ (5599)

3 Pain/ or Arthralgia/ (10755)

42 and 3 (720)

5 anterior knee pain.tw. (134)

6 PFPS.tw. (115)

7 ((patell\$ or femoropatell\$ or femoro-patell\$ or retropatell\$ or retro-patell\$) adj2 (pain or syndrome or dysfunction or sublux or malalign\$ or realign\$)).tw. (484)

8 ((lateral compression or lateral facet or lateral pressure or odd facet) adj syndrome).tw. (1)

9 ((chondromalac\$ or chondropath\$) adj2 (knee\$1 or patell\$ or femoropatell\$ or femoro-patell\$ or retropatell\$ or retro-patell\$)).tw.

(27)

10 or/5-9 (603)

111 or 4 or $10(997)$

12 Rehabilitation/ (46854)

13 Physical therapy modalities/ (4239)

14 exp Orthotic devices/ (1851)

15 (brace\$ or sleeve\$ or strap\$ or orthotic* or orthos\#s or bandage \$).tw. (3286)

16 realign $\$ . t w .(129)$

17 (physiotherapy or physical therapy).tw. (17720)

18 rehabilitat\$.tw. (55498)

19 (non-surg\$ or nonsurg\$ or non-operat\$ or nonoperat\$ or conserv\$).tw. (2863)

20 or/12-19 (71554)

2111 and 20 (477)

22 Randomized controlled trial.pt. (3195)

23 Controlled clinical trial.pt. (70)

24 Randomized Controlled Trials/ (1709)

25 Random Allocation/ (312)

26 Double-Blind Method/ (538)

27 or/22-26 (5541)

28 exp Animals/ not Humans/ (8174)

2927 not 28 (5511)

30 clinical trial.pt. (1167)

31 exp Clinical trials/ (3448)

32 (clinic\$ adj25 trial\$).tw. (6109)

33 ( (singl\$ or doubl\$ or trebl\$ or tripl\$) adj (mask\$ or blind\$)).tw. (2448)

34 Placebos/ (561)

35 placebo $\$$. tw. $(2744)$

36 random\$.tw. (14963)

37 exp Research design/ (18228)

Knee orthoses for treating patellofemoral pain syndrome (Review)

Copyright @ 2015 The Cochrane Collaboration. Published by John Wiley \& Sons, Ltd. 
38 (latin adj square).tw. (24)

39 or/30-38 (32656)

4039 not 28 (32063)

4140 not 29 (26708)

4221 and 41 (99)

\section{CINAHL (EBSCOHost)}

S1 (MH "Patellofemoral Pain Syndrome") $(1,005)$

S2 (MH "Knee”) OR (MH “Knee Injuries") OR (MH "Knee Joint”) OR (MH "Patella") (19,617)

S3 (MH "Arthralgia+") OR (MH "Pain”) $(55,507)$

S4 S2 AND S3 (2,193)

S5 TX anterior knee pain (486)

S6 TX PFPS (192)

S7 TX ((patell* or femoropatell* or femoro-patell* or retropatell* or retro-patell*) N2 (pain or syndrome or dysfunction or sublux or malalign* or realign*)) $(1,425)$

S8 TX ((lateral compression or lateral facet or lateral pressure or odd facet) N3 syndrome) (8)

S9 (MH “Chondromalacia Patella”) (64)

S10 TX ((chondromalac* or chondropath*) N2 (knee* or patell* or femoropatell* or femoro-patell* or retropatell* or retro-patell*)) $(104)$

S11 S5 OR S6 OR S7 OR S8 OR S9 OR S10 $(1,802)$

S12 S1 OR S4 OR S11 (3,308)

S13 (MH “Orthoses+") $(6,903)$

S14 TX (brace* or sleeve* or strap* or orthotic* or orthos\#s or bandage*) $(20,151)$

S15 S13 OR S14 (20,393)

S16 S12 AND S15 (343)

S17 PT Clinical Trial $(77,889)$

S18 (MH “Clinical Trials+”) $(187,289)$

S19 TI clinical trial* OR AB clinical trial* $(45,410)$

S20 TI ( (single blind* or double blind*) ) OR AB ( (single blind* or double blind*) ) $(21,470)$

S21 TI random* OR AB random* $(149,549)$

S22 S17 OR S18 OR S19 OR S20 OR S21 $(277,415)$

S23 S16 AND S22 (85)

\section{SPORTDiscus (EBSCOHost)}

S1 TX anterior knee pain (595)

S2 TX PFPS (334)

S3 TX ((patell* or femoropatell* or femoro-patell* or retropatell* or retro-patell*) N2 (pain or syndrome or dysfunction or sublux or malalign* or realign*)) $(1,357)$

S4 TX ((lateral compression or lateral facet or lateral pressure or odd facet) N2 syndrome) (10)

S5 TX ((chondromalac* or chondropath*) N2 (knee* or patell* or femoropatell* or femoro-patell* or retropatell* or retro-patell*)) (242)

S6 S1 OR S2 OR S3 OR S4 OR S5 $(1,926)$

S7 DE “ORTHOPEDIC apparatus" (2,529)

S8 TX (brace* or sleeve* or strap* or orthotic* or orthos\#s or bandage*) $(9,150)$

S9 S7 OR S8 $(10,112)$

S10 S6 AND S9 (195)

S11 TX ( (clinic* N3 trial) or (controlled N3 trial) or (comparative N3 trial) or (placebo N3 trial) or (prospective N3 trial) or (randomi? ed N3 trial) ) or TX ( (clinic* N3 study) or (controlled N3 study) or (comparative N3 study) or (placebo N3 study) or (prospective N3 study) or (randomi?ed N3 study) ) $(65,289)$

S12 (random* N7 allot*) or (random* N7 assign*) or (random* N7 basis*) or (random* N7 divid*) or (random* N7 order*) $(8,538)$

Knee orthoses for treating patellofemoral pain syndrome (Review)

Copyright $\odot 2015$ The Cochrane Collaboration. Published by John Wiley \& Sons, Ltd. 
S13 TX ( (singl* N7 blind*) or (doubl* N7 blind*) or (trebl* N7 blind*) or (tripl* N7 blind*) ) or TX ( (singl* N7 mask*) or (doubl* N7 mask $\left.^{*}\right)$ or $\left(\right.$ trebl$^{*} \mathrm{~N} 7$ mask $\left.^{*}\right)$ or $\left(\right.$ tripl $^{*} \mathrm{~N} 7$ mask $\left.\left.^{*}\right)\right)(5,465)$

S14 TX (cross\#over*) or TX (cross N1 over*) $(4,067)$

S15 TX randomi?ed control* trial* $^{*}(9,473)$

S16 TX ( (allocat* N3 condition*) or (allocat* N3 experiment*) or (allocat* N3 intervention*) or (allocat* N3 treatment*) or (allocat* N3 therap*) or (allocat* N3 control*) or (allocat* N3 group $\left.{ }^{*}\right)$ ) or TX ( (allot* N3 condition*) or (allot* N3 experiment*) or (allot* N3 intervention*) or (allot* N3 treatment*) or (allot* N3 therap*) or (allot* N3 control*) or (allot* N3 group*) ) or TX ( (assign* N3 condition*) or (assign* N3 experiment*) or (assign* N3 intervention*) or (assign* N3 treatment*) or (assign* N3 therap*) or (assign* N3 control*) or (assign* N3 group*) ) or TX ( (divid* N3 condition*) or (divid* N3 experiment*) or (divid* N3 intervention*) or

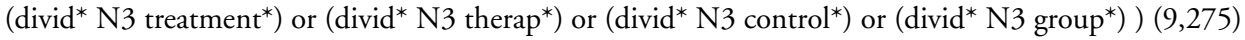

S17 TX placebo* $(7,914)$

S18 S11 or $S 12$ or $S 13$ or $S 14$ or $S 15$ or $S 16$ or $S 17(80,389)$

S19 S10 AND S18 (63)

\section{Physiotherapy Evidence Databases (PEDro Platform)}

\section{a) Simple Search}

1. Patella* and brac* (31)

2. Patella* and strap (4)

3. Patella* and ortho* (128)

4. Patella* and sleeve (2)

5. Patella* and bandage (1)

6. Knee and brac $^{*}(161)$

7. Knee and ortho* (1224)

8. Knee and strap (5)

9. Knee and sleeve (13)

10. Knee and bandage (65)

\section{b) Advanced Search}

Abstract and title: patell

Therapy: orthoses, taping, splinting

Body Part: lower leg or knee

Method: clinical trial

Total $=48$

\section{WHO International Clinical Trials Registry Platform}

1. Patell* and brac* (9)

2. Patell* and strap* (5)

3. Patell* and orthos* (9)

4. Patell* and orthot* (3)

5. Patell* and sleeve* $(0)$

6. Patell* and bandag* (4)

7. Knee and brac* (41)

8. Knee and strap* (16)

9. Knee and orthos* (28)

10. Knee and orthot* ${ }^{*}(21)$

11. Knee and sleeve* (3)

12. Knee and bandag* (20) 


\section{Current Controlled Trials}

1. Knee and brace (12)

2. Knee and strap (4)

3. Knee and orthosis (8)

4. Knee and orthotic (6)

5. Knee and sleeve (1)

6. Knee and bandage (10)

7. Knee and ortho* (1)

8. Knee and brac* $^{*}(0)$

9. Patell* and ortho* $(0)$

10. Patell* and $\operatorname{brac}^{*}(0)$

\section{OpenGrey}

1. Knee brac* (5)

2. Knee strap (0)

3. Knee ortho* (51)

4. Knee sleeve (0)

5. Knee bandage (0)

6. Patell* brac* $^{*}(1)$

7. Patell* ortho* (11)

8. Patell* $\operatorname{strap}(0)$

9. Patell* sleeve (0)

10. Patell* bandage $(0)$

\section{Orthopaedic Proceedings (Bone and Joint Journal Website)}

1. Patello* and random* (48)

2. Anterior knee pain and random* $(80)$

\section{CONTRIBUTIONSOFAUTHORS}

TS: contributed to the literature search; reviewed the search results for review eligibility and identified all included trials; adjudicated the data extraction and assessment of 'risk of bias' processes; conducted the data analysis; was involved in the writing and approval of the protocol and the final review; acts as guarantor.

BD: screened the search results for review eligibility and identified all included trials; independently performed the data extraction; assessed the 'risk of bias' for the included studies; provided judgements on the interpretation of the results and conclusions drawn; was involved in the writing and approval of the protocol and the final review.

TM: was involved in the final decisions regarding inclusion or exclusion of studies; independently undertook the data extraction; assessed the 'risk of bias' for the included studies; provided judgements on the interpretation of the results and conclusions drawn; was involved in the writing and approval of the protocol and the final review.

AC: provided judgements on the analysis approaches; provided judgement on the interpretation of the results and conclusions drawn; was involved in the writing and approval of the protocol and the final review. 


\section{DECLARATIONSOF INTEREST}

Toby O Smith: none known

Benjamin T Drew: currently holds a NIHR/HEE Clinical Doctoral Fellowship grant

Toby H Meek: none known

Allan B Clark: none known

\section{DIFFERENCES BETWEEN PROTOCOLANDREVIEW}

There were insufficient data to perform subgroup analyses of custom-made orthosis to a pre-fabricated (off-the-shelf) version, of people age 18 years or over versus those aged under 18 years, or the level of activity (participants who were professional athletes or in the military forces versus recreational athletes).

We merged two original comparators into one comparator on data analysis. The protocol stipulated the comparators 'knee orthosis versus no treatment' and 'knee orthosis and non-operative intervention (e.g. exercise) versus non-operative intervention alone'. On reflection of the results from the included studies, these appeared arbitrary distinctions where all participants received some form of treatment, be that exercise or basic military training, which would include knee exercises. Therefore we synthesised these two comparators into the single 'knee orthosis and non-operative intervention (e.g. exercise) versus non-operative intervention alone' comparator as presented in the review.

Due to the available data, it was not possible to present an informative 'Summary of Findings' table for all planned comparisons. Therefore we only presented a 'Summary of Findings' table for the main comparison (Knee orthosis and non-operative intervention (e.g. exercise) versus non-operative intervention alone).

It was not possible to perform a sensitivity analysis of the presentation of $90 \%$ of data versus greater than $10 \%$ lost to follow-up data due to insufficient data for such an analysis.

It was not possible to investigate outcomes dependent on the mode of knee orthoses such as length of time worn per day, whether the orthosis was worn only during physical activity, during therapeutic exercises or all day, since this had not been specifically investigated within the available literature for specific forms of knee orthoses.

It was not possible to assess publication bias for such small sample sizes: the largest number of trials pooled in this review was three. Consequently, it was not possible to ascertain whether the findings of this review were, or were not, affected by publication bias.

Knee orthoses for treating patellofemoral pain syndrome (Review) 